(Aus der gynäkologischen Klinik der Universität Köln [Direktor: Prof. H. Füth].)

\title{
Experimenteller Beitrag zur Frage der Verhütung postoperativer peritonealer Adhäsionen mittels arteigenen flïssigen Fettes ${ }^{1}$ ).
}

\author{
Von \\ Dr. Ernst Löhnberg, \\ Oberarzt der Klinik.
}

Das Problem der Verhütung postoperativer Adhäsionen hat schon viele Autoren beschäftigt, ohne daß es bisher gelungen wäre, eine brauchbare Methode, ein Mittel, das allen in Betracht kommenden Anforderungen genügte, ausfindig zu machen. Das große Interesse, das dieser Frage mit Entwicklung der Bauchchirurgie in wachsendem Maße entgegengebracht worden ist, illustriert wohl am besten ihre Bedeutung für die Praxis.

So erwünscht die Eigenschaft des. Peritoneums und des Netzes ist, durch Aneinanderlegen und rasches Verkleben entzündliche Prozesse der Bauchhöhle vor allem des kleinen Beckens abzuschließen und den Entzündungsherd zu lokalisieren, das Entstehen einer allgemeinen Peritonitis zu verhüten, so wenig wünschenswert sind die Folgezustände dieses Heilungsprozesses, die oft in Gestalt dauernd bestehenbleibender Adhäsionen und dadurch bedingter Beschwerden, Zerrungen der miteinander oder dem parietalen Peritoneum verlöteten Intestina ( $\mathrm{Ab}$ knickung, Strangulation) häufig zu späteren operativen Eingriffen Anlaß geben.

Noch öfter haben wir Gelegenheit das Entstehen derartiger peritonealer Adhäsionen zu beobachten im Anschluß an Operationen, die aus irgendwelchen Indikationen vorgenommen worden sind.

Das rasche Verkleben, die adhäsionsbildende Eigenschaft des Peritoneums ist ja ein Grundstein, auf dem die ganze Bauchchirurgie aufgebaut ist, sonst wäre das Gelingen einer Darmresektion, die Ausschaltung eines infektiösen Appendix- oder Adnexstumpfes einfach nicht denkbar. Aber die adhäsionsbildende Eigenschaft des Peritoneums bleibt häufig im Anschluß an operative Eingriffe nicht auf diesen beabsichtigten Zweck beschränkt. Die während der Operation gesetzte

1) Die Arbeit wurde angefertigt mit Unterstützung durch die HochhansStiftung. 
mechanische Schädigung des Peritoneums, das oft in großer. Ausdehnung verwundet worden ist, z. B. nach der Auslösung festverwachsener großer Adnextumoren, die oft nicht vollständig mögliche Peritonealisierung der Stümpfe, schließlich die im Anschluß an die Operation auftretende Exsudation im Operationsgebiet bilden die Ursache zu Verwachsungen, die in der Folge zu den heftigsten Beschwerden Anlaß geben können.

Derartige postoperative Adhäsionen sind ein notwendiges Übel, mit dem wir nach Bauchoperationen bis zu einem gewissen Grade rechnen müssen, auch selbst wenn die Rekonvaleszenz durch keinerlei manifeste entzündliche Erscheinungen im Bereich des Operationsgebietes gestört gewesen war. Besonders häufig haben wir Gelegenheit, das Entstehen derartiger postoperativer Adhäsionen zu beobachten nach gynäkologischen Operationen, bei denen infolge der anatomischen Anordnung der Genitalorgane in dem trichterförmig zulaufenden engen Raum des kleinen Beckens, der häufig hier gesetzten flächenhaften Verwundung des perietalen Peritoneums und nicht zuletzt infolge der relativen Ruhe in diesem Raum im Gegensatz zu der lebhaften Peristaltik der die Bauchhöhle anfüllenden Darmschlingen die Vorbedingungen für das Entstehen derartiger postoperativer Verwachsungen in besonders hohem Maße gegeben sind.

Es würde deshalb von großem Werte sein, wenn wir ein Mittel hätten, das uns in den Stand setzte, ohne selbst irgendwie schädigend. zu wirken, das Entstehen derartiger postoperativer Adhäsionen nach Möglichkeit zu verhindern. Diese Überlegung hat bisher schon eine ganze Reihe Autoren veranlaßt, die verschiedensten Mittel, die für diesen $Z$ weck geeignet erschienen, im Tierexperiment daraufhin zu prüfen. Aber die Ergebnisse dieser Versuche waren durchweg nicht so, daß man eine für den Menschen brauchbare Substanz entdeckt hätte, und auch die wenigen Versuche, in denen ein im Tierexperiment geprüftes Mittel am Menschen zur Anwendung gelangt ist, sind nicht dazu angetan gewesen, dem betreffenden Verfahren allgemeinen Eingang in unsere Therapie zu verschaffen.

Der Grundgedanke, der sich durch alle experimentellen Untersuchungen in dieser Richtung zieht, ist der, durch Applikation von öligen oder schleimigen Substanzen auf die lädierten Stellen des parietalen oder visceralen Peritoneums oder in deren Umgebung ein Verkleben und Verwachsen dieser Stellen zu verhüten, dadurch, daß die geschädigten Partien so lange in einem Zustand der Schlüpfrigkeit und des leichten Aneinandervorbeigleitens gehalten werden, bis das geschädigte Oberflächenepithel wieder :vollständig hergestellt ist, was nach den Beobachtungen Grasers innerhalb eines Zeitraumes von 4 Tagen etwa zu geschehen pflegt. 
postoperativer peritonealer Adhäsionen mittels arteigenen flüssigen Fettes. 499

Ich gebe zunächst in folgendem einen kurzen Überblick über die wichtigsten experimentellen Untersuchungen, die sich mit der Frage der Verhütung peritonealer Verwachsungen beschäftigt haben.

Die ersten positiven Vorschläge zur Verhütung postoperativer Adhäsionen und ihrer Folgezustände gehen auf P. Müller zurück. Müller empfahl (D. Ges. f. Gyn., I. Kongr., München 1886) die Anfüllung des Abdomens vor Schluß der Bauchwunde mit einer größeren Menge $(2400 \mathrm{~g})$ sterilisierter 7 prom. NaCl-Lösung, um der Gefahr der auf pseudomembranöser Verwachsung beruhenden Darmokklusion vorzubeugen. Durch den so hergestellten künstlichen Ascites sollte der Kontakt der Wundflächen von Darm und Amputationsstumpf miteinander und mit der Bauchwunde für eine gewisse Zeit aufgehoben werden bis die intraperitonealen Wundflächen wieder epithelialisiert waren. Bei einem Versuch mit diesem Verfahren ergaben sich bei einer Patientin mehrere unangenehme Symptome (Dyspnöe, Fieber, Pulsfrequenz), die Müller aus der raschen Resorption der Flüssigkeit erklärt. Zur Vermeidung dieser unangenehmen Nachwirkung empfahl Müller dann als das Ideal seiner Methode die permanente Irrigation der Bauchhöhle. So viel ich übersehe, ist dieser phantastische Vorschlag Müllers niemals in die Tat umgesetzt worden. In der Diskussion wies damals Ohlshausen auf die Gefahr des Schocks nach einem derartigen künstlichen Ascites hin, Landsberg hob die rasche Resorptionsfähigkeit der NaCl-Lösung, die dadurch den beabsichtigten Zweck nicht erfülle, hervor und die Gefahr der Maceration des Peritonealepithels mit anschließender Adhäsionsbildung, ferner die Gefahr der Infektion durch Schaffung eines aus NaCl-Blutmischung bestehenden günstigen Nährbodens für Mikroorganismen.

Duschinsky hat die Anwendung der Kochsalzeinbringung in die Bauchhöhle zur Verhütung von Adhäsionen nach dem Vorgehen von Müller nachgeprüft und fand bei weitem bessere Resultate, als er nach den Versuchen anderer Autoren wie Stern hätte erwarten sollen. Auch Duschinsky beobachtete bei Einführung größerer NaCl-Mengen in die Bauchhöhle Erscheinungen hochgradiger Dyspnöe, die sich aber erst nach Stunden verloren, und die ihre Ursache haben dürften in einer Verdrängung des Zwerchfells nach oben durch das. Flüssigkeitsvolumen. Nach der Ansicht Duschinskys sind die Resultate mit der Müllerschen $\mathrm{NaCl}-\mathrm{Füll}$ ung die bei weitem besten unter allen bisherigen Versuchen, so daß, wenn es gelänge die schweren Begleiterscheinungen zu umgehen, die Müllersche Methode ihm am ehesten geeignet erscheint, durch Kontaktverhinderung zwischen Darm und Peritoneum in der ersten Zeit post operationem die Neigung zu Adhäsionsbildung wesentlich zu verringern. Duschinsky hat dann weiter verschiedene andere Substanzen zur Verhütung peritonealer Adhäsionen experimentell ge- 
prüft. Versuche mit Glycerin ergaben, daß das Mittel nicht imstande ist, die Bildung von Adhäsionen sicher zu hindern. Weitere Versuche machte Duschinsk y mit Collodium und Goldschlägerhäutchen. Stern hatte schon vorher Collodium zu gleichem Zwecke verwandt und wollte im Collodium ein absolut sicheres Mittel gefunden haben, um Adhäsionen zwischen Netz und Bauchwand zu verhindern. Duschinsky konnte diese günstige Wirkung nicht bestätigen und fand in fast sämtlichen Fällen nach Collodium ausgiebige Verwachsungen an den bepinselten Stellen und sieht in diesem negativen Ergebnis eine Bestätigung der Versuche Dembowskys, der mit Celloidin, einer dem Collodium ganz ähnlichen Substanz, eine auffallende Neigung zu Adhäsionsbildung gefunden hatte. Auch die Versuche mit Goldschlägerhäutchen, mit denen Duschinsky Netzstümpfe überkleidete, hatten ein absolut negatives Ergebnis, und dürfte die auf den Fremdkörperreiz einer derartigen intraperitoneal applizierten Substanz einsetzende Bindegewebswucherung gerade erst recht dazu angetan sein, Adhäsionen zu erzeugen.

Ungünstige Resultate, die auch Stern schon mit der Anwendung der Müllerschen NaCl-Füllung der Bauchhöhle gemacht hatte, brachten diesen Autor auf den Gedanken, zu dem genannten Zwecke den Netzstumpf mit einer Fetthülle zu umgeben. An der Czern yschen Klinik, wo Stern seine Versuche anstellte, hatte man schon mehrmals nach Darmresektion und Operation stark verwachsener Ovarialcysten die Wundflächen mit sterilisiertem Jodoformvaselin bestrichen, um Adhäsionen zu verhüten. Da die Operation gut ausging, hatte man nicht feststellen können, ob die Einfettung der wunden Flächen die Entstehung von Adhäsionen verhindert hatte.

Ster $n$ experimentierte an Kaninchen. Er benutzte den nach Resektion eines Stückes Netz zurückgelassenen Netzstumpf als Indikator für die Brauchbarkeit eines gegen Adhäsionsbildung anzuwendenden Mittels. Er prüfte zu diesem Zwecke zunächst ein Fett, das Ungt. paraff. der Pharmakopöe, das Paraff. liq. und Paraff. solid. enthält, im Verhältnis $4: 1$. Stern konnte mit der Applikation dieser Fette den gewünschten Erfolg nicht erzielen und schiebt den Mißerfolg darauf, daß die bei Bauchhöhlentemperatur eintretende Verflüssigung des Fettes verhindere, daß der Stumpf in der notwendigen Dicke mit der Fettsubstanz umkleidet sei. Er wandte deshalb in einer anderen Versuchsreihe ein Paraffingemisch von zwei Teilen Paraff. liq. und einen Teil Paraff. solid. an, daß bei Körpertemperatur noch Salbenkonsistenz hatte. Auch das Résultat dieser Versuche war in der Hauptsache ein negatives. Zwar betont $S$ ter $n$, daß in dieser sowie seiner ersten Versuchsreihe das Paraffin stets völlig reizlos vertragen worden sei was nach meinen Versuchen unverständlich ist -, doch konnte er die Verhütung der..Adhäsionen nicht in der gewünschten Weise erzielen. 
Stern versuchte dann weiter den bei Körpertemperatur festen gewöhnlichen Hammeltalg, der also als „Hülle“ nach seiner Ansicht das denkbar beste leisten mußte. Stern stellte sich eine ätherische Lösung von Hammeltalg her und suchte den Stumpf des Netzes dadurch mit einer dünnen Talgschicht zu überziehen, da $B$ er ihn in die Lösung tauchte und diese verdampfen ließ. Doch ergab sich, daß dadurch keine feste zusammenhängende Talgmembran entstand, außerdem nahm der Stumpf infolge der durch die Ätherverdampfung hervorgerufenen Kälte ein verdächtig schwärzliches Aussehen an, so daß Stern von diesen Versuchen abließ. Auch Eintauchen in auf $50^{\circ}$ erhitzten Hammeltalg und Erstarrenlassen der so geschaffenen Stumpfhülle hatte nicht den gewünschten Erfolg. Eine reizende Wirkung des auf diese Weise in die Bauchhöhle gebrachten Hammeltalgs will Stern ebensowenig konstatiert haben wie bei den ersten Versuchen mit den verschiedenen Paraffingemischen. Die zum Teil recht beträchtlichen, nachträglich auftretenden Verwachsungen schiebt Stern auf die mannigfachen Läsionen, die das Netz bei der Operation erlitten hatte, allerdings stimmt ihn auch noch bedenklich der Umstand, daß der zuletzt angewandte Hammeltalg scheinbar überhaupt nicht resorbiert wurde und es nicht gleichgültig sein könne, eine derartige harte Masse auf die Dauer einem Individuum einzuverleiben. Auch die relativ hohe Temperatur, bei der die Substanz erst in flüssigem Zustand eingeführt werden konnte, erhöhten seine Bedenken. Ferner hat Stern dann noch Olivenöl intraperitoneal zur Verhütung von Adhäsionsbildung angewandt mit dem Ergebnis, daß eine größere Menge Olivenöl $(150 \mathrm{ccm})$ nicht resorbiert wird, sondern als stark reizendes Agens in der Peritonealhöhle verbleibt, daß kleinere Mengen $(15-20 \mathrm{ccm})$ den gesuchten Erfolg nicht haben. Die negativen Erfolge veranlaßten dann Stern, den Netzstumpf mit einer dünnen Collodiumschicht zu umkleiden und gelang es ihm in sechs Versuchen, Adhäsionsbildung zu verhüten. Die den Stumpf umkleidende Collodiummembran übt nach Sterns Ansicht dank ihrer Zartheit und Glätte einen Reiz auf das Peritoneum nicht aus. „Bepinselung des Stumpfes mit Collodium, so daß eine dünne glatte Membran entsteht, beugt konstant den Verwachsungen vor und läßt dabei eine schädliche Nebenwirkung nicht erkennen."

Einen ähnlichen Gedanken, durch eine trennende Schicht, wenn auch nur temporär, die beiden zu Verwachsung neigenden Gewebspartien vor einem Verkleben untereinander zu hüten, hatte schon Lauenstein, als er nach Trennung von Verwachsungen zwischen Gallenblase und Duodenum zwischen die gelösten Partien ein vierfingerbreites Stück protektive Silk einschob, dessen äußeres Ende er aus der teilweise offengelassenen Wunde herausleitete und nach $2 \times 24$ Stunden entfernte. 
Busch und Bibergeil haben an einer Anzahl von Versuchen an Hunden, die verschiedensten Fette und schleimigen Substanzen auf ihre Fähigkeit postoperative Adhäsionen zu verhindern, geprüft. Reines Olivenöl war nicht imstande, nachträgliche Adhäsionen zu verhüten. Zwar vermochte das normale Peritoneum die im Anfang ziemlich starke Reizung des Öls ohne Schädigung zu überwinden, doch erscheint den Autoren diese Reaktion des Peritoneums immerhin so erheblich, daß die Anwendung des Öls bei Menschen zum Zwecke der Adhäsionsverhinderung nicht rätlich erscheint.

Körte hat einige Male bei Menschen nach Lösung von starken Adhäsionen nach Magenulcus bzw. Relaparatomie nach Cholecystektomie kleine Mengen sterilen Olivenöls zwischen die gelösten Darmschlingen gegossen in der Absicht, die Wiederentstehung von Verwachsungen zu hindern. Das ÖI wurde anscheinend ohne Nachteil vertragen. Ob eine Verminderung von Verwachsungen der Serosaflächen erzielt wurde, ließ sich nicht feststellen.

Busch und Bibergeil prüften dann weiter festere Fette auf ihre adhäsionshemmende Fähigkeit, von der Überlegung ausgekend, daß sich mit ihnen leichter ein dünner Überzug über die ganze Bauchserosa herstellen lasse; sie verwandten zu diesem Zwecke Lanolin und Paraffin. Die vollständige Unbrauchbarkeit der genannten Fette für den beabsichtigten Zweck sehen Busch und Bibergeil vor allem in dem Umstand, daß die beiden Substanzen nicht vom Peritoneum resorbiert werden, sie bleiben in feiner Schicht auf der Peritonealfläche verteilt liegen und üben hier als mehr oder mindergroße Partikelchen einen Fremdkörperreiz aus, in dessen Gefolge die chronische Peritonitis dann sekundär erst recht zu ausgedehnten Verwachsungen führt. Auch. die mit verschiedenen schleimigen Mitteln angestellten Versuche zur Adhäsionsverhütung führten zu einem negativen Ergebnis. Am wenigsten reizend auf das Peritoneum wirkten Gummi arabicum und Carrageen (Aufschwemmung von isländischem Moos). Die Resorption dieser beiden Substanzen findet aber schon bald in den ersten 2 Tagen post op. statt, so daß aus diesem Grunde bei ausgedehnten Serosaschädigungen der Eintritt von Adhäsionen nicht verhindert werden kann. Sehr starke peritonitische Reizung mit stets folgender Adhäsionsbildung ergaben Versuche mit Agarlösung. Weniger stark reizend wirkte die Anwendung von 2proz. Gelatinelösung, doch blieb die Flüssigkeit infolge ihrer schnellen Resorption nicht lange genug mit den geschädigten Serosaflächen in Berührung, um Verwachsungen zu verhüten. Aus dem gleichen Grunde erwies sich $2^{1} / 2$ proz. isotonische Fibrolysinlösung als unzweckmäßig, die zwar ohne jeden Reiz vom Peritoneum vertragen, aber viel zu schnell resorbiert wurde.

Busch und Bibergeil heben dann noch hervor, daß gelegentlich 
von Relaparatomien gemachte Erfahrungen in dieser Richtung nur mit Vorsicht zu bewerten sind. Bei der kritischen Bewertung ihrer Versuche kommen die Verfasser resigniert zu dem Schluß, daß es ihnen nicht gelungen sei, ein adhäsionsverhütendes Mittel ausfindig zu machen, daß sie aber trotzdem ihre negativen Ergebnisse mitteilen, um andere von vergeblichen Bemühungen abzuhalten.

Das große Interesse aber, das der Frage der Verhütung postoperativer Adhäsionen entgegengebracht wurde, hat auch in der Folgezeit die verschiedensten Autoren veranlaßt, in dem angegebenen Sinne weiter zu arbeiten.

Vogel ging bei seinen tierexperimentellen Versuchen zur Verhütung von Adhäsionen zunächst von dem Gedanken aus, durch Anregung der Peristaltik gleich nach der Laparatomie die Intestina in möglichst steter Bewegung gegeneinander zu halten und durch die Vermeidung eines längeren Kontaktes der nach jeder Laparatomie mehr oder weniger gelähmten Darmsehlingen untereinander und mit dem parietalen Peritoneum die dadurch bedingte Verklebungsgefahr in den ersten Tagen nach der Laparatomie hintanzuhalten. Die möglichst zeitige Anregung der Peristaltik nach Laparatomien kann ja überhaupt die Entstehung von postoperativen Verwachsungen verhüten oder dieselben in den ersten Tagen; solange sie noch nicht fest und derb geworden sind, wieder sprengen, wie das besonders von Reichert und Riss mann hervorgehoben worden ist. Vogel suchte die Peristaltik im Tierversuch anzuregen durch entsprechende laxierende Diät (Darreichung von Runkelrüben) und durch chemische Mittel, subcutane Darreichung von Atrop. sulf. 2 mal täglich je 0,002. Die Anwendung der laxierenden Diät gab er wieder auf, da sie sich nicht auf den Menschen übertragen ließ, das Atropin erwies sich als wenig brauchbar, weil die Tiere es nicht gut vertrugen, obwohl die Erfolge quoad effectum ermutigend waren. Recht gute Erfolge erzielte er dann mit der subcutanen Anwendung von Physostigmin. salic., 3 mal täglich 0,0002 , das eine starke Peristaltik ohne unangenehme Nebenwirkung im Gefolge hatte. Doch ergaben die Versuche in dieser Richtung, daß mit der Anwendung peristaltikfördernder Mittel das Auftreten von Adhäsionen wohl verringert, aber nicht verhütet werden konnte. Vogel versuchte deshalb die aktive Bewegung der Därme zu unterstützen durch intraperitoneale Einverleibung einer schlüpfrigen, schleimigen Flüssigkeit, und zwar prüfte er zu diesem Zwecke eine Salepabkochung, gewöhnliches Hühnereiweiß direkt aus dem $\mathrm{Ei}$ und eine dickflüssige Lösung von Gummi arabicum ( 1 : 2 physiologische NaCl-Lösung), außerdem noch ein Mucingemisch. Von den angewandten Mitteln hat sich Vogel die sterile dickflüssige Lösung von Gummi arabicum in physiologischer Kochsalzlösung am besten bewährt zur Arregung der pas- 
siven Bewegung der Intestina in Kombination mit der Anregung aktiver Bewegung der Darmschlingen durch die peristaltikfördernde Injektion von Physostigmin. salic.

Versuche mit gerinnungshemmenden Mitteln, wie Magnes. sulf. 5-20 proz. und konzentrierter Lösung von Pepton zur Vermeidung der die Verklebung der Serosaflächen einleitenden Fibringerinnung, erwiesen sich als unbrauchbar. In einer späteren Publikation hat dann Vogel die intraperitoneale Einverleibung von Gummi arabicum mit Natr. citr. empfohlen. Die Gummilösung sollte die Resorption verlangsamen und durch ihre schlüpfrige Konsistenz die passive Beweglichkeit der Intestina gegeneinander fördern, das Natr. citr. die fibrinöse Verklebung durch Gerinnungshemmung hindern. Bis zum Jahre 1917 hatte Vogel das Verfahren in 11 Fällen bei Menschen angewandt (Centralbl. f. Chir. 1917 Nr. 30). Keiner dieser operierten Patienten hat wieder Adhäsionsbeschwerden bekommen. In einem Falle, der $3 \mathrm{mal}$ laparatomiert war (Appendektomie, Gastroenterostomie, Ileocolostomie), wurden in einer vierten wegen chronischen Ileus vorgenommenen Laparatomie ausgedehnte Verwachsungen festgestellt und gelöst und nach obiger Methode der Wiedereintritt von Adhäsionen zu verhüten gesucht. Bei einer fünften vorgenommenen Laparatomie fand sich Abknickung des oberen Ileums durch Hineinschlüpfen einer Darmschlinge in eine Peritonealtasche, die durch die frühere Ileocolostomie bedingt war, also eine innere Hernie, dagegen fehlten jegliche peritoneale Adhäsionen. Auf Grund seiner Erfahrungen im Tierexperiment und am Menschen glaubt Vogel die Anwendung von Gummi arabicumLösung zur Verhütung postoperativer Adhäsionen empfehlen zu dürfen.

Die Verhütung von Adhäsionsbildung durch frühzeitige Anregung der Peristaltik durch Physostigmin haben sich praktisch als wenig erfolgreich erwiesen und hatten von Uyeno an der Küttnerschen Klinik in dieser Richtung angestellte Tierexperimente keinen positiven Erfolg. Uye no versuchte dann auf Anregung ihres Chefs die Lösung experimentell erzeugter Adhäsionen durch Massage zu erzielen. Es gelang ihr in acht Versuchen an Kaninchen die vorher experimentell erzeugten Adhäsionen durch Massage zu lösen, wenn auch nicht immer vollständig. Die Massage war in den angeführten Fällen 20-40 Tage nach der ersten Verätzung der Darmschlingen an den Tieren begonnen worden. Die Massage hat sich ja zur Dehnung bzw. Lösung alter besonders perimetritischer Verwachsungen nach dem Vorgehen von ThureBrandt schon seit langem in der konservativen Gynäkologie ein, wenn auch nur recht bescheidenes therapeutisches Feld erobert. Daß aber energisch durchgeführte Massage in den ersten Wochen nach einer Laparatomie nach dem Vorgehen von U yeno imstande sein soll, postoperative Adhäsionsbildung zu verhüten oder frisch gebildete Adhäsionen 
zu Iösen, erscheint mir doch sehr unwahrscheinlich, vielmehr möchte ich glauben, daß durch eine derartige Behandlungsmethode mit Sicherheit vermehrte Exsudation im Operationsgebiet erzeugt wird, die nach unseren Erfahrungen erst recht zur Adhäsionsbildung führen muß und die Rekonvaleszenz beträchtlich hinausschiebt.

Im Anschluß hieran möchte ich dann noch kurz eine mechanische Maßnahme erwähnen, die von Payr angegeben ist: die Füllung der Darmschlingen mit Eisenverbindungen und Beeinflussung derselben durch den Elektromagneten. Das im Tierversuch eingehend durchge prüfte Verfahren erscheint aussichtsvoll nicht nur für die Erkennung, sondern auch für die Prophylaxe und Lösung frischer sowie die Dehnung alter Adhäsionen.

In ähnlicher Weise sucht Kroh durch seine „Saugmassage" des Abdomens alte peritoneale Adhäsionen zu lösen. Auch Kirchberg hat postoperative Adhäsionsbeschwerden durch Saugbehandlung erfolgreich beeinflußt.

In neuerer Zeit hat dann Pribram, auf Anregung seines Chefs Payr, durch die Einbringung von Glaskörpersubstanz die Entstehung peritonealer Adhäsionen zu verhüten gesucht. Pribram verwandte Glaskörpersubstanz aus den Augen frisch geschlachteter Kälber, die sich nach Entfernung der Cornea, Linse und Iris unter aseptischen Kautelen unter leichtem Druck in die Injektionsspritze pressen ließ. So gewonnene Glaskörpersubstanz ließ sich 2-3 Tage steril aufbewahren und erwies sich nach den angestellten Versuchen als eine Substanz, die, in einer Menge von 50-150 $\mathrm{ccm}$ intraperitoneal appliziert, imstande war, sich gleichmäßig im Peritonealraum zu verteilen und das Peritoneum glatt und schlüpfrig zu machen, ohne irgendwie reizend zu wirken und ohne auch zu schnell vom Peritoneum resorbiert zu werden.

Pribram weist auf die Schwierigkeit hin, im Tierexperiment mit Sicherheit Adhäsionsbildung zu erzeugen, und hat sich ihm zu diesem Zwecke das Zurücklassen von Gazetupfern in der Bauchhöhle, das Betupfen einzelner Partien der Darmserosa oder des Netzes mit Tinctura Jodi oder Bestreuen mit metallischem Magnesiumpulver am besten bewährt. Auf Grund seiner Versuche kommt Pribram zu dem Ergebnis, daß es durch die Einbringung von Glaskörpersubstanz möglich ist, primäre Adhäsionsbildung bei Katzen, Hunden und Kaninchen entweder zu verhindern oder wenigstens wesentlich zu beschränken, je nach den Reizmitteln, die zur Erzeugung der Adhäsionen angewandt worden war. Adhäsionsbildung bei bakterieller Infektion oder nach schweren und ausgedehnten chemischen Reizen können dagegen nicht verhindert werden.

In einer Diskussionsbemerkung zu Pribrams Vortrag auf dem 43. chirurgischen Kongreß macht Kocher auf eine Beobachting auf- 
merksam, die er bei einem Magenvolvulus gemacht hat, bei dem eine Chylusstauung mit Chyluscysten im Peritoneum zustande gekommen war. Dabei war auffällig, welche bequeme Verschiebung des Darmes, Magens und übrigen Bauchinhalts in dieser Chylusschmiere sich bewirken ließ. Kocher hat daraufhin Versuche gemacht, diese Chylusschmiere zu ersetzen, und zwar auf Grund der Übereinstimmung von Chylus mit homogenisierter Milch. Kocher hat in einer Reihe von Fällen statt des Chylus als Bauchschmiere diese homogenisierte und sterilisierte Milch angewandt. Statt physiologische NaCl-Lösung gießt Kocher ein kleines Quantum homogenisierter Milch ins Abdomen. Wenn man diese mit der Hand auf dem Bauchinhalt ausbreitet, so genügt eine kleine Menge, um (wenigstens für eine gewisse Zeit) zu verhüten, daß die Därme an einer Wunde ankleben. Bei der Wichtigkeit und den schlimmen Folgen von Adhäsionen scheint ihm jedes Mittel erwünscht, welches für die erste Zeit nach operativen Eingriffen Verklebungen und Verwachsungen verhütet, welche nach seinen Erfah. rungen auch nach aseptisch tadellos geheilten Bauchoperationen so häufig und ausgedehnt sich finden und bei Nachoperationen sehr große Schwierigkeiten bereiten. Erfahrungen mit dieser Methode nach längerer Beobachtung teilt Kocher nicht mit.

Im gleichen Jahre erschien dann eine experimentelle Arbeit von Sch miedt aus der Payrschen Klinik über Adhäsionsbeschränkung in der Bauchhöhle durch Hirudinbehandlung.

Vogel hatte schon, wie oben erwähnt, Versuche mit gerinnungshemmenden Mitteln zur Vermeidung der die Verklebung der Serosam flächen einleitenden Fibringerinnung gemacht, und zwar hatte er zu diesem Zwecke Magn. sulf. und konzentrierte Lösung von Pepton verwandt, ohne ein brauchbares Resultat zu erzielen. Weitere Versuche mit Blutegelextrakt unterlie $B$ er deshalb, da ihm von anderer Seite auf Grund experimenteller Versuche, die zu anderen Zwecken unternommen waren, mitgeteilt wurde, daß dasselbe das Peritoneum sehr stark reize und die Tiere sehr angriffe, ja oft geradezu töte. Sch miedt hat dann den Gedanken Vogels wieder aufgegriffen und die gerinnungshemmende Kraft des Hirudins auf die Verhütung peritonealer Adhäsionen bei intraperitonealer Einverleibung des Mittels geprüft. Die gerinnungshemmende Wirkung des Hirudins beruht nach Ansicht von Haykraft, Fuld und Spiro und Morawitz auf einer quantitativen Bindung an das fertige Fibrinferment, während Pekelharing annimmt, daß es schon auf die Thrombokinase wirke. Blut mit Hirudin versetzt läßt sich nur durch Zusatz von Fermentlösung und durch große Gewebsextraktmengen zur Gerinnung bringen (Jakoby). Haykraft und Buchanaan haben nachgewiesen, daß Hydrocelenflüssigkeit bei Zusatz von Fibrinferment, das in fast jedem Gewebe enthalten 
ist, gerinnt, und daß man diese Gerinnung durch Zusatz von Hirudin aufhalten kann. Demnach erschien es Schmiedt wahrscheinlich, daß Hirudin auch in der serösen Bauchflüssigkeit seine gerinnungshemmende Wirksamkeit entfaiten müsse. Sch miedt verwandte 0,02 bis 0,05 Hirudin meist in $50 \mathrm{ccm}$ NaCl-Lösung, der er 5-10 Tropfen Adrenalinlösung (1:1000) zusetzte, um die Resorption des Hirudins herabzusetzen. Die resorptionshemmende Kraft des Adrenalins bei intraperitonealer Einverleibung ist durch Versuche Glimms erwiesen. Die Einspritzungen von Hirudinlösung wurden an 4 aufeinander folgenden Tagen vorgenommen, um die Wirkung des Hirudins während dieser Zeit konstant zu erhalten, da erst nach dem genannten Zeitraum, wie schon erwähnt; die Regeneration der geschädigten Serosaepithelien einzutreten pflegt (Graser). Als adhäsionserregendes Mittel verwandte Schmiedt in seinen Versuchen das von $\mathrm{Payr}$ zu diesem Zwecke empfohlene Magn. metallic. in Pulverform. Schmiedt hat auf die angegebene Weise künstlich gebildete Adhäsionen verhindern oder ihre Entstehung wenigstens sehr einschränken können. Schädliche Nebenwirkungen hat er von dem Hirudin nicht beobachtet. Doch scheint ihm die Übertragbarkeit seiner Tierversuche auf den Menschen selbst noch recht zweifelhaft, vornehmlich wegen der Schwierigkeit der während mehrerer Tage nacheinander notwendig werdenden intraperitonealen Einbringung der Hirudinlösung; praktische Versuche am Menschen sind jedenfalls mit der Methode nicht gemacht worden.

Von den bisherigen zur Anwendung gelangten Substanzen, mögen sie tierischer oder pflanzlicher Herkunft gewesen sein, war keine imstande, sich einen Platz in unserer. Therapie zu erobern und die vielfach enthusiastischen Empfehlungen der betreffenden Experimentatoren sind nur zu bald verklungen, und man hat nichts mehr von den verschiedenen Methoden gehört.

Der Mißerfolg der bisherigen Versuche liegt meines Erachtens in erster Linie darin begründet, daß es sich bei den angewandten Mitteln, die die Entstehung von Verwachsungen verhüten sollten, um körperfremde Stoffe gehandelt hat, denen lediglich die Eigentümlichkeit einer Gleitschmiere zukam, die aber wohl gleichzeitig vor allem als Fremdkörper wirkten. Der Fremdkörperreiz dieser Substanzen auf das Peritoneum scheint aber hier durchweg das primär günstig wirkende Moment der Schlüpfrigmachung der peritonealen Flächen in seiner Wirkung zu übertreffen und die dadurch bedingte starke reaktive Peritonitis ihrerseits erst recht die Entstehung peritonealer Adhäsionen zu begünstigen, als wie beabsichtigt, zu verhüten.

Die günstigen Erfahrungen, die wir an unserer Klinik in den letzten Jahren mit der Deckung unvollkommen peritonealisierter Adnex- oder Uterusstümpfe durch freitransplantiertes Netz gemacht hatten, legten 
mir den Gedanken nahe, die Verhütung peritonealer Adhäsionen durch die Anwendung arteigenen Fettes in flüssigem Zustande zu versuchen.

Die freie Netzüberpflanzung, von Senn, Girgolaff, Loew y zuerst ausgeführt, ist bekanntlich angegeben zur Deckung von Serosadefekten und zum Aufnähen auf unsichere Darmnähte. Girgolaff hat im Tierexperiment an Hund und Katze die Brauchbarkeit freitransplantierter Netzstücke als Deckmaterial mangelhaft vereinigter oder des peritonealen Überzugs und der Muskelschicht teilweise beraubter Organe der Bauchhöhle (Magen, Dickdarm, Harnblase) erwiesen. Schon am 2. Tage konnte er eine genügend breite Verbindung zwischen den Gefäßen des ,Bodens" und denjenigen des aufgepflanzten Netzstückes nach weisen. Eine Nekrose trat niemals ein. In keinem Falle, wo eine aseptische Heilung erzielt wurde, entstanden Verwachsungen in der Bauchhöhle. Verletzungen der großen Bauchdrüse, Leberresektionen wurden mit derartigen Netzstücken bedeckt und ,gepfropft" (Bourres epiploiques, Loew y, Thèse de Paris 1901). Die transplantierten Netzstücke zeigten eine hohe Vitalität und erwiesen sich als durchaus geeignet, das Durchschneiden der Nähte, Nachblutungen und das Entstehen von Adhäsionen zu verhindern.

Andere Autoren, wie Springer, Sundholm hingegen haben ausgedehnte Verwachsungen derartig transplantierter Netzstücke mit den benachbarten Därmen und der Bauchwand beobachtet. Lexer hält auf Grund der Graserschen Untersuchungen diese Neigung des Netztransplantats zu Verwachsungen für verständlich und möchte der Transplantation subcutanen Fettgewebes auch bei derartigen Defekten der Bauchhöhle den Vorzug geben, besonders unter Berücksichtigung der experimentellen Erfahrungen Hilses, der nach intraperitonealer Transplantation subcutanen Fettgewebes keine Verwachsungen beobachtet hatte. Netzlappen wären nach Lexer bei Serosamuscularisdefekten im Bauchraum nur da zu verwenden, wo durch Verwachsungen mit der Nachbarschaft Störungen der Darmfunktion nicht eintreten können.

Wir haben in den letzten Jahren von der freien Netztransplantation bei der Deckung unvollkommen peritonealisierter Adnex- und Uterusstümpfe ausgiebig Gebrauch gemacht und niemals schädliche Folgen und das Entstehen von Verwachsungen danach beobachtet, soweit das aus der klinischen Beobachtung der Fälle festzustellen war.

Es schien mir deshalb der Gedanke erfolgversprechend und der experimentellen Prüfung wert, den Hauptbestandteil des Netzes, das Fett in flüssiger Form als Deckmaterial zu verwenden, und zwar von dem Gesichtspunkte der Bŕauchbarkeit zur Verhütung postoperativer Verwachsungen

Die Anwendung flüssigen Menschenfetts ist ja in der Chirurgie der letzten Jahre nach dem Vorgehen von Holländer als Humanol zu 
plastischen Zwecken vor allem mit gutem Erfolge zur Anwendung gebracht worden. Holländer verwandte zu plastischen Operationen (Auffüllung atrophischer Mammae, Ausgleich von Gesichtsdefekten) die subcutane Einbringung eines Gemisches von Menschenfett und Hammeltalg, da er die Erfahrung gemacht hatte, daß Menschenfett allein zu schnell resorbiert wurde. Weiter empfiehlt Holländer in einer späteren Mitteilung (Centralbl. f. Chir. 1918, Nr. 20) das Humanol als Füllmaterial zur Ausfüllung bei Knochenhöhlen mit Fistulierung in Form von Eingießung heißen Humanols. Mit dieser Methode erzielte Holländer in ca. 3 Wochen einen fistellosen Verschluß der Knochenhöhle. Statt der knochenadhärenten Narben erzielte man bewegliche und nicht eingezogene. Ohne die schädliche Nebenwirkung eines Fremakkörpers und deshalb auch nicht durch eine andere Fettoder Ölart ersetzbar, hat es für jedes Individuum den gleichen körpereigenen Wert. Diese von Holländer betonten Eigenschaften des körpereigenen Fettes lassen dasselbe in dem von uns beabsichtigten Sinne von vorneherein als besonders geeignet erscheinen.

Ma yer-Tübingen verwandte reines unvermischtes flüssiges Menschenfett zur Behandlung der Blasenschließmuskelinsuffiziens. Die Erfolge mit dieser Methode schiebt er auf die schwere Resorptionsfähigkeit des subcutan applizierten Menschenfettes, das nach seiner Ansicht wahrscheinlich dauernd oder doch sehr lange unaufgesaugt an der Stelle der Injektion zurückbleibt und so komprimierend und stïtzend auf den insuffizienten Schließmuskel bzw. die erweiterte Harnröhre einwirkt.

Vor kurzem erschien eine vorläufige Mitteilung von Eden und Lindig (Dtsch. med. Wochenschr. 23. IX. 1920), die'sich mit der Lösung desselben Problems der Verhütung postoperativer Verwachsungen durch das gleiche Mittel beschäftigt haben. Wie die beiden Autoren einleitend bemerken, erfuhren sie zufällig von Versuchen, welche jeder von ihnen unabhängig voneinander gemacht hatte, welche aber in gleicher Weise dahinzielten, durch Verwendung tierischen bzw. menschlichen Fettes in flüssigem Zustande, Verwachsungen in der Bauchhöhle zu verhindern.

Denselben Gedanken habe ich unabhängig von den beiden Autoren und ohne Vorwissen ihrer diesbezüglichen Arbeiten schon vor nun mehr Jahresfrist gehabt, konnte aber meine ersten tierexperimentellen Versuche zur Klärung dieser Frage durch die Ungunst äußerer Verhältnisse, Mangel an Tieren usw. erst im Juli 1920 etwa 3 Monate vor der Publikation Eden und Lindigs. beginnen. Ich habe bisher von einer vorläufigen Mitteilung Abstand genommen, da ich die Absicht hatte, durch ein ausgiebiges tierexperimentelles Material und entsprechend lange Beobachtung, mir ein möglichst einwandfreies Urteil über die Brauchbarkeit der Methode zu bilden. 
Ich habe meine Versuche an 42 Kaninchen gemacht, an denen im ganzen 63 Laparatomien bzw. Relaparatomien und 30 Sektionen vorgenommen wurden, und zwar handelte es sich durchweg um kräftige größere Tiere.

Die Versuchsanordnung gestaltete sich so, daß die seit 12 Stunden hungernden Tiere stets in Äthernarkose operiert wurden. Abscheren der Bauchhaare, restlose Enthaarung durch Aufstreichen von Bariumsulfatbrei, Abspülen der enthaarten Bauchhaut unter fließendem warmen Wasser, Abtrocknen mit sterilen Tupfer und zweimaliger Jodierung mit 10\% Jodtinktur. Das Operationsgebiet wurde durch besonders hergestelltes steriles Schlitztuch mit kleiner Öffnung abgedeckt. Operateur und assistierende Operationsschwester arbeiteten in Gummihandschuhen. Nahtmaterial war fast ausnahmslos Trockencatgut (Kuhn), Stärke 00, in geringem Umfange Jodcatgut, Stärke 0-1. Die Eröffnung der Bauchhöhle geschah in sämtlichen Fällen durch Längsschnitt in der Mittellinie, und zwar fast durchweg in der Oberbauchgegend in Höhe des Magens bzw. Netzes. Von der Laparatomie in der Unterbauchgegend, unterhalb des Nabels, habe ich nach einigen Versuchen wegen Unzweckmäßigkeit der Anordnung Abstand genommen. Das Netz ist beim Kaninchen verhältnismäßig schlecht entwickelt, kurz und reicht nicht tief herab, und da wir die Neigung des Netzes zu Verwachsungen bei unseren Versuchen in erster Linie berücksichtigen müssen, ist es natürlich notwendig, bei der Anlegung des Laparatomieschnittes auf die Topographie des Netzes Rücksicht zu nehmen. In einer ganzen Reihe von Publikationen, die sich mit der Erzeugung bzw. Verhütung peritonealer Adhäsionen beschäftigen, ist die genaue Anlegung des Bauchschnittes aus den Protokollen nicht ersichtlich. Man kann natürlich Adhäsionen des Netzes an der Bauchnarbe nur dann erwarten, wenn der Schnitt im Bereich der Topographie des Netzes angelegt worden ist; so habe ich die Eröffnung der Bauchhöhle fast immer in der Oberbauchgegend vorgenommen, so daß das dicht unter dem Bauchschnitt liegende Netz stets in Kontakt mit der Bauchwand stand und dadurch die Möglichkeit der Adhäsionsbildung erleichtert wurde. Bevor ich auf die Versuchsanordnung im einzelnen komme, will ich noch kurz eingehen auf die verschiedenen Mittel und Methoden, die von den einzelnen Autoren im Laufe der Zeit im Tierexperiment zur Erzeugung peritonealer Adhäsionen angewandt sind. Denni es ist natürlich eine notwendige Vorbedingung, daß wir eine einigermaßen sicherwirkende Methode zur Erzeugung peritonealer Adhäsionen zur Verfügung haben müssen, wenn wir Substanzen auf ihre adhäsionshemmende Wirkung tierexperimentell prüfen wollen.

Alle Autoren stimmen darin überein, daß ein mehr oder weniger ausgiebiger Verlust der Endothelien die Vorbedingung ist für das Ver- 
wachsen seröser Häute. Die Endothelien schützen die serösen Häute vor Verwachsungen; letztere können erst zustande kommen, wenn die Endothelien aus irgendwelchen Gründen verloren gegangen sind. Wir wissen, daß, wenn unbedeckte Bindegewebsschichten aneinanderstoßen, dieselben in kürzester Zeit miteinander verwachsen.

$\mathrm{Ob}$ einseitige Serosaschädigung schon allein für sich Adhäsionen verursachen kann oder ab doppelseitige Schädigung, d. h. die Schädigung zweier gegenüberliegender Serosaflächen eine Conditio sine qua non ist, darüber sind die Ansichten geteilt.

Graser hat schon nach einfacher Eventeration der Darmschlingen und oberflächlicher Schädigung durch Abreiben mit trockenem Tupfer ausgedehnte Adhäsionsbildung der Darmschlingen untereinander und mit dem parietalen Peritoneum beobachten können, auch wenn die Schädigung bzw. Reizung des Peritoneums nur auf einer Seite der beiden mit Peritoneum bekleideten und später miteinander verwachsenen Flächen angelegt worden war. Rißmann, Busch und Bibergeil erzielten ähnliche Resultate.

Kelterborn verwundete das Peritoneum parietale und die Serosa des Dünndarms mit scharfem Löffel und bekam auch hier keine Adhäsionen, stellte vielmehr fest, daß nach einigen Wochen die lädierten Stellen glatt überhäutet waren, wenn es zu keiner Zerstörung der Muscularis gekommen war. In ähnlicher Weise erbrachte Vogel den Beweis, daß die Schädigung zweier gegenüberliegender Serosaflächen nicht unbedingt zu Adhäsionsbildung führen muß, insofern er nach Reibung des parietalen Peritoneums und des Serosaüberzuges des Colon ascendens keinerlei Adhäsionsbildung feststellen konnte. Durch stärkere Schädigung des parietalen Peritoneums durch Gitterung (Incisionen mit dem Messer) und durch Schaben mit dem scharfen Löffel erzielte Vogel jedoch flächenhafte Adhäsionen und glaubt er in Übereinstimmung mit Saenger, daß stärkere Läsionen wohl meist von Adhäsionen gefolgt sind. Sa n ger excidierte bei Kaninchen größere Stücke des Peritoneum parietale der vorderen Bauchwand und beobachtete immer, daß die unverletzten Darmschlingen mit der Wunde verwuchsen. Es ist also für die Bildung von peritonealen Adhäsionen nach Saengers Ansicht nicht notwendig, daß zwei Wundflächen vorhanden sind, sondern es genügte schon eine einzige.

Kelterbor n konnte durch gleiche Versuche keine Adhäsionsbildung erzeugen. Auch ich sah verschiedentlich in meinen Versuchen streifenförmige Excisionen des parietalen Peritoneums in kreisförmiger Umgebung des Bauchschnitts, wenn am gegenüberliegenden Darm oder Netz kein Serosadefekt gesetzt war, in relativ kurzer Zeit ausheilen, ohne daB die geringste Adhärenz an der Stelle des gesetzten Peritonealdefektes aufgetreten war. Die Regenerationskraft des Peritoneums ist 
eben eine sehr große und, wenn keine sonstige stärkere Schädigung, vor allem keine Infektion zu einem einseitig gesetzten Peritonealdefekt hinzutritt, dürfte die folgenlose Überhäutung durch Überwuchern der Endothelien vom Rande her die Regel und die adhäsive Verklebung mit Bauchinhalt die Ausnahme sein. Auch von Dembowsky sah nach einseitiger Schädigung des parietalen Peritoneums durch Bürsten mit einer Zahnbürste, bis das Serosaepithel blutig geschunden aussah, keine Adhäsionsbildung auftreten.

Von weiteren mechanischen Schädigungen des Peritoneums, die im Tierexperiment zur Adhäsionsbildung vielfach benutzt sind, erwähne ich zunächst das Anlegen von Brandschorfen. Spiegelberg und Waldeyer beobachteten nach der Anwendung des Galvanokauters am Hundeuterus stets ausgedehnte Verwachsung des Mesometrium. Ähnliche Beobachtungen machte Maslowsky über das Verhalten von Brandschorfen in der Bauchhöhle von Hunden. Auch v. De mbowsky beobachtete nach Anlegen von Brandschorfen an den verschiedenen Stellen des parietalen Peritoneums die Entstehung der Adhäsionen.

Küstner und Kelterborn kamen zu anderen Resultaten. Küstner bestreitet auf Grund seiner klinischen Beobachtungen die Notwendigkeit, daß stets nach Brandschorfen Adhäsionen entstehen müssen. Kelterborn sah im Tierexperiment nach Verschorfung keine Adhäsionsbildung entstehen und glaubt, daß Brandschorfe meist nicht zu Verwachsungen führen, wenn aber solche entstehen, glaubt er, die Ursache dafür in der hinzutretenden Infektion erblicken zu müssen.

Vogel sah nach oberflächlicher Verschorfung des parietalen Peritoneums stets breite Verwachsungen, und zwar nicht nur des Netzes, sondern auch der Därme an der verschorften Stelle der Bauchwand auftreten, während die intensivere Anwendung des Glüheisens, die einen breiten tiefen Substanzdefekt zur Folge hatte, nicht von Adhäsionsbildung gefolgt war. Vogel sieht den Grund für diese auffällige Tatsache in der verschieden starken Intensität der Anwendung des Glüheisens in ähnlicher Weise wie Graser schon diesen Unterschied in bezug auf die Anwendung chemischer Mittel für die Adhäsionsbildung des Peritoneums feststellen konnte in der Weise, daß allzu starke chemische Reize keine Adhäsionen hervorrufen, sondern durch Verhinderung der prima intentio geradezu adhäsionshemmend wirken. Bei der oberflächlichen Anwendung des Galvanokauters kommt es eben nur zu einer Zerstörung der oberflächlichen Schicht der Endothelien, das freiliegende subendotheliale Bindegewebe verklebt und verwächst in kurzer Zeit, die prima intentio wird nicht gehindert. Bei intensiver Verschorfung kommt es hingegen zu mehr oder weniger starken Nekrotisierungen, wodurch die Verklebungen der geschädigten Partien, die prima intentio, gehindert wird. 
Von weiteren mechanischen Reizen, die als adhäsionsbildend gelten und häufig im Tierexperiment zu diesem Zwecke verwertet worden sind, erwähne ich noch Ligaturen, die am Peritoneum parietale oder am Darm bzw. Netz oder Leber zurückgelassen wurden. Spiegelberg und Waldeyer fanden bei ihren Versuchen, daß die Ligaturen innerhalb der Peritonealhöhle an und für sich keine intensiveren lokalperitonitischen Erscheinungen bedingen und daß sie kaum als fremde Körper den Geweben des Uterus und den Mesometrien gegenüber betrachtet werden können. Sie erregen in diesen Geweben keine irgendwie erheblichen Mortifikationsvorgänge, werden vielmehr sehr bald eng umschlossen und abgekapselt. In ähnlicher Weise stellte Kelterborn fest, daß Ligaturen in der Bauchhöhle meistenteils nicht Ursache von Adhäsionsbildung sind, daß sie vielmehr die Tendenz zeigen, sich abzukapseln.

Netzabbindungen, Ovariotomiestiele führen nach Bu m m, Fritsch, Stern u. a. immer zu Adhäsionen; andererseits sahen Steffens, Busch und Bibergeil selten Verwachsungen von ihnen ausgehen. Vogel konnte nach Abbindungen des großen Netzes in einer oder mehreren Portionen zum Teil unter gleichzeitiger Gitterung des parietalen Peritoneums in sämtlichen Fällen Adhäsionen des Netzstumpfes feststellen.

Fremdkörper, die in die Bauchhöhle eingebracht werden, führen nach allgemeiner Ansicht meist zu Adhäsionsbildung. Drains, Tampons, die längere Zeit in der Bauchhöhle liegen bleiben, werden für das Entstehen von Adhäsionen verantwortlich gemacht, wenn auch unsere klinischen Erfahrungen darauf hindeuten, daß das nicht immer der Fall zu sein braucht. Es sind zahlreiche derartige Beobachtungen mitgeteilt, wo nach voraufgegangener längerer Drainage bzw. Tamponade später bei einer wiederholten Laparotomie keinerlei Adhäsionsbildung gefunden wurde: Im Tierexperiment haben besonders Vogel und Pribra $m$ sich der in die Peritonealhöhle eingebrachten Fremdkörper zwecks Erzielung von Adhäsionen bedient. Vogel bezeichnet das Einbringen von Fremdkörpern als ganz sicheres Mittel, um Adhäsionen hervorzurufen und bedient er sich hierzu eines aseptischen Mulltupfers von $1-2 \mathrm{~cm}$ Dicke, den er zwischen die Darmschlingen legte. Auch nach Pribram, der die Schwierigkeit der Erzeugung peritonealer Adhäsionen im Tierexperiment hervorhebt wegen der wechselnden Reaktion des tierischen Peritoneums auf gleichartige Reize, hat sich das Zurücklassen kleiner Gazetupfer in der Bauchhöhle zur Erzeugung von Adhäsionen am besten bewährt.

Daß kleinere Fremdkörper, in die Bauchhöhle gebracht, sich weniger zur experimentellen Erzeugung von Verwachsungen eignen, geht aus Versuchen Roloffs und Hinsbergs hervor. Roloff brachte anschließend an Versuche Marchands Seidenfäden in. die Bauchhöhle 
und konnte bald lediglich bindegewebige Einkapselung des Fadens ohne größere Adhäsionsbildung feststellen, wie das in gleicher Weise von Gruzdew beobachtet wurde. Hinsberg injizierte nach dem Rate Ribberts eine Aufschwemmung von Lycopodiumsamen in die Bauchhöhle von Meerschweinchen und fand nie Anzeichen einer stärkeren peritonitischen Reizung zwischen den Darmschlingen; die Serosa war ïberall spiegelnd, lediglich fanden sich auf derselben hier und da gelbliche Knötchen, teils an der Grenze der Sichtbarkeit stehend, teils größer in einem feinen Netzwerk von Fibrinfäden liegend, in dessen Maschen eine feinkörnige, offenbar aus geronnenem Eiweiß bestehende Masse lag.

Weiter sei hier dann noch das Jodoformpulver erwähnt, dem seiner Struktur nach auch wohl ein Fremdkörperreiz zuzusprechen ist. Vogel brachte eine kleine Menge erbsengroß zwischen die Darmschlingen und fand nach 8 Tagen nicht nur keine Spur des eingebrachten Mittels mehr vor, sondern auch keinerlei Adhäsionsbildung. Das Jodoform dürfte hiernach wohl nur in den ersten Stunden nach der Einbringung als Fremdkörper wirken und bald zur Auflösung und Resorption gelangen.

Das Jodoform leitet über zu einer Gruppe von Mitteln, denen eine adhäsionsbildende Kraft zugesprochen wird, den chemischen Substanzen.

Vogel erzielte ausgedehnte flächenhafte Verwachsungen nach Betupfung benachbarter Darmschlingen durch einen in Sublimat getauchten Tupfer. Einen sehr starken chemischen Reiz wandte Vogel dann noch an durch Bestreichen des Darms mit Höllensteinstift. Es entstand sofort ein weißer Ätzschorf, jedoch fanden sich bei der Relaparotomie niemals Adhäsionen und erblickt Vogel die Ursache dafür darin, daß bei der Ätzwirkung chemischer Mittel analog der Wirkung von Brandschorfen allzu starke Reize keine Adhäsionen hervorrufen, sondern im Gegenteil durch Verhinderung der Prima intentio geradezu adhäsionshemmend wirken, was schon von Graser vorher betont worden ist.

Hiermit läßt sich eine klinische Beobachtung Payrs und Li nd ners in Einklang bringen, die bei Peritonitisfällen, die mit starker Eiterung einhergingen, seltener Adhäsionen gesehen haben, wie bei solchen, die nur von geringer Eiterung begleitet waren. Nach Schmiedt beruht die Ursache dieses Verhaltens auf dem Fermentgehalt des Eiters.

Von anderen chemischen Mitteln erwähne ich noch die Jodlösung, in Form der Tinctura Jodi oder der L u golschen Lösung, die von Heinz als ein Mittel angegeben wird, mit dem wir typische adhäsive Entzündung hervorrufen können. Schon 48 Stunden nach Injektion einer 2 proz. Jodjodnatrium-Lösung waren zahlreiche Darmschlingen zu einem unentwirrbaren Paket verwachsen. Auf der Darmoberfläche fand sich 
eine spinnwebig dünne Schicht von typischem Exsudatfibrin. Untềr dieser Schicht war die Serosa weißlich trübe verändert und zeigte ein in eigentümlicher Weise verändertes Gewebe von hyalinem Aussehen: Dasselbe Verhalten ist von Borst nach Injektion: von Jodlösung in die Peritonealhöhle von Meerschweinchen beschrieben. Vogel hat den Heinzschen Versuch mit Lugollösung nachgeprüft. Beide Tiere kollabierten und gingen nach einigen Tagen ein. Die Injektion ergab für den Tod keine Ursache (Kollaps), doch fanden sich mehrere noch nicht sehr feste fibrinöse Darmverklebungen. U ye no hat dann ebenfalls Lugollösung zur Erzeugung von Adhäsionen angewandt, und es gelang ihr, schon nach 10 Tagen feste bindegewebige Verwachsungen zu erzielen. Doch erwies sich die einfache Injektion in die Bauchhöhle als unsicher und gelang es ihr erst, die adhäsionsbildende Eigenschaft der Jodlösung besser zur Wirkung zu bringen, wenn sie zwei Darmschlingen aneinander fixierte durch Serosanaht oder umfassende Fadenschlingen und die sich berührendèn Flächen mit der Jodlösung bepinselte.

Dem intraperitonealen Bluterguß kommt nach Klotze, Vogel u. a. nur dann eine adhäsionsfördernde Wirkung zu, wenn gleichzeitig eine Schädigung des intakten Epithels stattfindet. Das Blut gerinnt dann an dieser verletzten Stelle ebenso wie in einem Blutgefä $B$ mit verletzter Intima und ist so die Ursache zu weit ausgedehnteren Verwachsungen, als sie die Verletzung allein gemacht haben würde. Im Gegensatz zu den genaniten Autoren konnte Schrü nder in seinen Versuchen nach Bluteinbringung und Serosaverletzung in keinem Falle Adhäsionsbildung beobachten, wenn keine Infektion hinzugetreten war. Daß die intraperitoneale Epithelverletzung eine größere sein muß, geht schon aus der Überlegung hervor, daß der, wenn auch meist nur geringe, Blutaustritt beim Platzen des Graafischen Follikels trotz der hier doch auch vorhandenen Epithelverletzung des Ovariums doch nie zu Adhäsionsbildung führt. Blut, welches von außen in eine vollkommen intakte Peritonealhöhle hineingebracht wird, wird in kurzer Zeit, ohne jede Adhäsionsbildung zu hinterlassen, resorbiert (Vogel, Graser). Es befindet sich eben nach Wegner in der Bauchhöhle, wie in einem Gefäß mit intaktem Endothel.

$\mathrm{Ob}$ eine bakterielle Infektion zu der gesetzten Serosaschädigung hinzutreten muß, um zu Adhäsionsbildung zu führen, wird von Rißmann, Fromme, Kelterborn, Schründer bejaht, während nach Walthard, Vogel, Busch und Bibergeil auch ohne Infektion Adhäsionen zustande kommen können. Jedenfalls dürfte nach unseren klinischen Erfahrungen die hinzukommende Infektion wohl sicher als ein begünstigendes Moment für das Auftreten von Verwachsungen anzusehen sein. Und in diesem Zusammenhange kommt wohl waueh den 
intraperitonealen Bluterguß eine besondere Bedeutung zu, insofern, als das angesammelte Blut die Entwicklung von Keimen erst recht begünstigt.

Wenn ich nun zu meinen eigenen Versuchen übergehe, so habe ich als adhäsionserzeugenden Reiz zunächst die einseitige Läsion des parietalen Peritoneums angewandt, und zwar durch Scarification des Peritoneums durch kreuzweises Ritzen des Peritoneums mit dem Messer. Die in fast allen Fällen eintretende glatte Überhäutung der gesetzten Defekte ohne den Eintritt von Adhäsionen ließen mich dazu übergehen, die Verletzung des Peritoneums an zwei korrespondierenden Flächen zu wählen, und zwar verwundete ich das parietale Peritoneum in der Umgebung des in der Oberbauchgegend angelegten Längsschnittes in einem Umkreis von etwa $3 \mathrm{~cm}$ Breite durch kreuzweise Scarification mit dem Messer teils in Verbindung mit streifenförmigen Excisionen des parietalen Peritoneums in Gestalt von schmalen, etwa $0,5: 3 \mathrm{~cm}$ langen, radiär zum Schnitt angelegten Längsstreifen. Gleichzeitig wurde an dem gegenüberliegenden Netz doppelseitige Epithelschädigung gesetzt in der Weise, daß das Netz vor die Bauchhöhle gezogen, auf eine trockene Kompresse gelagert und erst die eine, dann die andere Seite durch Ritzen mit dem Messer lädiert wurde, bis das Netz deutlich geschunden aussah. In einzelnen Fällen wurden dann noch Catgutligaturen angelegt, sei es, um dadurch die Entstehung von Adhäsionen noch mehr zu begünstigen oder eine durch die Ritzung mit dem Messer verursachte Netzblutung zu stillen. Auf diese Weise gelang es mir fast regelmäßig, Adhäsionsbildung zu erzielen. Die stärksten Adhäsionen erzielte ich aber in einzelnen Versuchen, in denen ich zu den genannten Schädigungen des parietalen Peritoneums und des Netzes dann noch oberflächliche Ritzungen des Serosaüberzuges des Magens vornahm und die gesamten so geschädigten Serosateile mit $10 \%$ Jodtinktur betupfte. Heinz, der zuerst das Jod als adhäsionserzeugendes Mittel anwandte, benutzte Lugollösung (bis $2 \%$ ). U ye no spritzte bei ihren Versuchen $5 \mathrm{ccm} 1$ proz. Jodjodnatrium-Lösung ein Uyeno konnte auch nach dieser relativ schwachen Jodlösung starke lokale und allgemeine Schädigung der Versuchstiere feststellen. In sechs von neun Tieren kam es zu Verwachsungen zwischen den Darmschlingen oder zwischen Darm und Nachbarorganen, während drei weitere Tiere in den ersten drei Tagen nach der Injektion zugrunde gingen, ohne daß irgendeine sichtbare peritoneale Schädigung (Fibrinauflagerung oder Verwachsung) nachzuweisen gewesen wäre, und muß dieser Exitus wohl als eine Jodschädigung aufgefaßt werden.

Auch mir gingen verschiedene Tiere nach kräftiger Jodierung in den folgenden 2-3 Wochen zugrunde. Es fanden sich zwar in diesen Fällen Verwachșungen, wie ich das stets nach kräftiger Jodapplikation 
beobachten konnte, aber dieselben waren doch nicht so stark und ausgedehnt, daß man nach dem Befund den Exitus hätte damit in Zusammenhang bringen können. Dagegen zeigten die Darmschlingen in größerer Ausdehnung und auch das parietale Peritoneum deutlich auch noch nach 14 Tagen eine bräunliche Verfärbung als Überrest der Jodapplikation. In diesen Fällen war es nicht nur zu einem Betupfen der lädierten Stellen gekommen, sondern es war auch etwas Jodtinktur in geringer Menge in die Bauchhöhle hineingelaufen. Die: gesamte so intraperitoneal applizierte Menge Jodtinktur betrug etwa $2-3 \mathrm{ccm}$. Ich glaube deshalb nicht fehl zu gehen, den eingetretenen Exitus in den angegebenen Fällen auf die zu reichliche Jodapplikation zurückführen zu sollen.

Ich bin deshalb in meinen übrigen Versuchen stets so vorgegangen, daß ich die Jodtinktur lediglich durch rasches Betupfen mit den geschädigten Stellen des parietalen Peritoneums und des Netzes in Berührung gebracht habe und es peinlich vermied, überschüssige Jodtinktur etwa von hier aus über die angrenzenden Partien der Bauchwand bzw. vor allem der Darmschlingen zu verbreiten. Hierzu reichte ein geringere Menge Jodtinktur ( $1 \mathrm{ccm}$ und weniger) aus.

Die Entstehung der durch vorstehende Maßnahmen sich bildenden peritonealen Adhäsionen suchte ich in meinen Versuchen zu verhindern durch die gleichzeitige Anwendung arteigenen Fettes in flüssigem Zustande.

Das hierzu notwendige Material entnahm ich frisch getöteten gemästeten Kaninchen, und zwar aus den meist recht gut entwickelten Fettlagern in der Umgebung der Nieren, längs den langen Muskeln an der Vorderfläche der Wirbelsäule, aus den Fettdepots, die sich subcutan auf dem Rücken der Tiere von der Halsmuskulatur nach abwärts ziehen und aus dem zwischen den Darmschlingen angehäuften Fett. Die Ausbeute ist nur bei besonders schweren Tieren eine reichliche, oft mußte ich das von mehreren Tieren gewonnene Fett gleichzeitig verarbeiten, um ein reichliches Quantum zu erhalten. Das so gewonnene Fett wird mehrere Stunden unter fließendem Wasser gewässert, um es von Blutbeimengung zu befreien, dann wird das gröbere Bindegewebe nach Möglichkeit herauspräpariert und das Fett in kleine Stückchen zerschnitten, worauf es nochmals mehrere Stunden gewässert wird. Das so präparierte Fett wurde im Wasserbad geschmolzen und durch Heißwasserfilter filtriert und das so erhaltene goldgelbe 01 in sterile Erlenmeyer-Kolben gegeben und nochmals im Trockensterilisator sterilisiert und steril verschlossen aufgehoben. Durch bakteriologische Untersuchung wurde die Keimfreiheit festgestellt und bei Verwendung nach längerem -Aufheben vor dem Gebrauch durch wiederholte bakteriologische Untersuchung auf Sterilität geprüft. 
Das so gewonnene Fett erstarrt nach dem Erkalten zu einer schweineschmalzähnlichen konsistenten Masse. In Abderhaldens Biochemischem Handlexikon, III. Aufl., Berlin 1911, finden wir über die physikalischen Eigenschaften des Fettes des Hauskaninchens folgende Zahlen:

$\begin{array}{ccc}\text { Spez. Gewicht } & \text { Erstarrungspunkt } & \text { Schmelzpunkt } \\ \text { bei } 15 \% 0,9342 & 22-24^{\circ} \mathrm{C} & 40-42^{\circ} \mathrm{C}\end{array}$

Ich habe zunächst in vier Vorversuchen mit dem so gewonnenen. Kaninchenfett versucht festzustellen, wie die Tiere auf die intraperitoneale Einverleibung des Fettes reagierten und welche Veränderungen sich nach verschieden langer Zeit in der Bauchhöhle nachweisen ließen.

Ich lasse die diesbezüglichen Versuchsprotokolle im Auszuge folgen:

Versuch 1. Schwarzes $q$ Kaninchen Nr. 3. Körpergewicht $1890 \mathrm{~g}$.

30. VII. 1920. In Äthernarkose Eröffnung der Bauchhöhle durch $2 \mathrm{~cm}$ langen Längsschnitt. Injektion von $20 \mathrm{ccm}$ flüssigen, körperwarmen Kaninchenfettes durch eingebundene stumpfe Kanüle. Sofortiger Schluß der Bauchhöhle durch dreischichtige Naht: fortlaufende Peritoneummuskelnaht, überwallende Muskelfasciennaht, Hautnaht.

31. VII. Tier sitzt ruhig, macht kranken Eindruck, frißt nicht,

1. VIII. Tier lebhafter, geringe Nahrungsaufnahme.

19. VIII. In Äthernarkose Relaparotomie. Körpergewicht $1875 \mathrm{~g}$ (-15). $6 \mathrm{~cm}$ langer Längsschnitt seitlich des ersten fest verheilten Leibschnittes.

Befund der Bauchhöhle: In der Umgebung des Laparotomieschnittes ist das parietale Peritoneum in einer Ausdehnung von Kleinhandtellergröße von einer weißlich fettigen Schicht bedeckt, die das Peritoneum wie eine Membran gleichmäßig überkleidet; desgleichen sind die anliegenden Darmschlingen in ihrem Serosaüberzug von einer ähnlichen feinen Schicht bedeckt. An einzelnen Stellen dieser Auflagerung sieht man feine zottenartige Fortsätze. Verwachsungen der Bauchnarbe mit den Intestinis bestehen nicht, auch nicht zwischen den Darmschlingen untereinander. Flüssiges Fett ist nicht mehr in der Bauchhöhle vorhanden. - Schluß der Bauchhöhle.

18. IX. Tier getötet $d$ urch Chloroform. Körpergewicht $2225 \mathrm{~g}(+380)$. Keine Verwachsung der vorderen Bauchwand mit den Intestinis, auch nicht zwischen den Darmschlingen untereinander. Die peritonealen Auflagerungen sind in ihrer Ausdehnung und Stärke deutlich zurückgegangen, vor allem die zottenartigen Fortsätze.

Histologischer Befund eines Stückes der Bauchwand im Bereich einer derartigen Auflagerung: Lockeres zellreiches Bindegewebe mit zahlreichen neu gebildeten Capillaren. Vereinzelte kleinzellige Infiltrate. In den Lüeken des Gewebes Fett in größeren und kleineren Tropfen eingelagert, zum Teil intracellulär. Der freie Rand der Auflagerung ist mit Endothel bedeckt. An einzelnen Stellen sieht man stark ausgeprägte zottenartige Wucherungen, die ebenfalls aus Bindegewebe und Capillaren bestehen, und die auch Fetteinschlüsse aufweisen. Thre Oberfläche weist nur vereinzelt Endothelzellenbelag auf.

Versuch 2. Graues $\bigcirc$ Kaninchen Nr. 2. Körpergewicht $1895 \mathrm{~g}$.

30. VII. In Äthernarkose Eröffnung der Bauchhöhle durch $2 \mathrm{~cm}$ langen Mittelschnitt. Injektion von $30 \mathrm{ccm}$. flüssigen, körperwarmen Kaninchẹfettes. Sofortiger Schluß der Bauchhöhle.

31. VII. Tier macht 'schwerkranken. Eindruck, sitzt zusammengekauert, frißt nicht. 
1. VIII. Etwas lebhafter, frißt noch nicht.

2. VIII. Geringe Nahrungsaufnahme.

19. VIII. Rela paroto mie. Körpergewicht $1840 \mathrm{~g}(-55)$.

Eröffnung der Bauchhöhle durch $6 \mathrm{~cm}$ langen Längsschnitt seitlich dés ersten fest verheilten Leibschnittes. Kein flüssiges Fett mehr in der Bauchhöhle. In der Umgebung der Bauchnarbe ist das parietale Peritoneum in einer Ausdehnung von über. Handtellergröße mit einer weißlich fettigen. Schicht bedeckt, desgleichen findet sich eine ähnliche Schicht auf der Serosa der.Darmschlingen, dieselben fast in ganzer Ausdehnung überziehend. Ein dünner Netzzipfel ist an der Bauchwand dicht nebèn dem Schnitt verwachsen, sonstige Adhäsionen zwischen den Darmschlingen untereinander oder mit dem parietalen Peritoneum sind nicht vorhanden.

Resektion eines kleinen Stückes der Bauchwand im Bereich der geschilderten Auflagerung zwecks histologischer Untersuchung. Bauchnaht.

Histologischer Befund: Die Anflagerungen bestehen vorwiegend aus organisiertem Fibrin und Granulationsgewebe.

18. IX: 2. Relaparotomie. Körpergewicht $2245 \mathrm{~g}(+350)$.

An der Stelle der. Bauchwandexcision hat sich eine walnußgroße Hernie gebildet. Bruchpforte daumendick.

Die Adhäsion des dünnen Netzzipfels (s. oben) ist etwas breiter und fester geworden; sonstiger Bauchinhalt ist nicht adhärént. Die peritonealen Auflagerungen noch deutlich sichtbar, aber feiner und zarter. Auch zwischen den Darmschlingen sind die Auflagerungen deutlich zurückgebildet und nur noch in umschriebenen Bezirken vorhanden. Verwachsungen zwischen den Darmschlingen bestehen nicht. Schluß der Bauchhöhle und Plastik der Hernie.

Versuch 3. Graues 우 Kaninchen Nr. 1. Körpergewicht $2100 \mathrm{~g}$.

30. VII. In Äthernarkose Eröffnung der: Bauchhöhle durch $2 \mathrm{~cm}$ langen Mittelschnitt. Injektion von $30 \mathrm{ccm}$ flüssigen, körperwarmen Kaninchenfettes. Schluß der Bauchhöhle.

31. VII. Tier macht schwerkranken Eindruck, frißt nicht.

1. VIII. Etwas munterer, beschnuppert Nahrung.

2. VIII. Geringe Nahrungsaufnahme:

21. VIII. Getötet durch Chloroform. Körpergewicht $1980 \mathrm{~g}(-120)$.

Kein flüssiges Fett in der Bauchhöhle, das parietale Peritoneum ist in großer Ausdehnung von einer dünnen, fettigen, gelblichen Schicht überzogen, die schon makroskopisch ein Gerüst von feineren Fäden erkennen läßt, so daß dadurch die Auflagerungen einen membranartigen Charakter erhalten. Auch die Darmschlingen sind von derartigen fettmembranähnlichen Auflagerungen bedeckt, die sich leicht von dem Serosaüberzug der Darmschlingen abziehen lassen. Diese Auflagerungen lassen schon makroskopisch, besonders beim Betrachten unter Wasser, zottenartige Bildungen erkennen. Adhäsionen der Bauchwand mit den Darmschlingen sind nicht vorhanden, auch nicht zwischen den Intestinis.

Histologischer Befund eines excidierten Bauchwandstückes: Auf dem Peritonealüberzug lockermaschige, zottige, an Fettgewebe erinnernde Auflagerungen. Entzündliche Infiltrationen sind nicht nachweisbar. Das Gewebe besteht vorwiegend aus jungem Bindegewebe und neu gebildeten Capillaren; stellenweise erkennt man zwischen Maschen in reichlicher Menge Fett, bald in größeren, bald in kleineren Tropfen liegend, in den Zellen selbst ist Fett nur in ganz spärlicher Menge als feine Tröpfchen erkennbar. Die Auflagerung, vor allem auch die zottenartigen Fortsätze, sind mit Endothelbelag bedeckt.

Versuch 4. Gravies ơ Kaninchen Nr. 4. 'Körpergewicht $1900 \mathrm{~g}$.

21. VIII: In Äthernarkose $2 \mathrm{~cm}$ langer Längsschnitt. Injektion von $10 \mathrm{ccm}$ flüssigem Kaninchenfett. 
22. VIII. Tier macht schwerkranken Eindruck, frißt nicht, stark beschleunigte Atmung.

23. VIII. Tot im Stall. Körpergewicht $1880 \mathrm{~g}(-20)$.

Sektionsbefund: In der Bauchhöhle kein flüssiges Fett mehr. Dagegen ist die peritoneale Auskleidung der Bauchhöhle und der Serosaüberzug der Darmschlingen mit einer matten, hauchartigen, gleichmäßig verteilten feinen Fettschicht überzogen. Irgendwelche zottenartige Excrescenzen oder fadenartige Bildungen sind nicht erkennbar. Desgleichen finden sich keine Adhäsionen.

Als Todesursache wird doppelseitige Pneumonie festgestellt, die auch histologisch nachgewiesen wird. Für Fettembolie ergibt die histologische Untersuchung der Lungen keinen Anhalt.

Das Ergebnis dieser vier Vorversuche wurde nach einem Zeitraum von 3-21 Tagen nachkontrolliert, und zwar in 2 Fällen durch Relaparotomie, in 2 Fällen durch Sektion. Zunächst ist festzustellen, daß die Tiere auf die intraperitoneale Einverleibung des Fettes mit deutlichem Krankheitsgefühl reagierten, und zwar ergab sich, daß die Intensität und Dauer dieser Reaktion sich nach der Menge des einverleibten Fettes richtete. Die Tiere machten am 1. Tage einen ausgesprochen kranken Eindruck, saßen ruhig zusammengekauert mit beschleunigter Atmung und wurden erst meist vom 3. Tage an munterer und nahmen Nahrung zu sich. Der Laparotomie als solcher ist für diese Erscheinung wohl kaum eine auslösende Ursache zuzusprechen, da sowohl die Kürze des Eingriffs, der nur einige Minuten dauerte, wie auch die Unbedeutenheit der Operation als solcher hierfür nicht verantwortlich gemacht werden kann. Schon am 3. Tage nach der Operation fand sich kein flüssiges Fett mehr in der Bauchhöhle. Das Fett fand sich vielmehr in bald dünnerer, bald dickerer Schicht gleichmäßig fein verteilt anf dem gesamten parietalen und visceralen Peritoneum verbreitet. Nach 21 Tagen zeigten diese das Peritoneum bedeckenden Fettschichten einen ausgesprochen zottenartigen Charakter, der besonders deutlich an dem einen Tier in die Erscheinung trat, das $30 \mathrm{ccm}$ Fett erhalten hatte. Bei diesem letzteren Tiere fand sich dann auch als Zeichen der stärkeren peritonealen Reaktion ein dünner Netzzipfel an der Bauchwand adhärent, während in den übrigen 3 Fällen keinerlei Adhäsionen weder mit der Bauchwand noch mit den Darmschlingen nachweisbar waren.

In den beiden folgenden Versuchsgruppen ging ich dann zur eigentlichen Prüfung der adhäsionshemmenden Wirkung des Kaninchenfettes bei gleichzeitiger Peritonealschädigung über, und zwar verwandte ich zunächst noch das Fett nach der oben angeführten Herstellungsart durch einfaches Zerlassen im. Wasserbad.

Versuch 5a. Graues of Kaninchen Nr. 5. Körpergewicht $2170 \mathrm{~g}$.

24. VIII. In Äthernarkose $4 \mathrm{~cm}$ langer Mittelschnitt. Scarification des angrenzenden parietalen Peritoneums durch Ritzen und Schaben mit der Scalpellspitze. Schluß des Peritoneums und der Muskelschicht durch fortlaufende Naht 
bis auf kleine Öffnung für eingebundene Kanüle. Injektion von $10 \mathrm{ccm}$ flüssigen Kaninchenfettes. Definitiver Schluß der Bauchhöhle und exakte Bauchnaht.

25. VIII. Tier macht schwerkranken Eindruck, frißt nicht.

26. VIII. Etwas lebhafter, noch keine Nahrungsaufnahme.

27. VIII. Tier springt umher, frißt.

31. VIII. Relaparotomie. Körpergewicht $2083 \mathrm{~g}$ (-87).

Eröffnung der Bauchhöhle etwas oberhalb der ersten Laparotomienarbe in der Mittellinie. Beim Durchtrennen der Bauchdecken fällt die starke Gefäßerweiterung und der Blutreichtum der Bauchwand auf. Kein flüssiges Fett mehr in der Bauchhöhle. Das parietale Peritoneum und die Darmserosa sind von einem gleichmäßig verteilten fettigen Belag überzogen. Die scarificierte Partie in der Umgebung des Laparotomieschnittes ist besonders stark von dieser Fettschicht bedeckt, aber vollkommen frei von Adhäsionen. Ebensowenig sind zwischen den Darmschlingen Verwachsungen nachweisbar.

9. X. Tier getötet durch Chloroform. Körpergewicht $2835 \mathrm{~g}(+752)$.

Bauchnarbe fest verheilt, vollkommen frei von Adhäsionen. Die peritonealen Auflagerungen sind bis auf kleine inselförmige, gelbweiße Herde zurückgebildet. Die Darmschlingen sind glatt und spiegelnd und weisen keinerlei Auflagerungen mehr auf. Auf dem Mesenterium sieht man vereinzelte feine stecknadelkopf- bis hirsekorngroße weißliche Stellen, in deren Umgebung reichlich Gefäßentwicklung sichtbar ist und die als Fetteinschlüsse anzusprechen sind.

Versuch 5b. Schwarzes 은 Kaninchen Nr.6. Körpergewicht 2520 g. (Kontrolltier.)

24. VIII. In Äthernarkose Laparotomie. Dieselbe Versuchsanordnung wie unter a, nur keine Fettinjektion.

Schon am Abend des Operationstages ist das Tier munter und nimmt Nahrung.

25. VIIT. Springt lebhaft umher und frißt, als wenn es nicht operiert wäre.

31. VIII. In Äthernarkose Rela paroto mie. Körpergewicht $2648 \mathrm{~g}(+72)$. Unterhalb des ersten Bauchschnittes. Peritoneum parietale an der Stelle des ersten Bauchschnittes und in seiner Umgebung im Bereich der Scarification vollkommen glatt und spiegelnd; keinerlei Adhäsionen, auch sonst zwischen den Darmschlingen keine Verwachsung.

Versuch 6a. Graues ơ Kaninchen Nr. 7. Körpergewicht $1820 \mathrm{~g}$.

26. VIII. In Äthernarkose $4 \mathrm{~cm}$ Längsschnitt in Mittellinie. Scarification des angrenzenden parietalen Peritoneums in einem Umkreis von $3 \mathrm{~cm}$ durch Ritzen und Schaben mit der Messerspitze. Verschluß des Peritoneums und der Muskelschicht durch fortlaufende Catgutnaht bis auf kleine Öffnung für eingebundene stumpfe Kanüle, durch die $20 \mathrm{~cm}$ Kaninchenfett injiziert wird; definitiver Schluß der Bauchhöhle.

27. VIII. Tier macht schwerkranken Eindruck, frißt nicht.

28. VIII. Noch keine Nahrungsaufnahme.

1. IX. Auch heute hat sich das Tier noch nicht wieder erholt, nimmt nur wenig Nahrung.

4. IX. Getötet durch Chloroform. Körpergewicht $1740 \mathrm{~g}(-80)$.

Sektion: In der Bauchhöhle in den abhängigen Partien, besonders steißwärts, finden sich etwa $10 \mathrm{ccm}$ einer gelblich-weißen, cremeartigen Masse. Von der gleichen Masse, die offenbar das eingespritzte Fett darstellt, findet sich eine gleichmäßig verteilte Schicht in der Bauchhöhle auf dem parietalen Peritoneum in ganzer Ausdehnung, wie auch auf dem Serosaüberzug der Darmschlingen. Die Därme sind nicht gebläht. Die Leber zeigt ebenfalls auf ihrer Oberfläche diese Fettschicht, und zwar besonders intensiv.

Mikroskopisch besteht diese Masse aus Fettkugeln und Eiterkörperchen, keine Mikroorganismen. 
Baktexiologisch blieben die angelegten Kulturen steril.

Erwärmt wird diese Masse weicher, flüssiger, verbreitet deutlich den charakteristischen scharfen Geruch des geschmolzenen Kaninchenfettes, wird aber nicht klar wie dieses sonst.

Versuch 6b. Graues 우 Kaninchen Nr. 8. Körpergewicht 1400 g. (Kontrolltier.)

26. VंIII: In Âthernarkose $4 \mathrm{~cm}$ langer Längsschnitt in der Mittellinie. Die gleiche Versuchsanordnung wie bei a, nur keine Fettinjektion.

27. VIII. Tier munter, frißt, zeigt keinerlei Beeinträchtigung des Befindens.

4. IX. In Äthernarkose Rela parotomie. Körpergewicht $1495 \mathrm{~g}(+95)$.

$6 \mathrm{~cm}$ Längsschnitt seitlich der ersten Operationsnarbe. Peritoneum parietale an der Stelle der Bauchnarbe und im Bereich der Scarification vollkommen glatt und spiegelnd, frei von Adhäsionen, auch sonst zwischen den Darmschlingen keine Verwachsungen vorhanden.

Aus diesen Versuchen ergab sich nur zunächst, daß die einseitige Schädigung des Peritoneums durch Scarification in der Umgebung des Laparotomieschnittes nicht ausreichend war zur experimentellen Erzeugung von Adhäisionen, daß vielmehr die gesetzte Verwundung des Peritonealüberzugs schon nach 8 Tagen vollkommen abgeheilt und glatt überhäutet war, ohne daß Verwachsungen aufgetreten waren. Ich bin deshalb in meinen späteren Versuchen zu stärkeren Schädigungen des Peritoneums übergegangen.

Ferner gewann ich aus den bisherigen Versuchen den Eindruck, daß die intraperitoneale Einverleibung des Kaninchenfettes in der geschilderten Weise eine nicht unbedeutende peritoneale Reizung verursachte, die sich äußerte einerseits in dem Befinden: die Tiere machten während der ersten beiden Tage einen deutlich schwerkranken Eindruck, in den folgenden Tagen trat dann allerdings meist eine rasche Besserung auf, andererseits in den objektiv nachweisbaren Veränderungen des Peritoneums. Das parietale und viscerale Peritoneum war überzogen von einer mehr oder weniger gleichmäßig verteilten Fett. fibrinschicht, die zum Teil in ausgesprochen zottenartigen Auflagerungen angeordnet war (Versuch 3). In einem anderen Falle (Versuch 6a) enthielt die in den abhängigen Partien der Bauchhöhle angesammelte weißlich-gelbe cremeartige Masse neben Fett in großen Mengen Leukocyten und Fibringerinnsel.

Wenn es auch in den bisherigen Fällen zu ausgesprochenen Verwachsungen nicht gekommen war, so schien es mir doch nicht unwahrscheinlich, daß bei Hinzukommen einer stärkeren Peritonealläsion oder einer Infektion vor allem solche zottenartigen Bildungen vielleicht erst recht das Entstehen von Verwachsungen begünstigt hätten, statt es, wie beabsichtigt. war, zu verhüten.

Ich habe dann später aus der genannten Versuchsgruppe die Tiere Nr. 3, 2 und 5, bei denen die Veränderungen in der Bauchhöhle erstmalig durch Relaparotomie festgestellt waren, nach einem weiteren 
Zwischenraum von 30-39 Tagen," so daß im ganzen seit der ersten Laparotomie und der Fetteinbringung 46-50 Tage vergangen waren, durch Sektion in 2 Fällen bzw. erneute Relaparotomie in einem Fall nachrevidiert, um mir Gewißheit darüber zu verschaffen; was aus den erstmalig festgestellten peritonealen Veränderungen geworden war, und ob nicht doch noch nachträglich Adhäsionsbildung aufgetreten war. Es fanden sich auch jetzt keine Adhäsionen, lediglich war die in Fall 2 schon erstmalig festgestellte Netzadhäsion etwas ausgedehnter geworden. Die peritonealen Auflagerungen waren geschrumpft, aber in allen Fällen noch deutlich sichtbar.

Die Entstehung der gesehilderten intraperitonealen zottenartigen Fettmembranen und der mit Leukocyten durchsetzten Fettlager mußte als Folge einer durch die intraperitoneale Fetteinverleibung verursachten reaktiven Peritonitis aufgefaßt werden. Es schien mir nicht ausgeschlossen, daß die Ursache für diese letztere zu suchen sei in der chemischen Zusammensetzung des verwandten Fettes. Bei der angewandten Herstellungsweise des zur Injektion benutzten Kaninchenfettes, das, wie erwähnt, durch Zerlassen im Wasserbad und nachträgliche Sterilisation gewonnen war; war es natürlich nicht zu vermeiden, daß eine Menge von Verunreinigung, so Spuren von Eiweißkörpern, Eiweißabbauprodukte, Salze usw. in der Lösung enthalten war. Es schien mir nicht unwahrscheinlich, daß diesen Beimengungen des Fettes für die Entstehung der reaktiven Peritonitis vielleicht eine gewisse Bedeutung zuzusprechen war. Ich suchte deshalb durch eine andere Herstellungsweise mir ein chemisch reines Fett, das möglichst frei von Beimengung war, als Ausgangsmaterial für meine weiteren Versuche herzustellen.

Ich bediente mich zu diesem Zwecke der Herstellung flüssigen Kaninchenfettes durch Ätherextraktion aus frischem Fettgewebe. Die Extraktion wurde im Soxhletschen Apparat vorgenommen, und zwar im pathologisch-physiologisehen Institut der Universität, dessen Hilfsmittel mir zu diesem Zwecke in bereitwilligster Weise zur Verfügung gestellt wurden. Es sei mir gestattet auch an dieser Stelle Herrn Geh.Rat Hering für sein liebenswürdiges Entgegenkommen und Herrn Privatdozent B. Kisch für seine stets freundliche sachkundige Beratung meinen ergebensten Dank auszusprechen.

Die Extraktion im Soxhletapparat wurde in folgender Weise ausgeführt: Das zu extrahierende Fettgèwebe, von frisch getöteten Kaninchen entnommen, wurde ausgewaschen und zerkleinert und in eine Extraktionshülse: von Schleicher und Schüll gefüllt. Die Hülse. wurde nicht ganz angefüllt, um zu verhüten, daß kleine Teilchen der Substanz vom Äther weggeschwemmt wurden. Die Extraktion wirde in dẻr gebräuchlichen Art durchgeführt. Der Äther durch Erhitzen des Ex: 
traktes auf dem elektrisch geheizten Sandbade schließlich entfernt und das zurückbleibende reine Extrakt zu den Versuchen verwandt. Auch dieses Kaninchenfett ist im chemischen Sinne keineswegs analytisch reines Fett, denn es enthält alle jene ätherlöslichen Substanzen, die aus dem Fettgewebe mit extrahiert wurden. Immerhin ist deren Menge nur sehr gering, und das Präparat jedenfalls bedeutend reiner als ein durch Auskochen gewonnenes Kaninchenfett. Zweifellos wird das Fett durch Ausziehen mit Äther, also gewissermaßen auf kaltem Wege, seiner ursprünglichen Zusammensetzung nach ähnlicher gewonnen, als wenn man es durch Auslassen im Wasserbade oder gar durch Schmelzen im Tiegel gewinnt. Beim Erhitzen treten bekanntlich Zersetzungsprodukte des Glycerins auf, die sich schon äußerlich durch scharfen Geruch kenntlich machen, während das mit Äther ausgezogene Fett nach Abdampfen des Äthers völlig geruchlos war. Das so durch Extraktion gewonnene Fett erwies sich als keimfrei und bleibt, unter Luftabschluß aufbewahrt, lange Zeit steril, wie durch wiederholt angestellte bakteriologische Nachprüfung festgestellt wurde.

Es ist bisher bei ähnlichen Versuchen meines Wissens in dieser Weise gewonnenes Fett nicht benutzt worden.

In einigen Fällen wurden zu den Versuchen auch Fett benutzt, das durch Ätherextraktion von durch Auskochen gewonnenem Kaninchenfett erhalten war. Es zeigte sich bei der Ätherextraktion dieses ausgekochten Fettes ein merklicher Rückstand krystallinischer Art, der in der Extraktionshülse verblieb.

Ich darf vielleicht hier einige Bemerkungen über die Zusammensetzung und Eigenschaften der Fette, insbesondere der tierischen Fette einflechten. Die tierischen Fette sind hauptsächlich Ester der drei Fettsäuren Palmitin-, Stearin- und ölsäure. Die völlig reinen Neutralfette sind farb-, geschmack- und geruchlos; ihre Konsistenz ist verschieden, sie hängt vom relativen Mengenverhältnis ab. In den festeren Fetten überwiegt das Tripalmitin und Tristearin, während die flüssigen einen höheren Gehalt an Tripalmitin und Triolein aufweisen.

Fette sind unlöslich in Wasser, schwerlöslich in Alkohol, leichtlöslich in Äther, Benzol, Chloroform, Tetrachlorkohlenstoff. Sie lassen. sich ohne chemische Veränderung bis auf $300^{\circ}$ erhitzen. Bei dieser Temperatur sieden sie unter teilweiser Zersetzung, wobei verschiedene meist unangenehm riechende Produkte entstehen, besonders Acrolein, das von der Zersetzung des Glycerins herrührt.

Die Fette halten sich in chemisch reinem Zustande lange Zeit unverändert. Da sie jedoch meist Beimengungen, namentlich Eiweißkörper enthalten, so erleiden sie beim Aufbewahren unter Luftzutritt allmählich eine Zersetzung, bekommen unangenehmen Geschmack und Geruch sowie sauere Reaktion, sie werden ranzig, $d . h$. sie erleiden eine teilweise 
Spaltung in Glycerin und Fettsäuren; letztere gehen durch Oxydation in flüchtige, unangenehm riechende Stoffe über.

In den folgenden Versuchen suchte ich zunächst mir die Frage zu beantworten, ob bei der intraperitonealen Einverleibung des durch Ätherextraktion gewonnenen Fettes sich ein Unterschied ergab gegen das in der ersten Versuchsgruppe verwandte, durch Auslassen im Wasserbad gewonnene Fett, und zwar sowohl hinsichtlich der Einwirkung auf das Befinden der Tiere wie auch vor allem auf die am Peritoneum sich zeigenden Veränderungen.

In den folgenden drei Vorversuchen beschränkte ich mich deshalb lediglich zunächst auf die intraperitoneale Einverleibung des durch Ätherextraktion dargestellten Kaninehenfettes ohne jede absichtliche Schädigung des Peritoneums.

Versuch 7. Schwarz-weiß geflecktes $O$ Kaninchen Nr. 10. Körpergewicht 2335 g.

16. IX. 1920. In Äthernarkose $2 \mathrm{~cm}$ langer Mittelschnitt. Sofortiger SchluB der Bauchhöhle bis auf eingebundene stumpfe Kanïle, durch die $10 \mathrm{ccm}$ flüssigen Kaninchenfettes (gewonnen durch Ätherextraktion aus frischem Fettgewebe) injiziert wird. Endgültiger Schluß der Bauchhöhle.

17. IX. Tier schon lebhaft, beschnuppert Nahrung.

18. IX. Frißt, springt munter umher.

24. IX. Getötet durch Chloroform. Körpergewicht $2310 \mathrm{~g}(-25)$.

Sektion: Laparotomiewunde verheilt, Peritonealwunde kaum noch sichtbar. Keine Adhäsionen an derselben, auch nicht zwischen den Darmschlingen. Kein flüssiges Fett in der Bauchhöhle. Überall auf dem parietalen Peritoneum und auf dem Serosaüberzug der Darmschlingen findet sich ein fein verteilter, weißlichgelber Fettbelag, auch auf der Leber und in der Zwerchfellkuppe. Dieser Fettbelag läßt sich größtenteils leicht abwischen, in einzelnen Partien, z. B. auf der Leberoberfläche, haftet er fester.

Versuch 8. Schwarz-weiß geflecktes 우 Kaninchen Nr. 11. Körpergewicht $1840 \mathrm{~g}$.

21. IX. 1920. In Äthernarkose $2 \mathrm{~cm}$ langer Mittelschnitt. Sofortiger Schluß bis auf eingebundene stumpfe Kanüle, durch die $10 \mathrm{ccm}$ flüssigen Kaninchenfettes (gewonnen durch Ätherextraktion aus frischem Fettgewebe) injiziert wird. Vor Schluß der Bauchdecken preßt das Tier plötzlich ein Konvolut von Darmschlingen vor die Bauchdecken, die sich aber bald unter tiefer werdender Narkose reponieren lassen.

22. IX. Tier macht kranken Eindruck, frißt nicht.

23. IX. Tier lebhafter, frißt etwas.

9. X. In Äthernarkose Rela parotomie. Körpergewicht $1650 \mathrm{~g}(-190)$.

$6 \mathrm{~cm}$ langer Längsschnitt rechts des ersten Bauchschnitts, der fest verheilt ist. Keine Adhäsionen an der alten Bauchnarbe, auch nicht zwischen den Darmschlingen. Kein flüssiges Fett in der Bauchhöhle, dagegen ist das parietale und viscerale Peritoneum wie überzogen von dünnen, gelblich-weißen Auflagerungen, die sich nicht mehr abwischen lassen wie bei dem vorhergehenden Versuch, jedoch sich zum Teil als dünne zusammenhängende Membranen leicht abziehen lassen.

Versuch 9. Schwarzes $\odot$ Kaninchen Nr. 9. Körpergewicht $2050 \mathrm{~g}$.

7. IX. 1920. In Äthernarkose $2 \mathrm{~cm}$ langer Mittelschnitt, durch eingebundene Kanüle Injektion von $10 \mathrm{ccm}$ flüssigen Kaninchenfettes (gewonnen durch Ätherextraktion aus ausgelassenem Fett), definitiver Schluß der Bauchhöhle. 
8. IX. Tier schon lebhaft, frißt etwas.

9. IX. Tier springt munter umher, frißt.

9. X. Rela parotomie. Körpergewicht $2440 \mathrm{~g}(+390)$.

$6 \mathrm{~cm}$ langer Längsschnitt oberhalb des ersten fest verheilten Bauchschnitts. Keine Adhäsionen an der Bauchnarbe, auch nicht zwischen den Darmschlingen. Kein flüssiges Fett in der Bauchhöhle, dagegen finden sich feine fettmembranähnliche Auflágerungen auf dem parietalen Peritoneum, besonders in der Umgebung des Bauchschnitts und auf den Darmschlingen, und zwar hier vornehmlich in Form kleinerer fleckiger Herde.

Histologischer Bef und eines excidierten Bauchwandstückes im Bereich der geschilderten Auflagerungen: Lockermaschiges Gewebe (Peritoneum), darauf schwach entzündliches Granulationsgewebe, Zelldetritus in spärlicher Menge und deutlich Fetteinlagerungen. Keine Leukocyten, sondern mehr oder weniger Rundzellen.

21. XII. 2. Relaparotomie. Körpergewicht $2920 \mathrm{~g}(+870)$.

Eröffnung der Bauchhöhle durch Längsschnitt links neben dem alten fest verheilten Bauchschnitt. Keine Adhäsionen im Bereich der Bauchnarben. Die fettmembranartigen Auflagerungen sind bedeutend geringer geworden, auf Peritoneum parietale und auf den Darmschlingen nur noch vereinzelte isolierte Herde, desgleichen im Netz.

Histologischer Befund einer Bauchwandexcision im Bereich einer derartigen Auflagerung: Lockeres grobmaschiges Bindegewebe mit reichlich Capillaren, in den Gewebsmaschen Fett in großen und kleinen Tropfen eingelagert, zum Teil in den Zellen liegend. Die freie Oberfläche der Auflagerung ist glatt mit Endothel überkleidet und weist keine zottenartigen Fortsätze auf.

30. I. 1921. Nach mehrtägigem Kranksein heute tot im Stall.

Sektion: Keine Adhäsionen in der Bauchhöhle. Die Auflagerungen sind bis auf ganz spärliche, kleine, flache, gelbe Stellen auf dem parietalen Peritoneum verschwunden. Vereinzelt finden sich derartige Auflagerungen auch auf der Leberoberfläche.

Als Todesursache ergibt sich doppelseitige pneumonische Infiltration und eitrige Bronchitis.

Histologischer Befund eines Leberstückchens mit einer derartigen Auflagerung: Flache bindegewebige Auflagerung, die einen sich gleichmäßig hinziehenden Saum von Fetteinlagerungen enthält. Das Fett in größeren und klejneren Tropfen liegt teils in den Zellen, teils zwischen denselben. Die freie Oberfläche dieser fettgewebsähnlichen Auflagerung ist mit zusammenhängendem Endothel bekleidet.

Nach diesen Vorversuchen gewann ich den Eindruck, daß das che. misch reine durch Äther in der genannten Weise extrahierte Kaninchenfett bei intraperitonealer Einverleibung von den Tieren besser vertragen wurde wie das zuvor angewandte durch einfaches Auslassen gewonnene Fett. Die Tiere reagierten nicht so stark bei der Verwendung des ätherextrahierten Fettes, sie machten nicht den schwerkranken Eindruck, erholten sich rascher und nahmen schon am 1. Tag wieder Nahrung zu sich.

Was das Verhalten des Peritoneums angeht, so schien mix auch, soweit sich das an den wenigen Versuchen schon beurteilen lie $B$, das ätherextrahierte Fett bei gleichen Mengen und ungefähr gleichen zeit- 
lichen Zwischenräumen in größerem Umfange resorbiert zu wérden, wie ich das vorher gesehen hatte, jedenfalls fanden sich keine größeren Fettansammlungen in der Bauchhöhle, auch schienen mir die auf dem parietalen und visceralen Peritoneum sich bildenden Fettauflagerungen nicht so umfangreich und zarter zu sein, auch fand sich nicht die ausgesprochene Zottenbildung, wie oben erwähnt.

Diese scheinbar günstigere Reaktion des Organismus, vor allem des Peritoneums, veranlaBten mich dann, das ätherextrahierte Fett in meinen folgenden Versuchen ausschließlich $\mathrm{zu}$ benutzen.

Versuch 10a. Silbergraues ${ }^{x}$ Kaninchen Nr. 12. Körpergewicht $2890 \mathrm{~g}$.

11. X. 1920. $4 \mathrm{~cm}$ langer Mittelschnitt Oberbauchgegend. Jederseits des Peritoneums wird das parietale Peritoneum im Umkreis von etwa $3 \mathrm{~cm}$ durch kreuzweises Ritzen mit der Messerspitze scarificiert. Das dem Bauchschnitt gegenüberliegende Netz wird in seinem Serosa überzug in gleicher Weise durch Ritzen mit dem Messer geschädigt. Schluß der Bauchhöhle bis auf eingebundene stumpje Kanüle, durch welche $10 \mathrm{ccm}$ flüssiges Kaninchenfett (gewonnen durch Ätherextraktion aus frischem Fettgewebe) injiziert wird. Definitiver Schluß der Bauchhöhle.

12. X. Tier lebhaft, frißt.

Glatte Heilung.

26. X. Rela parotomie. Körpergewicht $3280 \mathrm{~g}(+390)$.

Links neben der alten Bauchnarbe etwa $5 \mathrm{~cm}$ langer Längsschnitt. Keine Adhäsionen an der Bauchnarbe. Die scarificierte Stelle ist vollkommen glatt, zum Teil bedeckt mit.einer feinen fettmembranartigen Auflagerung, deren Oberfläche auch glatt erscheint und die sich allmählich im das umgebende normale Peritoneum fortsetzt. Keine Verwachsungen zwischen den Intestinis. Win Stüok der Bauchwand mit dieser Auflagerung wird zür Untersuchung excidiert. Schluß der Bauchhöhle.

Histologischer Befund der Excision: Peritoneum verdickt, Schivielenbildung. Auf demselben lockermaschige Auflagerungen, die reichlich Fett in großen und kleinen Tropfen eingesprengt enthalten. In den tieferen Schichten ist das Fett reichlicher vorhanden und sieht man hier an einzelnên Stellen kleinzellige Infiltration geringen Grades.

Versuch 10b. Graves ơ Kaninehen Nr. 13. Körpergewicht 2180 g. (Kontrolltier:)

11. X. 1920. $4 \mathrm{~cm}$ langer Längsschnitt Oberbauchgegend. Versuchsanordnung dieselbe wie bei a, nur kein Fett. Schluß der Bauehhöhle.

Glatte Heilung.

26. X. Relaparotomie. Körpergewicht $2360 \mathrm{~g}(+180)$.

$6 \mathrm{~cm}$ langer Längsschnitt seitlich der ersten Bauchnarbe. Peritoneum parietale an der Schnittlinie und an der Stelle der Scarification vollkommen glatt und spiegelnd. Eine dünne fadenförmige Adhäsion zieht von hier zum Netz, sonst keinerlei Verwachsungen weder der Bauc wand noch des geschädigten Netzes mit der Umgebung.

Versuch 11a. Grau-weiß gefleektes Kaninchen of Nr. 14. Körpergewicht $2110 \mathrm{~g}$.

21. X. 1920. $5 \mathrm{~cm}$ langer längsschnitt in Oberbauchgegend. Verwundung des parietalen Peritoneums bds. vom Schnitt auf etwa $3 \mathrm{~cm}$ Breite durch Ritzung und Abschaben mit dem Messer. Desgleichen Vorziehen und oberflächliches Ritzen des Netzes auf beiden Seiten. Schluß der Bauchhöhle bis auf eingebundene stumpfe 
Kanüle, durch welche $20 \mathrm{ccm}$ flüssigen Kaninchenfettes (gewonnen durch Ätherextraktion aus ausgelassenem Fett) injiziert wird. Definitiver Schluß der Bauchhöhle. Tier nimmt schon am Abend des Operationstages Nahrung zu sich.

22. X. Tier lebhafter, friBt.

4. XI. Rela parotomie. Körpergewicht $1950 \mathrm{~g}(-160)$.

Längsschnitt rechts von alter Narbe, die nicht p. p. geheilt ist, sondern eine eitrig belegte, narbig eingezogene Stelle darstellt, in welcher noch Catgutfäden. sichtbar sind. Bauchdecken fallen durch Blutreichtum auf, Peritoneum parietale spiegelnd. In nächster Umgebung der Schnittlinie an der Stelle der Scarification. bedeckt mit schleierartigen Fettmembranen. Eine Verwachsung ist weder an der Stelle der Bauchwunde noch am Peritoneum sichtbar. Auch auf den übrigen Teilen des parietalen Peritoneums wie auch auf dem Serosaüberzug der Darmschlingen sieht man feine hauchartige Fettauflagerungen. Größere Anhäufungen von Fett sind nicht vorhanden. Streifenförmige Resektion eines Bauchwandstïckes zwecks Untersuchung.

Histologischer Befund: Der Peritonealüberzug ist stark aufgelockert, weist neben spärlichen Rundzelleninfiltraten reichlich neu gebildete Capillaren auf.

4. I. 1921. Getötet durch Chloroform. Körpergewicht $2260 \mathrm{~g}(+310)$.

Der zweite Laparotomieschnitt ist verheilt. Verwachsungen mit der Bauchwand bestehen nicht. Die peritonealen Auflagerungen sind stark zurückgebildet, nur noch vereinzelte inselförmige, kleine gelblich-weiße Auflagerungen mit matter glänzender Oberfläche, besonders deutlich auf der Leberoberfläche. Excision. eines Leberstückchens.

Histologischer Bef und desselben: Ziemlich gleichmäBig sich hinziehende bindegewebige Auflagerung von zum Teil lockermaschigem Aufbau. Das eingelagerte Fett erscheint in zusammenhängenden Lagern teils intracellulär, zum Teil zwischen den Zellen angeordnet. Die Auflagerung ist von cinem zusammenhängenden Endothelbelag bekleidet, Das histologische Bild erinnert an Fettgewebe.

Versuch $11 \mathrm{~b}$. Grau-gelbes o Kaninchen Nr. 15. Körpergewicht $1750 \mathrm{~g}$. (Kontrolltier.)

21. X. $5 \mathrm{~cm}$ langer Längsschnitt in Oberbauchgegend. Versuchsanordnung wie unter a, nur kein Fett.

Glatte Heilung.

4. XI. 1920. Rela parotomie. Körpergewicht $1860 \mathrm{~g}(+110)$.

Bauchnarbe peritonealwärts glatt und spiegelnd. Keine Adhäsionen weder zum Netz noch zu den Darmschlingen. Schluß der Bauchhöhle.

Da in den vorstehenden Versuchsgruppen 10 und 11 die gesetzte Schädigung des Peritoneums in den Kontrollversuchen sich als nicht genügend erwiesen hatte, um Adhäsionen zu erzeugen, habe ich in den folgenden Versuchsgruppen stärkere Reize angewandt.

Versuch 12a. Graues $O$ Kaninchen Nr. 16. Körpergewicht 1650 g.

28. X. 1920. $5 \mathrm{~cm}$ langer Längsschnitt in Oberbauchgegend. Ausgiebige Scarification des parietalen Peritoneums in der Umgebung des Bauchschnittes. Vorziehen des Netzes vor die Bauchwunde, Reiben desselben mit trockenem Tupfer und Ritzen seiner Oberfläche auf beiden Seiten mit dem Messer. SchluB der Bauchhöhle bis auf eingebundene stumpfe Kanüle, durch welche $10 \mathrm{ccm}$ flüssigen Kaninchenfettes (gewonnen durch Ätherextraktion aus frischem Fettgewebe) injiziert wird. Definitiver Schluß der Bauchhöhle.

29. X.' Tier schon wieder munter, frißt etwas.

30. X. Tier springt lebhaft umher.

6. XI. Getötet durch Chloroform. Körpergewicht $1820 \mathrm{~g}(+170)$. 
Sektion: Kein flüssiges Fett mehr in der Bauchhöhle, Bauchnarbe peritonealwärts vollkommen frei, keine Adhäsionen, jedoch an der Stelle der Scarification feine fettmembranartige Auflagerungen. Derartige teilweise schleierartige Auflagerungen befinden sich noch an den versehiedensten Stellen des parietalen Peritoneums, wenn auch zarter, und auf dem Serosaüiberzug der Darmschlingen, desgleichen auf der Oberfläche der Leber. Das Netz ist geschrumpft zuisammengerollt, im übrigen aber nicht adhärent. Auch zwischen den Darmschlingen sind keine Adhäsionen nachweisbar.

Versuch 12b. Grau-weißes \& Kaninchen Nr. 17. Körpergewicht $1770 \mathrm{~g}$. (Kontrolltier.)

28. X. $5 \mathrm{~cm}$ langer Längsschnitt in Oberbauchgegend. Die gleiche Versuchsanordnung wie unter a, nur kein Fett. Schluß der Bauchhöhle.

Glatte Heilung.

6. XI. Getötet durch Chloroform. Körpergewicht $1930 \mathrm{~g}(+\mathrm{I} 60)$.

Sektion: Fadenförmige Adhäsion eines Netzzipfels zur vorderen Bauchwand seitlich des Bauchschnittes an die Stelle der Scarification, sonst keine Verwachsungen.

Versuch 13a. Graues 우 Kaninchen Nr. 18. Körpergewicht $3990 \mathrm{~g}$.

20. XI. $5 \mathrm{~cm}$ langer Längsschnitt in Oberbauchgegend. Vom Schnittrand aus werden auf beiden Seiten etwa $0,5 \mathrm{~cm}$ breite und $3 \mathrm{~cm}$ lange Streifen des parietalen Peritoneums mit der Schere excidiert (jederseits 3 Streifen), keine Blutung. SchluB der Bauchhöhle bis auf eingebundene stumpfe Kanüle, durch welche $20 \mathrm{ccm}$ flüssigen Kaninchenfettes (gewonnen durch Ätherextraktion aus frischem Fettgewebe) injiziert werden. Definitiver Schluß der Bauchhöhle.

21. XI. Tier sitzt ruhig, macht angegriffenen Eindruck.

22. XI. Immer noch krank, frißt nicht.

24: XI. Munter, springt umher, frißt.

11. XII. Ohne daß dem Tier in den letzten Wochen etwas anzumerken gewesen wäre, heute Exitus. Körpergewicht $3560 \mathrm{~g}(-430)$.

Sektion: Laparotomienarbe fest verheilt, Das parietale Peritoneum ist überzogen mit einer fettmembranähnlichen Auflagerung, die sich auch zum Teil auf den Darmschlingen, auf der Leberoberfläche und in der Zwerchfellkuppe findet. Die Bauchnarbe ist vollkommen frei von Verwachsungen, auch an der Stelle der excidierten Peritonealstreifen; desgleichen befinden sich zwischen den Darmschlingen und dem Netz keine Verwachsungen.

Bakteriologische Untersuchung des Bauchhöhlenabstriches ergibt Keimfreiheit.

Ein Stuick der Bauchwand an der Stelle der gesetzten Peritonealschädigung wird excidiert zwecks histologischer Untersuchung. Bef und: Peritoneum schwielig verdickt, noch deutlich Defekte des Endothels aufweisend, in den tieferen Schichten vereinzelt kleinzellige Infiltrate. Bedeckt ist das Peritoneum von einem teilweise fest haftendem lockermaschigen Gewebe, das nicht gleichmäßig sich hinzieht, sondern ausgesprochen zottenartige Erhebungen aufweist. In diesem lockeren Gewebe eingelagert, vornehmlich in den tieferen Schichten, reichlich Fett in gröBeren und kleineren Tropfen.

Versuch 13b. Schwarzes $\circlearrowleft$ Kaninchen Nr. 19. Körpergewicht $2100 \mathrm{~g}$. (Kontrolltier.)

20. XI. $5 \mathrm{~cm}$ langer Längsschnitt in Oberbauchgegend. Die gleiche Versuchsanordnung wie bei a, nur kein Fett.

Glatte Heilung.

11. XII. Rela parotomie. Körpergewicht $2235 \mathrm{~g}(+135)$.

Laparotomieschnitt fest verheilt, Bauchnarbe peritonealwärts vollkommen glatt und spiegelnd, keinerlei Adhäsionen. 
Versuch 14a. Weiß-schwarz geflecktes $\sigma^{7}$ Kaninchen Nr. 30. Körpergewicht $1850 \mathrm{~g}$.

18. XII. 1920. $5 \mathrm{~cm}$ langer Mittelschnitt in Oberbauchgegend. Streifenförmige Excision des parietalen Peritoneums im Umkreis des Bauchschnitts. Vorziehen des Netzes, Abklemmen eines Zipfels durch 2 Klemmen, Resektion des Netzzipfels und Ersetzen der Klemmen durch 2 Catgutligaturen, Schluß der Bauchhöhle bis auf eingebundene stumpfe Kanüle. Injektion von $10 \mathrm{ccm}$ flüssigen Kaninchenfettes (gewonnen durch Ätherextraktion aus ausgelassenem Fett). Definitiver Schluß der Bauchhöhle.

19. XII. Tier schon munter, frißt etwas.

20. XII. Lebhaft, gute Nahrungsaufnahme.

18. I 1921. Getötet durch Chloroform. Körpergewicht $1900 \mathrm{~g}(+50)$.

Sektionsbefund: Bauchnarbe peritonealwärts vollkommen glatt, bedeckt im Bereich der Peritonealschädigung von feiner membranöser, fest haftender Auflagerung, die aber ihrerseits auch glatt und spiegelnd ist und keinerlei Verwachsungen mit dem Netz oder den sonstigen Intestinis aufweist. Auf dem Peritoneum der übrigen Bauchwand sieht man vereinzelt auch derartig feine Auflagerungen in geringer Ausdehnung inselförmig angeordnet. Das Netz ist an der Stelle der Resektion verdickt zusammengerollt, aber frei und nicht adhärent, die Catgutfäden sind resorbiert. Auf dem Serosaüberzug der Darmschlingen und der Leberoberfläche sieht man ebenfalls vereinzelte der oben geschilderten feinen Auflagerungen. Die Auflagerungen sind im Vergleich zu den früheren Versuchen sehr spärlich und scheint das Fett schon gröBtenteils resorbiert. Adhäsionen sind zwischen den. Intestinis nicht nachweisbar. Schluß der Bauchhöhle nach Excision eines Stückes der Bauchwand im Bereich der geschilderten Auflagerung.

Histologischer Befund: Auf dem Peritoneum lockere, in Organisation. begriffene, zum Teil schon vollständig organisierte fibrinöse Auflagerungen, die teilweise einen ausgesprochenen zottigen Charakter haben. In diesem lockermaschigen Gewebe erkennt man überall Fett in größeren und kleineren Tropfen eingelagert. Die Auflagerungen sind größtenteils von Endothel bedeckt. Die tiefer gelegenen Bindegewebsschichten sind zum Teil aufgelockert und hier und da von jungen Granulationsgeweben durchsetzt. An einzelnen Stellen sieht man zugrunde gegangene quergestreifte Muskulatur (zurückzuführen auf die hier gesetzte Schädigung der Bauchwand: die excidierten Peritonealstreifen sind zum Teil mit der oberflächlichen Muskelschicht abgetragen) in jungem Granulationsgewebe liegend.

Histologischer Befund eines Leberstückchens mit Fettmembranauflagerung: Die Auflagerung besteht aus lockerem Fettgewebe, das stellenweise cystenartige Erweiterungen aufweist, in denen anscheinend Fetttropfen ausgefallen sind. Die Innenauskleidung dieser cystischen Bildungen besteht aus einfachem Endothel. Entzündliche Veränderungen sind nicht feststellbar, an einzelnen Stellen finden sich Fremdkörperriesenzellen.

Versuch 14b. Grau-weiß geflecktes 우 Kaninchen Nr. 31. Körpergewicht $1680 \mathrm{~g}$. (Kontrolltier.)

18. XII. 1920. $5 \mathrm{~cm}$ langer Mittelschnitt in Oberbauchgegend. Die gleiche Versuchsanordnung wie bei a, nur kein Fett.

Glatte Heilung.

18. I. 1921. Rela parotomie. Körpergewicht $1770 \mathrm{~g}(+90)$.

Seitlich des ersten fest verheilten Bauchschnitts. Bauchwunde peritonealwärts glatt und spiegelnd. Das Netz ist mit einer dünnen strangförmigen Adhäsion seitlich des Leibschnittes im Bereich der gesetzten Peritonealschädigung adhärent, jedoch ist die Verwachsung leicht zu lösen. Sonst keine Adhäsionen nachweisbar.

Versuch zur Erzengung ausgedehnterer festerer Adhäsionen: 
postoperativer peritonealer Adhäsionen mittels arteigenen flïssigen Fettes. 531

In der Umgebung des Relaparotomieschnittes wird das parietale Peritoneum kräftig scarificiert. Ausgiebige Jodierung dieser Stelle mit 10 proz. Jodtinktur. Vorziehen des Netzes vor die Bauchwand und ebenfalls Jodierung desselben bds., desgleichen reichliche Jodierung der vorliegenden Darmschlingen und des Magens, so daß im ganzen eine Menge von etwa 4-5 ccm Jodtinktur gebraucht ist.

Noch vor Schluß der Bauchhöhle kommt das Tier ad exitum. Der Exitus ist wohl mit Sicherheit auf die Schädigung durch die intraperitoneale Jodanwendung zurückzuführen.

Ich habe deshalb in meinen folgenden Versuchen die Jodtinktur nur in geringer Menge lediglich zum Betupfen der geschädigten Serosastellen angewandt.

Versuch 15a. Graues ơ Kaninchen Nr. 33. Körpergewicht $1420 \mathrm{~g}$.

28. XII. 1920. $5 \mathrm{~cm}$ langer Mittelschnitt in Oberbauchgegend. Streifenförmige Excision and Scarification des angrenzenden parietalen Peritoneums. Vorziehen des Netzes und Lagern desselben auf eine trockene Gazeplatte, Abschaben der beiden Flächen mit der Messerspitze, bis das Netz im ganzen geschunden und leicht blutig aussieht. Desgleichen oberflächliche Abschabung der Serosa der Magenvorderfläche. Sämtliche verwundeten Partien des Netzes, Magens und parietalen Peritoneums werden mit 10 proz. Jodtinktur betupft, darauf SchluB der Bauchhöhle bis auf eingebundene stumpfe Kanüle, durch welche $10 \mathrm{ccm}$ flüssigen Kaninchenfettes (gewonnen durch Ätherextraktion aus frischem Fettgewebe) injiziert werden. Definitiver Schluß der Bauchhöhle.

29. XII. Tier sitzt ruhig, frißt nicht.

30. XII. Lebhafter, nimmt Nahrung.

11. I. 1921. Getötet durch Chloroform. Körpergewicht $1350 \mathrm{~g}(-70)$.

Sektionsbefund: Keine Adhäsionen der Bauchnarbe mit Netz oder Darmschlingen. Die Stelle des Bauchschnitts vorwiegend im Bereich der gesetzten Peritonealschädigungen ist mit feinen fettmembranähnlichen Auflagerungen bedeckt, die makroskopisch glatt und spiegelnd erscheinen. Das Netz ist ebenfalls bds. mit derartigen feinen Auflagerungen bedeckt, aber nicht verwachsen, auch nicht mit dem darunter liegenden Magen, an dessen Oberfläche die gesetzte Schädigung nicht mehr kenntlich ist.

Flüssiges Fett oder größere Fettansammlungen sind in der Bauchhöhle nicht vorhanden.

Histologischer Befund eines aus der Bauchwand excidierten Stückes: Der Peritonealüberzug ist in ein lockeres capillarreiches Bindegewebe umgewandelt, wo man stellenweise neben dem verdickten Peritoneum kleinere, capillarreiche, zottenartige, ebenfalls aus lockermaschigem Bindegewebe bestehende Partien erkennt. Auch hier findet sich reichlich neu gebildetes Bindegewebe und Capillaren. In dem lockermaschigen Gewebe erkennt man deutlich Fett in größeren und kleineren Partikelchen eingelagert.

Versuch 15b. Schwarzes ơ Kaninchen Nx. 34. Körpergewicht $1430 \mathrm{~g}$. (Kontrolltier.)

28. XII. 1920. $5 \mathrm{~cm}$ langer Mittelschnitt in Oberbauchgegend. Im übrigen die gleiche Versuchsanordnung wie bei a, nur kein Fett.

29. XII. Tier springt munter umher, frißt.

11. I. 1921. Getötet durch Chloroform. Körpergewicht $1485 \mathrm{~g}(+55)$.

Sektionsbefund: Bauchschnitt fest verheilt. Bauchnarbe peritonealwärts glatt und spiegelnd; links neben derselben im Bereich der gesetzten Peritonealschädigung ist das Netz mit einem etwa $4 \mathrm{~cm}$ breiten Zipfel adhärent, desgleichen finden sich breite feste Adhäsionen zwischen Netz, Magen und Leber. 
Versuch 16a. Graues 오 Kaninchen Nr: 35. Körpergewicht $1440 \mathrm{~g}$.

25. XII. 1920. $5 \mathrm{~cm}$ langer Mittelschnitt in Oberbauchgegend. Scarification des parietalen Peritoneums im Umkreis des Bauchschnittes, bis das Peritoneum stark geschunden aussieht. Vorziehen des Netzes, Lagerung auf Gazeplatte und Abschaben der beiden Seiten desselben, bis auch hier deutliche oberflächliche Defekte und punktförmige Blutaustritte auftreten. Jodierung der verwundeten Peritonealflächen durch Betupfen mit 10 proz. Jodtinktur. Schluß der Bauchhöhle bis auf eingebundene stumpfe Kanüle, durch die $10 \mathrm{ccm}$ flüssigen Kaninchenfettes (gewonnen durch Atherextraktion aus frischem Fettgewebe) injiziert werden. Definitiver Schluß der Bauchhöhle.

30. XII. Tier sitzt ruhig, frißt noch nicht.

31. XII. Etwas lebhafter, beschnuppert Nahrung.

1. I. 1921. Springt munter umher, frißt.

26. I. Getötet durch Chloroform. Körpergewicht $1280 \mathrm{~g}(-160)$.

Sektionsbefund: Bauchschnitt p. p. geheilt. Das parietale Peritoneum weist inselförmige Auflagerungen von Fettmembranen auf, besonders ausgeprägt an der Stelle der gesetzten Peritonealschädigung zu beiden Seiten des Bauchschnittes. Ähnliche feine Auflagerungen befinden sich auch auf den Darmschlingen und der Leberoberfläche. Flüssiges Fett oder größere Fettanhäufungen sind in der Bauchhöhle, auch in den abhängigen Partien, nicht vorhanden.

Verwachsungen der Bauchwand mit den Intestinis sind nicht vorhanden, auch nicht zwischen den Darmschlingen untereinander. Das Netz macht einen verkümmerten geschrumpften Eindruck und ziehen vom Netz zum Magen und Leber vereinzelte fadenförmige Adhäsionen, die aber gleich zerreißen. Das Netz weist noch eine schwache Braunfärbung auf, als Überrest der voraufgegangenen Jodierung.

Histologischer Befund eines excidierten Banchwandstückes im Bereich des geschädigten Peritoneums und der geschilderten Auflagerung: Das schwielig verdickte Peritoneum ist bedeckt mit einer lockermaschigen, an Fettgewebe erinnernden Auflagerung, die an einzelnen Stellen feine zottenartige Erhebungen trägt. Im übrigen zieht sich diese Auflagerung ziemlich in gleichmäßiger Schicht hin und ist oberflächlich, besonders auch im Bereich der zottenartigen Erhebungen, von Endothel bedeckt. Entzündliche Infiltration nicht nachweisbar, neu gebildete Capillaren in ziemlicher Menge vorhanden. Zwischen den Maschen erkennt man reichlich in größeren und kleineren Tropfen eingelagertes Fett.

Versuch 16b. Grau-gelbes $\subseteq$ Kaninchen Nr. 36. Körpergewicht $900 \mathrm{~g}$. (Kontrolltier.)

29. XII. 1920. $5 \mathrm{~cm}$ langer Mittelschnitt in Oberbauchgegend. Dieselbe Versuchsanordnung wie bei a, nur kein Fett.

30. XII. Tier sitzt ruhig, frißt nicht, war schon vor der Operation sehr elend und schwach.

31. XII. Etwas munterer, frißt.

26. I. 1.921. Heute tot im Stall gefunden, nachdem schon einige Tage vorher sehr elend gewesen. Körpergewicht $790 \mathrm{~g}$ (- -110$)$.

Sektionsbefund: Laparotomieschnitt p. p. geheilt. Zwischen der Bauchwandnarbe und dem Netz breite, feste Adhäsion. Der Netzzipfel weist noch deutlich schwachbraune Färbung von der voraufgegangenen Jodierung auf. Sonst keine Adhäsionen.

Der eingetretene Exitus ist nach dem Befund der Sektion wohl auf die große allgemeine Schwächlichkeit und geringe Widerstandskraft des Tieres zurück. zuführen. 
Überblicken wir kritisch das Ergebnis dieser fünf Versuchsgruppen (12-16), so ergibt sich zunächst, was die experimentelle Erzeugung peritonealer Adhäsionen angeht, daß einseitig gesetzte Läsion des Peritoneums, auch wenn sie recht ausgiebig ist, in Form von streifenförmigen Adhäsionen (Versuch 13) nicht genügt, um Adhäsionen hervorzurufen. In den übrigen 4 Fällen gelang es mir, bei Anlegung der peritonealen Läsionen an zwei gegenüberliegenden Stellen (Bauchwand, Netz bzw. Magen) beim Kontrolltier regelmäßig Adhäsionen zu erzeugen, die als dünne strangförmige Adhäsionen eines Netzzipfels an der Bauchwand auftraten nach kräftiger Scarification des an den Laparotomieschnitt angrenzenden parietalen Peritoneums der Bauchwand und kräftiger Schädigung der beiden Seiten des gegenüberliegenden Netzes durch Reiben und Ritzen seiner Oberfläche bzw. Resektion eines Netzzipfels und Anlegen zweier Catgutligaturen (Versuch 12-14).

Stärkere und festere Adhäsionen erzielte ich, wenn ich zu den vorgenannten mechanischen Verletzungen des Peritoneums noch eine chemische Schädigung durch Betupfen mit 10 proz. Jodtinktur hinzu. fügte (Versuch 15, 16). Die angewandte Jodmenge muß möglichst gering sein, man muß sich auf ein Betupfen der Peritonealflächen beschränken, da eine größere Menge Jodtinktur intraperitoneal von den Tieren nicht vertragen wird, wie das der in Fall $14 \mathrm{~b}$ gleich nach der Jodierung eingetretene Exitus beweist.

Die Veränderungen in der Peritonealhöhle wurden durch Sektion am 8. bis 30. Tage nach der Operation und Fetteinbringung festgestellt.

Das zur Verhütung der Adhäsionen injizierte ätherextrahierte Kaninchenfett war bei der absolut gleichen Versuchsanordnung wie in den von Adhäsionen gefolgten Kontrollversuchen (möglichst gleichgroße Versuchstiere, gleiche Schädigung des Peritoneums) imstande, in 4 Fällen die Entstehung von Adhäsionen zu verhüten, nur in einem Fall (16a) fanden sich feine Adhäsionen zwischen Netz, Magen und Leber.

Was zunächst die Menge des injizierten Fettes angeht, so injizierte ich jedesmal $10 \mathrm{ccm}$, nur in einem Fall (13a) verabfolgte ich $20 \mathrm{ccm}$. Dieses Tier reagierte auf die größere Menge mit einem ausgesprochen stärkeren Krankheitsgefühl. Erst am 3. Tage nach der Operation wurde das Tier lebhafter und nahm Nahrung zu sich, während die Tiere, die nur $10 \mathrm{ccm}$ erhalten hatten, meist schon am ersten, spätestens aber am 2. Tage nach der Operation munter waren und fraßen. Diese Beobachtung schien mir darauf hinzuweisen, daß von der Menge des eingebrachten Fettes die Reizwirkung auf das Peritoneum direkt abhängig sei. Es mußte also unser Bestreben sein, die möglichst kleinste Menge Fett zu verwenden, die gerade noch ausreichend war, den ge- 
wünschten Erfolg zu erreichen. Nach meinen Erfahrungen scheint mir $10 \mathrm{ccm}$ Fett die für Kaninchen optimale Menge darzustellen und für den in Betracht kommenden Zweck ausreichend zu sein.

Durch entsprechendes Neigen der Kanüle bzw. der Injektionsspritze bei der langsamen Injektion des Fettes suchte ich zu erreichen, daß das Fett zunächst die geschädigten Partien benetzte. Da die Tiere gleich nach dem Erwachen aus Narkose wieder sitzende Stellung, d. h. Bauchlage einnehmen, war also auch nachher der Kontakt des eingebrachten Fettes mit den geschädigten Peritonealstellen ein inniger. Die Injektion erfolgte stets - das möchte ich noch bemerken - in möglichst langsamer Weise. Meist genügte die senkrechte Haltung der leichtgehenden Spritze oder ein ganz schwacher Druck, um das Fett infolge der Schwere des Stempels von selbst einlaufen zu lassen. Spritzt man das Fett zu schnell ein, dann pressen die Tiere, besonders bei oberflächlicher Narkose, leicht das Fett teilweise heraus und der Versuch wird ungenau und die Bauchwunde wird mit Fett überschwemmt, was sich bei der geschilderten Versuchsanordnung mit eingebundener Kanüle sonst ganz exakt vermeiden läßt.

Die in den Vorversuchen 7-9 mit dem ätherextrahierten Fett im Gegensatz zu dem einfach ausgelassenen Fett gemachten günstigen Erfahrungen betreffs Resorptionsfähigkeit des Fettes und der geringeren Ausdehnung der sich bildenden peritonealen Auflagerungen konnte ich in den Versuchen $10-16$ bestätigen.

Das in einigen Fällen verwandte ätherextrahierte Fett aus vorher ausgelassenem Fett (Versuch 9, 11a, 14a) zeigte in der Wirkung keinen nachweisbaren Unterschied gegenüber dem sonst ausschließlich verwandten ätherextrahierten Fett aus frischem Fettgewebe.

Die Resorption des eingebrachten Fettes schien bei der Art des injizierten Materials schneller vonstatten zu gehen, jedenfalls fand sich bei der Revision nach 8 Tagen kein flüssiges Fett oder Fett in größerer Menge angesammelt (wie Versuch 6a) in der Bauchhöhle. Die fettmembranähnlichen Auflagerungen auf dem parietalen Peritoneum und auf der Darmserosa waren zarter, feiner und gleichmäßiger, zum Teil schleierartig ausgebreitet, auch waren die an einzelnen Stellen vorhandenen, besonders mikroskopisch nachweisbaren zottenartigen Excrescenzen nicht so ausgedehnt und umfangreich wie die nach der Verwendung des einfach ausgelassenen Fettes beobachteten. Diese feinen Fettfibrinschleier waren an den verschiedensten Stellen der Peritonealauskleidung der Bauchhöhle und auf dem Serosaüberzug der Intestina vorhanden, besonders ausgeprägt an den Stellen, wo durch die genannten mechanischen Maßnahmen das Peritoneum geschädigt war.

Auch in dieser Versuchsgruppe der mit ätherextrahiertem Fett beschickten Tiere habe ich, um das spätere Schicksal der intraperitonealen 
Veränderungen festzustellen, an zwei überlebenden Tieren (Nr. 9 und 14) durch wiederholte Relaparotomie bzw. Sektion den Befund nachkontrolliert. Bei Nr.9 zuerst 70 Tage nach der ersten Relaparotomie und später 40 Tage nach der zweiten Relaparotomie, also zuletzt 142 Tage nach der ursprünglichen Fetteinbringung; bei Nr. 1460 Tage nach der ersten Relaparotomie, also 74 Tage nach der Fetteinbringung. In beiden Fällen waren auch jetzt keine Adhäsionen eingetreten. Die fettmembranartigen Auflagerungen waren stark geschrumpft spärlicher geworden, aber noch deutlich vorhanden im Bereich der gesetzten Peritonealschädigung der Bauchwand und auf der Leberoberfläche.

Histologisch fand sich Zunahme des Bindegewebes und Schrumpfung der maschenartigen Zwischenräume. Die Fetteinlagerungen waren geringer geworden und lagen die Fetttropfen vorwiegend intracellulär, so daß die Auflagerungen den Eindruck von Fettgewebe machten. Dieser Befund fand sich auch noch nach einem Zeitraum von 142 Tagen.

Die Reaktion des Peritoneums auf die Einverleibung des durch Äther extrahierten Fettes gegenüber dem einfachen ausgelassenen Fett war also, wie wir gesehen haben, aus den erwähnten Gründen bedeutend geringer, aber zweifellos war doch immer noch eine gewisse Reizwirkung auf die Serosa festzustellen.

Ich versuchte deshalb das Fett noch in anderer Form zu dem beabsichtigten Zweck zu verwenden, und zwar als Emulsion. Hierbei leitete mich der Gedanke, daß das in der Emulsion in Form feinster Tröpfchen gleichmäBig suspendierte Fett sich schneller und gleichmäßiger auf dem parietalen und visceralen Peritoneum verbreiten möchte wie das gewöhnliche Fett, daß dadurch die Schnelligkeit der Resorption des Fettes vielleicht begünstigt werden könnte, ohne die adhäsionshemmende Wirkung desselben herabzusetzen.

Die Emulsion habe ich hergestellt nach der von Porges und $\mathrm{Neu-}$ bauer angegebenen Methode, jedoch habe ich den Äther nicht entfernt, sondern die Emulsion mit dem Äthergehalt zur Injektion benutzt. Ich nahm $10 \mathrm{ccm}$ des durch Ätherextraktion aus frischem Fettgewebe gewonnenen Kaninchenfettes, löste dasselbe in $20 \mathrm{ccm}$ reinen Narkoseäther und versetzte die so erhaltene klare Lösung mit $20 \mathrm{ccm}$ alkalischer Normosallösung. Das Gemenge stellt eine leicht milchig getrübte Emulsion dar. Das Gemisch wurde in ein Wasserbad von $40^{\circ}$ gestellt, um die Flüssigkeit bis zum Moment der Einspritzung auf Körpertemperatur zu halten. Da der Äther bei $35^{\circ}$ siedet, entwich dadurch ein gewisses Quantum Äther, so daß die Gesamtmenge der Emulsion bei der Injektion etwas reduziert war, und zwar, wie ich durch Nachmessen feststellte, jedesmal um etwa 5-10 ccm.

Ich lasse nunmehr die Versuchsprotokolle der mit Kaninchenfettemulsion behandelten Tiere folgen. Im ersten Versuch suchte ich mir 
Klarheit darüber zu verschaffen, wie die Tiere die ätherhaltige Emulsion vertrugen und welche Veränderungen nach 14 Tagen in der Bauchhöhle vorhanden waren.

Versuch 17. Graues ơ Kaninchen Nr. 20. Körpergewicht $1620 \mathrm{~g}$.

23. XI. 1920. $3 \mathrm{~cm}$ langer Mittelschnitt. Sofortiger Schluß der Bauchhöhle bis auf eingebundene Kanüle, durch die eine Emulsion von der Zusammensetzung $10 \mathrm{ccm}$ Kaninchenfett gelöst in $20 \mathrm{ccm}$ Aeth. puriss. + Zusatz von $20 \mathrm{ccm}$ Normosallösung injiziert wird. Definitiver Schluß der Bauchhöhle.

24. XI. Tier schon etwas munter, beschnuppert Nahrung.

25. XI. Lebhafter, frißt.

4. XII. Relaparotomie. Körpergewicht $1380 \mathrm{~g}(-240)$.

$10 \mathrm{~cm}$ Längsschnitt rechts neben der alten fest verheilten Narbe. Bauchdecken sehr gefäßreich. Bauchnarbe peritonealwärts frei von Adhäsionen. Auf dem parietalen Peritoneum wie auf der Darmserosa sieht man diffus verbreitet feine schleierartige Fettüberzüge von der gleichen Beschaffenheit, wie wir es oben nach der Anwendung des reinen unvermischten Fettes gesehen haben. Flüssiges Fett ist in der Bauchhöhle nicht vorhanden.

Aus diesem Vorversuch gewann ich nach der 14 Tage post op. vorgenommenen Revision der Bauchhöhle den Eindruck, daß die Veränderungen an der Peritonealauskleidung der Bauchhöhle und an den Intestinis sich nicht wesentlich unterschieden von den nach der Anwendung des einfachen unvermischten Kaninchenfettes nach gleich langer Zeit. Dagegen schien mir, daß das Tier die Feftemulsion besser vertrage als das unvermischte reine Fett, nicht so lange krank war und sich schneller erhole. Ich ging deshalb dazu über, in den folgenden vier Versuchen mir ein Urteil zu bilden über die adhäsionshemmende Wirkung des Kaninchenfettes als Emulsion. In den beiden ersten Versuchen legte ich gleichzeitig Kontrollversuche an, während ich in den beiden anderen Versuchen auf Kontrollversuche verzichtete und bei den Versuchstieren solche Peritonealschädigungen setzte, die nach meinen Erfahrungen ziemlich sicher zu Adhäsionsbildung disponierten.

Versuch 18a. Graues ㅇ Kaninchen Nr. 21. Körpergewicht $1620 \mathrm{~g}$.

26. XI. 1920. $5 \mathrm{~cm}$ langer Mittelschnitt in Oberbauchgegend. Verwundung des parietalen Peritoneums im Umkreis des Laparotomieschnittes durch Scarification mit dem Messer, so daß das Peritoneum stark geschunden und blutig suggiliert aussieht. Vorziehen des Netzes und Scarification desselben auf beiden Seiten. Schluß der Bauchhöhle bis auf eingebundene stumpfe Kanüle, durch welche Emulsion, bestehend aus $10 \mathrm{ccm}$ ätherextrahiertem Kaninchenfett, $20 \mathrm{ccm}$ Aeth. puriss., $20 \mathrm{ccm}$ Normosal, injiziert wird. Definitiver Schluß der Bauchhöhle.

27. XI. Tier sitzt ruhig, frißt noch nicht.

28. XI. Lebhafter, frißt etwas.

23. XII. Getötet durch Chloroform. Körpergewicht $15050 \mathrm{~g}(-70)$.

Sektionsbefund: Laparotomieschnitt fest verheilt. Von der Bauchnarbe zieht eine fadenförmige Adhäsion zu einer Darmschlinge. Die seitlichen Partien des parietalen Peritoneums im Bereich der Scarification sind frei von Verwachsungen, desgleichen ist das Netz nicht adhärent. Auf dem Peritoneum parietale finden sich sehleierartige Auflagerungen, besonders im Bereich der gesetzten Peritoneal- 
schädigung; ebenso ist die Darmserosa in ziemlicher Ausdehnung mit solchen membranartigen Auflagerungen bedeckt, besonders stark sind dieselben vorhanden auf der Leberoberfläche und in der Zwerchfellkuppe. An einzelnen Stellen finden sich zwischen den Darmschlingen weißlich-gelbe Massen, die mikroskopisch aus Fett, Leukocyten und Fibrin bestehen (vgl. Versuch 6a).

Histologischer Befund einer Bauchwandexcision im Bereich der geschilderten Auflagerungen: Die Auflagerung besteht aus lockermaschigem, zellreichen Bindegewebe, das zahlreiche zottenartige Erhebungen trägt. Vornehmlich in den unteren Schichten dieser Auflagerungen ist Fett in größeren und kleineren Tropfen eingelagert.

Versuch 18b. Graues $O$ Kaninchen Nr. 22. Körpergewicht 1520 g. (Kontrolltier.)

26. XI. 1920. $5 \mathrm{~cm}$ langer Mittelschnitt in Oberbauchgegend. Dieselbe Versuchsanordnung wie bei a, nur kein Fett.

Glatte Rekonvaleszenz.

23. XI. Rela parotomie. Körpergewicht $1800 \mathrm{~g}(+280)$.

Längsschnitt seitlich der alten fest verheilten Narbe. Keinerlèi Adhäsionen im Bereich der Bauchnarbe und des verwundeten Peritoneums. Schluß der Bauchhöhle.

Versuch 19a. Graues ơ Kaninchen Nr. 24. Körpergewicht $1900 \mathrm{~g}$.

30. XI. $5 \mathrm{~cm}$ langer Mittelschnitt in Oberbauchgegend. Scarification des parietalen Peritoneums im Umkreis des Bauchschnittes. Vorziehen des Netzes, Lagerung auf Gazekompresse, Reiben mit trockenem Tupfer und Ritzen mit der Messerspitze auf beiden Seiten, bis dasselbe deutlich geschunden aussieht. Schluß der Bauchhöhle bis auf eingebundene stumpfe Kanüle, durch die Emulsion aus $10 \mathrm{ccm}$ Kaninehenfett, $20 \mathrm{ccm}$ Aeth. puriss. und $20 \mathrm{ccm}$ Normosallösung injiziert wird. Definitiver Schluß der Bauchhöhle.

31. XI. Tier schon etwas munter, frißt.

1. XII. Lebhaft, erholt sich rasch.

7. I. 1921. Réla parotomie. Körpergewicht $2145 \mathrm{~g}(+245)$.

Eröffnung der Bauchhöhle seitlich des ersten fest verheilten Bauchschnittes. Bauchnarbe peritonealwärts frei von Adhäsionen. Die geschädigten Stellen des parietalen Peritoneums sind mit fettmembranartigen Auflagerungen bedeckt, an denen makroskopisch schon feine zottenartige Auswüchse zu erkennen sind. Zwischen Leber und Netz fadenförmige Adhäsionen. Excision eines Bauchwandstückes zur Untersuchung. Schluß der Bauchhöhle.

Histologischer Befund der Bauchwandexcision: Das Peritoneum ist durchweg schwielig verdickt und weist eine zusammenhängende Auflagerung von lockerem, maschenreichem Bindegewebe auf mit zahlreichen neu gebildeten Capillaren. Dieser Überzug stellt nicht eine glatte Fläche dar, sondern weist zahlreiche zottenartige Bindungen auf, die aus zellreichem jungen Bindegewebe und Capillaren bestehen. In den grobmaschigen Zwischenräumen dieses Gewebes, besonders in den basalen Schichten, sind zahlreiche große und kleine Fetteinlagerungen eingesprengt.

28. II. Tier getötet durch Chloroform. Körpergewicht $2320 \mathrm{~g}(+185)$.

Sektionsbefund: In der Laparotomienarbe sind noch deutlich Catgutligaturen sichtbar. Die Fettauflagerungen sind auch heute noch gut erkenntlich, aber im allgemeinen flacher und von glatterer Oberfläche, nur an einer Stelle dicht neben der eingezogenen Bauchnarbe erkennt man eine zottenartige Bildung. Verwachsungen der vorderen Bauchwand mit den Intestinis bestehen nicht. Zwischen der Oberfläche der Leber und dem Netz sind deutlich flächenhafte Adhäsionen aufgetreten an der Stelle, wo bei der ersten Relaparotomie schon fadenförmige Adhäsionen festgestellt wurden. 
Histologischer Befund der excidierten Bauchnarbe (alte Naht): Auf dem schwielig verdickten Peritoneum erkennt man Fett in zusammenhängender Schicht in größeren und kleineren Tropfen, zum großen Teil in den Zellen, zum Teil zwischen denselben gelagert. An einzelnen Stellen hat sich das Fett zwischen die verdickten Schichten des Peritonealüberzugs gedrängt und ist teilweise zwischen den einzelnen Muskelbündeln in der Tiefe sichtbar. An der Stelle der Vereinigung der beiden Bauchwandseiten sieht man deutlich eine Einziehung des Peritoneums, hier sind die Fettauflagerungen besonders dick und in der durch die Einkrempelung der Wundränder gebildeten Nische erkennt man die gleichmäßig homogene, strukturlose Masse des vereinigenden Catgutfadens in reichliches Granulationsgewebe eingebettet. Die Oberfläche dieser Fettauflagerungen ist zum Teil von lockermaschig zellreichem Bindegewebe bedeckt, das an einzelnen Stellen auch noch Fetteinlagerungen enthält. Auf der Oberfläche des den Catgutfaden umhüllenden Granulationsgewebes bilden diese lockeren Bindegewebswucherungen eine büschelförmige Erhebung. Auch hier findet sich Fett in größeren und kleineren Tropfen eingelagert. Die Auflagerungen sind größtenteils von gewuchertem Endothel bedeckt.

Versuch 19b. Graues o Kaninchen Nr. 25. Körpergewicht 1680 g. (Kontrolltier.)

30. XI. $5 \mathrm{~cm}$ langer Mittelschnitt in Oberbauchgegend. Die gleiche Versuchsanordnung wie bei a, nur kein Fett.

Glatte Rekonvaleszenz.

7. I. 1921. Rela parotomie. Körpergewicht $1985 \mathrm{~g}(+305)$.

Eröffnung der Bauchhöhle durch $6 \mathrm{~cm}$ langen Schnitt seitlich des ersten fest verheilten Bauchschnittes: Zwei fadenförmige Adhäsionen, die sich leicht lösen lassen, ziehen vom Netz zur vorderen Bauchwand an die Stelle der gesetzten Peritonealschädigung, die im übrigen glatt und spiegelnd ersoheint; sonst keine Adhäsionen nachweisbar.

Versuch 20. Graues 우 Kaninchen Nr. 29. Körpergewicht $1730 \mathrm{~g}$.

$5 \mathrm{~cm}$ langer Mittelschnitt in Oberbauchgegend, kräftige Scarification des Peritoneum parietale im. Umkreis des Laparotomieschnittes. Eventeration und doppelseitige Ritzung des Netzes. Schluß der Bauchhöhle bis auf eingebundene stumpfe Kanüle, durch welche Emulsion aus $10 \mathrm{ccm}$ ätherextrahiertem Kaninchenfett, $30 \mathrm{ccm}$ Aeth. puriss. und $20 \mathrm{ccm}$ Normosallösung injiziert wird. Gleich nach der Injektion geht das Tier unter den Erscheinungen des Narkosentodes ein, obwohl die Narkose vor der Injektion nicht besonders tief gewesen war. Der Exitus ist wohl mit Sicherheit zurückzuführen auf die relativ große Menge des mit der Injektion intraperitoneal einverleibten Äthers und die rasche Resorptionsfähigkeit des zarten feinen Peritoneums bei dem verhältnismäßig schwachen, jungen Tiere.

Versuch 21. Weiß-schwarz geflecktes $Q$ Kaninchen Nr.32. Körpergewicht $1760 \mathrm{~g}$.

20. XII. $5 \mathrm{~cm}$ langer Mittelschnitt in Oberbauchgegend. Streifenförmige Excision des parietalen Peritoneums unter oberflächlicher Mitnahme von Muskelsubstanz an einzelnen Stellen. Resektion eines Netzzipfels, Catgutligatur. Fortlaufende Bauchnaht bis auf eingebundene stumpfe Kanüle, durch welche Emulsion. aus $10 \mathrm{ccm}$ ätherextrahiertem Kaninchenfett, $10 \mathrm{ccm}$ Aeth. puriss., $10 \mathrm{ccm}$ Normosallösung injiziert wird: Definitiver Schluß - der Bauchhöhle.

21. XII. Frißt noch nicht.

22. XII. Lebhafter, frißt etwas.

23. XII. Heute morgen tot im Stall. Körpergewicht $1670 \mathrm{~g}(-90)$.

Sektions bef und: Laparotomieschnitt schon fest verheilt, reizlos. Keinerlei 
Adhäsionen weder an der Bauchnarbe noch am Netz oder zwischen den Darmschlingen. Das Peritoneum parietale und der Serosaüberzug der Darmschlingen sind von einer hauchartigen Schicht feinsten Fettes überzogen; keine Fettansammlung in den abhängigen Partien. Darmschlingen nicht gebläht.

Bakteriologisch bleibt der Bauchhöhlenabstrich steril. Im Lungenpräparat kein Anhalt für Fettembolie. Exitus nicht einwandfrei klargestellt.

Aus diesen vier Versuchsgruppen 18-21 konnte ich die nach dem Vorversuch 17 ausgesprochene Vermutung, daß die Tiere das Fett als Emulsion besser vertragen würden, nicht bestätigen. Zwei Tiere (18 und 19a) erholten sich zwar relativ rasch, waren schon am 1 . bzw. am 2. Tag auffallend munter und fraßen. Vielleicht ist dies zurückzuführen auf einen gewissen stimulierenden Reiz des intraperitoneal einverleibten resorbierten Äthers, der nur noch in einer relativ geringen Menge in der Emulsion vorhanden war. Diese belebende Wirkung des Äthers auf den Allgemeinzustand ist ja eine Erscheinung, die bei der Ätherbehandlung der Peritonitis von den verschiedensten Autoren hervorgehoben wird (Benthin, Sigwart, Seubert, Dubs u. a.):

In Versuch 20 dagegen ging das Tier gleich nach der Einbringung des Äthers zugrunde, und scheint mir der Exitus in diesem Falle, bei dem die zur Emulsion benutzte Äthermenge besonders groß war $(30 \mathrm{ccm})$; mit der schnellen Resorption des Äthers zusammenzuhängen. Ähnliches erlebte Seifert bei seinen Tierversuchen mit Katzen: bei regelrechter Narkose hatte nicht selten die Resorption des intraperitoneal eingeführten Äthers den Narkosentod der Katzen zur Folge. In Versuch 21 trat am 3. Tag post op. der Exitus ein, ohne daß die Todesursache durch die Sektion klargestellt werden konnte.

Besonders aber interessierte mich die Wirkung der Fettemulsion auf das Peritoneum vor allem bezüglich der Verhütung von Adhäsionen nach entsprechender Schädigung einzelner Peritonealbezirke. Hier ist nun zu sagen, daß die Peritonealhöhle nach Einverleibung des emulgierten Fettes dasselbe Bild bot, wie nach der Injektion des reinen unvermischten ätherextrahierten Kaninchenfettes: gleichmäßig ausgebreitete feine schleierartige Überzüge auf dem parietalen und visceralen Peritoneum in den ersten Tagen nach der Operation, gröbere; zum Teil inselförmig angeordnete lockere Auflagerungen vornehṃlich an den Stellen der gesetzten Peritonealschädigung nach einem Zeitraum ron etwa 2-4 Wochen, und Rückbildung dieser Auflagerungen durch Resorption und Organisation nach einem längeren Zeitraum. In einem Falle (18a) fanden sich an einzelnen Stellen angehäuft weißlichgelbe Massen aus Fett, Leukocyten und Fibrin bestehend, wie wir das auch im Falle 6 a nach Einverleibung von ausgelassenem Kaninchenfett gesehen haben.

Die oben erwähnten zottenartigen Fortsätze der peritonealen Auflagerungen waren in den beiden hier in Betracht kommenden Fällen 
18 und $19 \mathrm{a}$, besonders in dem letzteren Falle, ziemlich reichlich entwickelt und dürfte hier neben der eingebrachten Fettemulsion wohl in erster Linie der nach 12 Wochen noch nicht resorbierte Catgutfaden und der von demselben ausgehende Reiz für diese stärkere Bindegewebswucherung verantwortlich zu machen sein.

Histologisch boten diese Auflagerungen genau das gleiche Bild, wie wir es auch bei den Fällen nach unvermischtem ätherextrahierten und nach einfachem ausgelassenen Fett in den voraufgehenden Ausführungen wiederholt geschildert haben.

Adhäsionen traten nur in einem Falle nicht auf. Die beiden Fälle 20 und 21, die gleich nach der Operation oder am 3. Tage post op. ad exitum gekommen sind, lassen sich für die Entstehung von Adhäsionen noch nicht verwerten. Im Fall 19a fand sich eine fadenförmige Adhäsion zwischen Leber und Netz, die, wie bei der 51 Tage später, also 89 Tage nach der Einbringung der Fettemulsion vorgenommenen Sektion sich herausstellte, noch fester geworden war. In einem Fall (18a) fand sich eine dünne fadenförmige Adhäsion von der Bauchnarbe zum Darm ziehend. Es war das der Fall, in dem auch die Fettansammlung in größeren Lagern zwischen den Darmschlingen vorhanden war, und dürfte die Bildung dieses Gemisches aus Fett, Leukocyten und Fibrin im Zusammenhang mit den hier besonders ausgesprochenen zottenartigen Fortsätzen der peritonealen Auflagerungen und der feinen Adhäsionen wohl im Sinne einer stärkeren peritonealen Reaktion auf den Reiz der einverleibten Emulsion zu deuten sein.

Vielleicht ist dem Äthergehalt der Emulsion hier eine schädigende Wirkung zuzusprechen, da nach den klinischen Beobachtungen Se uberts den Äthereingießungen in die Bauchhöhle ein adhäsionsförderndes Moment zukommt.

Es war also nach der Anwendung der Kaninchenfettemulsion nicht nur die Reaktion des Peritoneums nicht geringer, sondern im Gegenteil eher stärker, da die nachträglich entstandenen Veränderungen in der Peritonealhöhle mehr denen glichen, wie wir sie nach der Einverleibung des einfachen ausgelassenen Kaninchenfettes beobachtet haben, obwohl zur Darstellung der Emulsion als Ausgangsmaterial ätherextrahiertes reines Fett verwandt worden war. Es mußte aber unser Bestreben sein, das zum Zwecke der Verhütung von Adhäsionen einverleibte Fett in einer Form, Menge und Beschaffenheit zur Anwendung zu bringen, so daß die Reaktion des Peritoneums eine möglichst geringe blieb. Ich habe deshalb auf Grund der gemachten Beobachtungen von weiteren Versuchen mit Kaninchenfettemulsion Abstand genommen.

Nach meinen bisherigen Erfahrungen hatte ich die Überzeugung gewonnen, daß bei der Verwendung arteigenen Fettes zur Verhütung 
postoperativer peritonealer Adhäsionen mittels arteigenen flüssigen Fettes. $\quad 541$

von Adhäsionen sich das durch Ätherextraktion aus frischem Fettgewebe gewonnene reine Kaninchenfett am besten bewährte.

Diese im Tierexperiment mit arteigenem Fett gemachten günstigen Erfahrungen eröffneten einen guten Ausblick auf die Verwendung der Methode beim Menschen, auf die intraperitoneale Anwendung flüssigen menschlichen Fettes zur Verhütung von Adhäsionen nach Laparotomien.

Doch schien es zweckmäßig, zuvor im Tierexperiment diese vermutete Wirkung des menschlichen Fettes auszuprobieren, vor allem auch festzustellen, wie sich das Peritoneum der Tiere gegenüber dem einverleibten artfremden Fette verhalte, ob und wie das artfremde Material resorbiert würde und welche Veränderungen am Peritoneum nachweisbar waren, ob endlich das artfremde menschliche Fett in gleicher Weise wie das arteigene imstande war, beim Tier die Ausbildung von Verwachsungen hintanzuhalten.

Das Fett des Menschen unterscheidet sich vom Kaninchenfett, was seine physikalischen und chemischen Eigenschaften angeht, in ziemlich beträchtlicher Weise.

Menschenfett zeigt bei Zimmertemperatur eine salbenartige Konsistenz und ist von schwachgelber Farbe. Es befindet sich im lebenden Organismus in flüssigem tröpfchenförmigen Zustande. Es ist nahezu geruchlos und besteht fast nur aus den Glyceriden der ölsäure, Palmitin und Stearinsäure. Die Zusammensetzung des Menschenfettes ist Schwankungen unterworfen, welche durch Geschlecht und Körperregion, der dasselbe entstammt, bedingt werden.

Wir finden bei Brahm in Abderhaldens Biochemischem Hand. lexikon folgende Werte der physikalischen Eigenschaften für das Fett des Erwachsenen:

$\begin{array}{ccc}\text { Spez. Gewicht } & \text { Erstarrungspunkt } & \text { Schmelzpunkt } \\ \text { bei } 25^{\circ} 0,903 & 15^{\circ} \mathrm{C} & 17,5^{\circ} \mathrm{C}\end{array}$

Das Fett des Säuglings unterscheidet sich von dem Fett des Erwachsenen, und sind es besonders der Schmelzpunkt und der höhere Grad an festen Fettsäureglyceriden, die das Säuglingsfett auszeichnen. Mit zunehmendem Alter nimmt der Ölsäuregehalt zu, um im 2. Lebensjahre den Ölsäurewert und damit auch den Schmelzpunkt des Fettes der Erwachsenen zu erreichen. Der Gehalt steigt von 43,3\% des Neugeborenen bis $65 \%$ im 2. Lebensjahre. Das Fett Neugeborener ist konsistenter als das des Erwachsenen. Der Schmelzpunkt wurde bei $51^{\circ}$ gefunden (K nö pfel ma c her, Jahrb. d. Kinderheilk. 45, 197, 1897), während, wie aus obiger Tabelle ersichtlich, der Schmelzpunkt des Fettes des Erwachsenen schon bei $17,5^{\circ} \mathrm{C}$ liegt.

Dieser relativ niedrige Schmelzpunkt des Menschenfettes ist aber für uns nach Lage der Dinge der allein maßgebende, da für unsere 
folgenden Versuche und auch wohl sonst stets das durch Operation gewonnene frische Fettgewebe des Erwachsenen das Ausgangsmaterial bilden muB. Als derartiges Fettgewebe kommt in Betracht operativ entfernte Lipome, Netzhernien, überschüssiges Fett aus dicken fettreichen Bauchdecken. Eden und Lindig nahmen das für ihre Versuche notwendige Fettgewebe aus fettreichen Bauchdecken und aus Lipomen. Mir selbst diente als Ausgangsmaterial das bei der Operation einer Netzhernie resezierte sehr fettreiche Netz. Das Fettgewebe wurde ausgewaschen und vom Blut gereinigt, in kleine Stückchen geschnitten und von gröberen Bindegewebsteilen befreit. Darauf wurde das Fettgewebe, um es noch mehr zu zerkleinern, durch eine Hackmaschine mit engmaschigem Sieb gedreht. Die Gewinnung des flüssigen Menschenfettes geschah dann nach meinen im Tierversuch mitKaninchenfett gemachten Erfahrungen durch Ätherextraktion im Soxhletapparat in der oben beschriebenen Weise.

Für die plastische Verwendung des flüssigen Menschenfettes bei subcutaner Anwendung nach Holländer oder Ma yer scheint es ziemlich gleichgültig zu sein, welchen Körperteilen das Fettgewebe, aus dem das flüssige Fett gewonnen wird, entstammt. Ich halte es aber nicht für ausgeschlossen, daß die Herkunft des Ausgangsmaterials bei der intraperitonealen Anwendung des flüssigen Menschenfettes eine gewisse Bedeutung hat und möchte glauben, daß das ursprünglich intraperitoneale Fettgewebe, das Netzfett auch für die spätere intraperitoneale Transplantation im flüssigen Zustande das geeignetste Material darstellt, da ja, wie Brah $\mathrm{m}$ hervorhebt, die Zusammensetzung des Menschenfettes Schwankungen unterworfen ist, welche durch Geschlecht und Körperregion, der dasselbe entstammt, bedingt werden.

Ich habe auch hier zunächst in einem Vorversuch die Toleranz des Tieres gegenüber der intraperitonealen Einverleibung des artfremden menschlichen Fettes festgestellt.

Versuch 22. Schwarzes $\odot$ Kaninchen Nr. 23. Körpergewicht $2740 \mathrm{~g}$.

27. XI. 1920. $2 \mathrm{~cm}$ langer Mittelschnitt in Oberbauchgegend. Sofortiger Schluß der Bauchhöhle bis auf eingebundene stumpfe Kanüle, durch die $10 \mathrm{ccm}$ ätherextrahiertes flüssiges. Menschenfett injiziert wird; definitiver Schluß der Bauchhöhle.

28. XI. Tier schon recht munter, frißt.

29. XI. Lebhaft, springt umher.

31. XI. Relaparotomie. Körpergewicht $2755 \mathrm{~g}(+15)$.

Eröffnung der Bauchhöhle seitlich des ersten schon fest verheilten Bauchschnittes. Bauchnarbe peritonealwärts vollkommen frei. Die Darmsehlingen und auch das parietale Peritoneum wiesen stellenweise feine hauchartige Fettauflagerungen auf, die vollkommen glatt sind und an denen weder ein Fibrinnetz noch gar zottige Bildungen zu erkennen sind. Verwachsungen der Darmschlingen untereinander oder zwischen Bauchwand und Intestinis bestehen nicht. Schluß der Bauchhöhle. 
14. I. 1921. Tier getötet durch Chloroform. Körpergewicht $2910 \mathrm{~g}(+155)$.

Sektionsbefund: Die beiden Bauchschnitte sind vollkommen vernarbt und peritonealwärts frei von Verwachsungen. Auch zwischen den Darmschlingen und den übrigen Intestinis sind keine Adhäsionen nachweisbar. Das parietale Peritoneum und der Serosauiberzug der Darmschlingen ist fast vollkommen frei von Auflagerungen, nur an einzelnen Stellen, vor allem am parietalen Peritoneum und an der Leberoberfläche sind vereinzelte gelblich-weiße Fleckchen vorhanden, deren Oberfläche vollkommen glatt und spiegelnd ist.

Histologischer Befund eines Leberstückchens mit einer derartigen Auflagerung: Gleichmäßig sich hinziehende Auflagerung, bestehend aus zellreichem Bindegewebe mit reichlich Capillaren. In den Lücken des Gewebes liegt Fett in größeren und kleineren Tropfen zum großen Teil intracellulär eingelagert. Die Oberfläche ist von Endothel überzogen.

Aus diesem Vorversuch ging hervor, daß die Tiere das artfremde Menschenfett gut vertragen, jedenfalls ließ die schnelle Rekonvaleszenz nach der Einbringung des Fettes darauf schließen, daß der Tierkörper auf das artfremde Material sicher nicht mit einem stärkeren Krankheitszustand reagierte als auf das arteigene Fett. Was die Reaktion des Peritoneums auf das artfremde Fett angeht, so hatte es auch den Anschein, daß eher eine geringere Reizwirkung von seiten der peritonealen Blätter festzustellen war als in den bisherigen Versuchen mit arteigenem Fett.

Ich ging dann dazu über, das menschliche Fett auf seine adhäsionshemmende Kraft im Tierversuch zu prüfen und lasse in folgendem die betreffenden Versuchsprotokolle folgen.

Versuch 23a. Graues \& Kaninchen Nr. 26. Körpergewicht $1620 \mathrm{~g}$.

2. XII. 1920. $5 \mathrm{~cm}$ langer Mittelschnitt in Oberbauchgegend. Im Umkreis des Bauchschnittes werden schmale Streifen des parietalen Peritoneums excidiert, darauf die ganze Partie kräftig scarificiert und die so geschädigte Peritonealfläche mit 10 proz. Jodtinktur betupft.

Bauchnaht bis auf eingebundene Kanüle, durch die $10 \mathrm{ccm}$ ätherextrahiertes flüssiges Menschenfett körperwarm injiziert werden. Definitiver SchluB der Bauchhöhle.

3. XII. Tier schon etwas munter, beschnuppert Nahrung.

4. XII. Lebhaft, frißt.

22. XII. Relaparotomie. Körpergewicht $1865 \mathrm{~g}(+245)$.

$6 \mathrm{~cm}$ langer Längsschnitt seitlich der ersten fest verheilten Bauchnarbe. Bauchnarbe peritonealwärts vollkommen frei, keinerlei Adhäsionen. An der Stelle der Verwundung weist das parietale Peritoneum eine dünne festhaftende Auflagerung auf, deren Oberfläche glatt und spiegelnd ist. Am Peritoneum parietale und auf der Serosa der Darmschlingen sind keine derartigen zottigen Auflagerungen festzustellen, wie wir sie in den früheren Fällen nach Kaninchenfettinjektion häufig gesehen haben. Dagegen finden sich im Netz vereinzelte hirsekorn- bis linsengroße, weißlich-gelbe Einlagerungen, die als Fetteinschlüsse angesprochen werden; im übrigen ist das Netz auch frei von Adhäsionsbildung. Flüssiges Fett oder Anhäufungen von Fett an einzelnen Stellen sind nicht nachweisbar.

Resektion eines Netzstückchens mit den geschilderten Einlagerungen und eines Stücks der Bauchwand.

Histologischer Befund des excidierten Netzstückes bestätigt die makro- 
skopische Diagnose. Es handelt sich um Fettansammlung, die in lockeres Bindegewebe eingekapselt ist.

Befund der Bauchwandexcision: Der Peritonealüberzug ist umgewandelt in lockermaschiges Bindegewebe, das in den Gewebslücken Fetteinlagerungen enthält, und zwar sind diese Fetteinschlüsse teils als Tropfen intracellulär, teils zwischen den Zellen gelagert und bald in dickerer bald in dünnerer Schicht angeordnet. Basalwärts liegt diese Fettschicht der Muskulatur zum Teil dicht an, an einzelnen Stellen sich zapfenförmig in sie hinein erstreckend. Der freie Rand dieser an Fettgewebe erinnernden Auflagerung wird gebildet von einer Schicht Iockermaschigen Bindegewebes, die an einzelnen Stellen kleinere zottenartige Erhebungen aufweist.

20. II. 1921. Tier getötet durch Chloroform. Körpergewicht $2230 \mathrm{~g}$ $(+365)$.

Beide Bauchschnitte fest verheilt und peritonealwärts frei von Verwachsungen. Die Auflagerung in der Umgebung des alten Laparotomieschnittes ist als ganz dünne Membran noch kenntlich. Sonst findet sich am parietalen Peritoneum keine Auflagerung mehr. Im Netz sind keine Fetteinlagerungen (s. oben) mehr zu entdecken, dagegen auf der Leberoberfläche ganz vereinzelte glatte gelbliche Auflagerungen.

Histologischer Befund eines excrdierten Bauchwandstückchens: Das zum Teil schwielig verdickte Peritoneum ist von einer bindegewebigen Auflagerung bedeckt, die in ihren lockermaschigen Zwischenräumen Fett in großen und kleineren Fetttropfen eingelagert enthält. Die Fetttropfen liegen zum Teil intra-, zum Teil intercellulär. An einzelnen Stellen sind größere Hohlräume erkenntlich, wo Fett ausgefallen ist. Die oberflächliche Schicht ist mit einem teils ein-, teils mehrschichtigen Endothelbelag bedeckt. Die ganze Auflagerung, die sich nach den Seiten allmählich verdünnt und ins angrenzende Peritoneum verliert, erinnert in ihrem Aufbau an Fettgewebe. Das Fett hat gegenüber dem ersten Präparat durch Resorption an Menge merklich abgenommen.

Histologischer Befund eines excidierten Leberstückchens: Auflagerung von lockermaschigem zellreichen Bindegewebe, sich gleichmäßig hinziehend und nach den Seiten zu allmählich an Dicke abnehmend. Zahlreiche kleinere Hohlräume, aus denen Fett ausgefallen ist, erkennt man in der Auflagerung, in welcher im übrigen das Fett gleichmäßig angeordnet in größeren und kleineren Tropfen zum Teil in den Zellen eingelagert ist. Der freie Rand der Auflagerung ist von zusammenhängendem Endothelbelag bedeckt.

Versuch 23 b. Graues 오 Kaninchen Nr. 27. Körpergewicht 1985 g. (Kontrolltier.)

2. XIT. 1920. $5 \mathrm{~cm}$ langer Mittelschnitt in Oberbauchgegend. Dieselbe Versuchsanordnung wie bei a, nur kein Fett.

Glatte Rekonvaleszenz.

22. XII. Relaparotomie. Körpergewicht $2080 \mathrm{~g}(+95)$.

Eröffnung der Bauchhöhle durch $6 \mathrm{~cm}$ langen Schnitt seitlich des ersten fest verheilten Bauchschnittes. Es finden sich zwei fadenförmige dünne Adhäsionen vom Netz zur vorderen Bauchwand an die Stelle der gesetzten Peritonealschädigung ziehend.

Versuch 24. Schwarzes ơ Kaninchen Nr. 28. Körpergewicht 1760 g.

9. XII. 1920. $5 \mathrm{~cm}$ langer Mittelschnitt in Oberbauchgegend. Kräftige Scarification des parietalen Peritoneums zu beiden Seiten des Bauchschnittes. Vorziehen des Netzes und Ritzen desselben auf beiden Seiten. Betupfen der geschädigten Stellen des parietalen Peritoneums und des Netzes mit 10 proz. Jodtinktur. Fortlaufende Bauchnaht bis auf eingebundene stumpfe Kanüle, durch welche $10 \mathrm{ccm}$ äther- 
extrahiertes körperwarmes Menschenfett injiziert werden. Definitiver Schluß der Bauchhöhle.

10. XII. Tier schon etwas lebhaft.

11. XII. Tier munter, frißt.

23. XII. Getötet durch Chloroform. Körpergewicht $1920 \mathrm{~g}(+160)$.

Sektionsbefund: Bauchnarbe fest verheilt. Keine Verwachsungen der Bauchwand mit Netz oder Darm. Flüssiges Fett oder größere Fettanhäufungen sind in der Bauchhöhle nicht nachweisbar. Auf dem parietalen Peritoneum an der scarifizierten Stelle neben dem Bauchschnitt erkennt man eine zarte Auflagerung von glatter spiegelnder Oberfläche. Vereinzelt findet man derartige Auflagerungen auch noch auf dem übrigen parietalen Peritoneum auf der Leberoberfläche und in der Zwerchfellkuppe.

Versuch 25a. Graues ơ Kaninchen Nr. 37. Körpergewicht $1950 \mathrm{~g}$.

$5 \mathrm{~cm}$ langer Mittelschnitt in Oberbauchgegend. Das Netz wird vorgezogen und auf beiden Seiten durch Ritzen mit dem Messer wundgemacht, an zwei Stellen stärkerer Blutaustritt, so daß Unterbindung durch zwei Catgutnähte notwendig wird. Scarification des parietalen Peritoneums im Umkreis des Bauchschnittes und Excision mehrerer schmaler Peritonealstreifen. Kräftige Jodierung der geschädigten Serosastellen. Schluß der Bauchhöhle bis auf eingebundene stumpfe Kanüle, durch welche $10 \mathrm{ecm}$ ätherextrahierten, körperwarmen Menschenfetts injiziert werden.

Schon abends am Operationstag ist das Tier munter.

6. I. 1921. Springt lebhaft umher, gute Nahrungsaufnahme.

27. I. Getötet durch Chloroform. Körpergewicht $1980 \mathrm{~g}(+30)$.

Sektionsbefund: Keine Adhäsionen der Bauchwand mit Netz oder Darm. Kein flüssiges Fett oder Fett in größerer Ansammlung in der Bauchhöhle, dagegen finden sich auf dem parietalen Peritoneum; auf der Darmserosa, auf der Leberoberfläche feine fettmembranartige Auflagerungen, die zwischen Leber und $Z_{\text {werch- }}$ fellkuppe besonders stark sind. Hier finden sich verschiedene feine fadenförmige Adhäsionen zwischen Leber, Magen und Netz, die sich beim vorsichtigen Anfassen schon lösen.

Histologischer Befund eines excidierten Bauchwandstückes: Stark verdicktes Peritoneum bedeckt von lockermaschigem jungem Bindegewebe, das sich an einzelnen Stellen in zottenartigen feinen Verästelungen emporhebt, an andern Stellen wieder dem Peritoneum glatt anliegt. Reichlich neugebildete Capillaren sind erkennbar. In den Maschen dieser Auflagerungen Fett in größeren und kleineren Tropfen eingelagert.

Versuch 25b. Granes o Kaninchen Nr. 38. Körpergewicht $2120 \mathrm{~g}$.

5. I. 1921. $5 \mathrm{~cm}$ langer Mittelschnitt in Oberbanchgegend. Die gleiche Versuchsanordnung wie bei a, nur kein Fett.

Glatte Rekonvaleszenz.

27. I. Getötet durch Chloroform. Körpergewicht $2000 \mathrm{~g}$ (-120).

Sektionsbefund: Breite feste Verwachsung vom Netz zur vorderen Bauchwand an die Stelle der Scarification, desgleichen ist der Magen und der untere Leberrand in die Adhärenzen mit hineingezogen. Die Verwachsungen sind so derb und fest, daß eine stumpfe Lösung unmöglich ist.

Versuch 26a. Graugelbes $\subseteq$ Kaninchen Nr. 39. Körpergewicht $1250 \mathrm{~g}$.

13. I. 1921. $5 \mathrm{~cm}$ langer Mittelschnitt in Oberbauchgegend. Verwundung des perietalen Peritoneums durch ausgiebige Scarification, Vorziehen des Netzes und Ritzung desselben auf beiden Seiten, desgleichen wird der Serosaüberzug des Magens mit der Messerspitze mehrfach geritzt. Bepinseln der geschädigten Serosastellen mit Jodtinktur. Hierbei wird etwas reichlich Jodtinktur benutzt, 
so daß etwas von derselben zwischen die Darmschlingen läuft. For talafende Bauchnaht bis auf eingebundene stumpfe Kanüle, durch welche $10 \mathrm{ccm}$ ätherextrahiertes körperwarmes Menschenfett injiziert werden. Definitiver Schluß der Bauchhöhle.

14. I. Tier sitzt ruhig, macht schwerkranken Eindruck, frißt nicht.

15. I. Noch nicht erholt, verweigert Nahrung.

17. I. Lebhafter, geringe Nahrungsaufnahme.

19. I. Getötet durch Chloroform. Körpergewicht $1070 \mathrm{~g}$ (- 180).

Sektionsbefund: Bauchnarbe peritonealwärts frei von Adhäsionen, dagegen zwischen Netz, Magen und Leber zahlreiche feinere fadenförmig sich anspannende Adhäsionen, die sich leicht sprengen lassen. Auf dem parietalen Peritoneum und auf den Darmschlingen und der Leberoberfläche sieht man zahlreiche feine Auflagerungen, in denen man an einzelnen Stellen deutlich ein fadenförmiges Gerüst erkennt. In einzelnen Partien sieht man ausgesprochen zottenartige Bildungen. Überall in der Bauchhöhle erkennt man noch deutlich einen schwach gelbbraunen Farbenton als Überrest der angewandten Jodtinktur.

Bakteriolog is ch: Bauchhöhlenabstrich steril.

Histologischer Befund eines excidierten Bauchwandstückchens: Auf dem gequollenen Peritonealïberzug reichlich lockermaschige Gewebsauflagerung, die aus Capillaren und jungem Bindegewebe bestehen. In den Maschen dieser Auflagerung, in der man netzförmig angeordnetes Fibrin erkennt, ist Fett in gröBeren und kleineren Tropfen eingelagert. Die Oberfläche der Auflagerung ist von stellenweise stark gewuchertem, zottenartig sich erhebenden Endothel überzogen.

Versuch 26b. Graues or Kaninchen Nr. 40. Körpergewicht 2570 g. (Kontrolliert.)

13. I. 1921. $5 \mathrm{~cm}$ langer Mittelschnitt in Oberbauchgegend. Die gleiche Versuchsanordnung wie bei a, auch die gleiche reichliche Jodierung, nur kein Fett.

14. I. Schwer krank, frißt nicht.

16. I. Sitzt noch immer ruhig und verweigert Nahrung.

19. I. Heute früh tot im Stall. Körpergewicht $2420 \mathrm{~g}(-150)$.

Sektionsbefund: An der vorderen Bauchwand ist das Netz mit einem breiten Zipfel adhärent, desgleichen finden sich ausgedehnte Verwachsungen zwischen Netz, Magen und Leber und zwischen den Darmschlingen, die zum Teil wie zu einem Konvolut zusammengeballt sind. Die Verwachsungen sind noch nicht fest und lassen sich leicht trennen. Auch hier zeigt die Bauchhöhle die gleiche von Jod herrührende Farbe wie bei a.

Auch hier ergibt die bakteriologische Untersuchung des Bauchhöhlenabstrichs Keimfreiheit, so daß wir es mit einer abakteriellen Peritonitis zu tun haben im Gefolge der allzu reichlichen Jodeinwirkung, auf die auch wohl der Exitus zurückgeführt werden muB.

Versuch 27a. Graues ơ Kaninchen Nr. 41.' Körpergewicht 2360 g.

15. I. 1921. $5 \mathrm{~cm}$ langer Mittelschnitt in Oberbauchgegend. Kräftige Scarification des angrenzenden parietalen Peritoneums. Vorziehen des gut entwickelten Netzes und ausgiebiges Ritzen desselben auf beiden Seiten bis es blutig suggiliert aussieht; an einer Stelle stärkere Blutung, die durch Catgutligatur gestillt wird. Ferner wird der Serosaüberzug der Vorderfläche des Magens durch Ritzen mit der Messerspitze geschädigt. Betupfen der geschädigten Stellen mit Jodtinktur. Schluß der Bauchhöhle bis auf eingebundene stumpfe Kanüle, durch welche $10 \mathrm{com}$ ätherextrahiertes körperwarmes Menschenfett injiziert werden.

16. T. Tier sitzt ruhig, frißt noch nicht.

17. I. Lebhaft, frißt.

12. II. Getötet durch Chloroform. Körpergewicht $2320 \mathrm{~g}(-40)$. 
Sektionsbefund: Bauchnarbe peritonealwärts frei von Verwachsungen. Die Stelle der Peritonealschädigung seitlich des Bauchschnittes ist mit einer zarten fettmembranartigen Auflagerung bedeckt; derartige. dünne Auflagerungen befinden sich, wenn auch nicht so ausgedehnt, an verschiedenen andern Stellen des parietalen Peritoneums. Ebenso sieht man die Serosa der Darmschlingen von derartigen-zarten Auflagerungen bedeckt, besonders deutlich und reichlich sind diese Auflagerungen auf der Leberoberfläche vorhanden. Das Netz selbst ist geschrumpft, mit seinem freien Ende etwas zusammengerollt, im übrigen aber frei und nicht verwachsen. Die Serosa des Magens ist vollkommen glatt und spiegelnd und ist nichts mehr von der gesetzten Schädigung zu erkennen. An einzelnen Stellen der geschilderten Auflagerungen erkennt man noch deutlich eine schwach gelbbraune Verfärbung als Überrest der stattgehabten Jodierung.

Histologischer Befund eines Leberstückchens mit einer derartigen Auflagerung: Leberoberfläche (Kapsel) ist von einem jungen Bindegewebe mit reichlicher Capillarbildung bedeckt, in dem sich hier und da lockere Maschen neben Resorptionszellen nachweisen lassen. In den Maschen finden sich bald größere, bald kleinere Fetttropfen, ebenso in den Resorptionszellen. Die äußere Schicht dieser Bindegewebsneubildung ist von einem flachen Endothelbelag bedeckt, der stellenweise allerdings bald größere bald kleinere zottige Erhebungen aus jungem Bindegewebe mit Capillaren aufweist.

Versuch $27 \mathrm{~b}$. Kleines graugelbes 우 Kaninchen Nr. 42. Körpergewicht 845 g. (Kontrolltier.)

15. I. 1921. $5 \mathrm{~cm}$ langer Mittelschnitt in Oberbauchgegend. Die gleiche Versuchsanordnung wie bei a, nur kein Fett.

16. I. Tier sitzt ruhig, frißt nicht.

18. I. Munterer, nimmt Nahrung.

12. II. Getötet durch Chloroform. Körpergewicht $870 \mathrm{~g}(+25)$.

Sektionsbefund: An der Stelle der Peritonealnarbe bzw. auf die gesetzte seitliche Peritonealschädigung übergreifend ist ein breiter Netzzipfel adhärent und läßt sich stumpf nicht lọsen. Im übrigen ist die Bauchhöhle frei von Adhäsionen. Die geschädigte Magenserosa ist vollkommen glatt und spiegelnd. Auch bei diesem Kontrolitier erkennt man am Netz, vor allem an der verwachsenen Partie, aber auch sonst an einzelnen Stellen des Peritonealüberzugs noch deutlich eine schwach gelbbraune Verfärbung als Rest der Jodierung.

Überblicken wir das Ergebnis dieser fünf Versuchsgruppen (23 bis 27), so ist zunächst zu sagen, daß die gesetzten Peritonealschädigungen in den angelegten Kontrollversuchen jedesmal zu Verwachsungen geführt haben. Abgesehen von den mechanischen Läsionen wurden die betreffenden Peritonealflächen auch noch durch Jodtinktur chemisch geschädigt und führten die genannten Maßnahmen stets zu festen Adhäsionen, nur in $23 \mathrm{~b}$, in welchem Falle die Schädigung nur einseitig angelegt war im Gegensatz zu den in den übrigen Versuchen stets an zwei gegenüberliegenden Flächen gesetzten Schädigungen, kam es lediglich zu zwei dünnen fadenförmigen Adhäsionen. Es wird dadurch bestätigt, was ich früher schon hervorgehoben habe, daß nach meinen Erfahrungen doppelseitige Peritonealschädigungen an korrespondierenden Stellen angelegt werden müssen, um mit einiger Sicherheit Adhäsionen zu erzeugen.

Daß zu reichliche intraperitoneale Jodanwendung die Tiere schwer 
schädigt, geht aus 26 b hervor, in welchem Falle das Kontrolltier nach zu starker Jodierung sich nicht von dem. Eingriff erholte und am 6. Tag nach der Operation ad exitum kam, ohne daß sonst eine Ursache für den Exitus festzustellen gewesen wäre, wie wir das in ähnlicher Weise bei Versuch $14 \mathrm{~b}$ gesehen hatten. Daß das eigentliche "Fettier" in diesem Versuche nicht in gleicher Zeit ad exitum kam, allerdings auch schwerkrank wurde - es wurde gleichzeitig mit dem eingegangenen Kontrolltier getötet --, hängt vielleicht mit einer zufälligen höheren Widerstandskraft zusammen. $\mathrm{Ob}$ in diesem Falle der Eintritt des Exitus durch einen gewissen resorptionshemmenden Einfluß des Fettes auf die Peritonealflächen aufgehalten worden ist, möchte ich aus diesem einen Falle nicht entscheiden.

Wie verhielten sich nun die Tiere gegenüber dem artfremden Fett? Vermochte das eingebrachte menschliche Fett die Entstehung von Adhäsionen zu verhindern oder zu verringern, und welche Veränderungen waren an dem Peritoneum nachweisbar?

Die geringe Reaktion des Tierkörpers und vor allem des Peritoneums auf das artfremde Fett war mir schon bei dem Vorversuch 22 aufgefallen, und brachten mir die folgenden Versuche die Überzeugung, daß meine Beobachtungen im Vorversuch richtig waren. Die Tiere vertrugen das artfremde Fett ausnehmend gut. Schon am Tage der Operation, spätestens am Tage darauf waren sie munter und nahmen Nahrung zu sich (23a, 24, 25a, 27a), nur in Versuch 26 zeigte das Tier ein schweres Krankheitsgefühl, was in diesem Falle, wie schon erwähnt, auf die starke Schädigung durch zu reichliche intraperitoneale Jodierung zurückzuführen war, die beim Kontrolltier dieses Versuches am 6 . Tage zum Exitus geführt hat. Dieses gute. Befinden der Tiere in den 4 genannten Fällen war wenigstens ein gleich gutes, wie nach der Einbringung des arteigenen Fettes, vielleicht sogar ein besseres.

Der Einfluß des Fettes auf das Befinden und den Zustand der Tiere geht in ziemlich deutlicher Weise hervor aus den Gewichtsnotierungen der einzelnen Tiere vor der Fetteinbringung und bei der späteren Nachkontrolle und aus der aus diesen Zahlen errechneten $\mathrm{Zu}$ - oder $\mathrm{Ab}$ nahme des Körpergewichtes.

Ich möchte hier einige Bemerkungen einflechten über die Schwankungen im Gewicht der Tiere, und inwiefern uns die Gewichtskurve einen Rückschluß erlaubt auf die Reaktion des Tierkörpers bei der Anwendung der in ihrer Darstellung bzw. Herkunft verschiedenen Fette.

Die Größe einer eventuellen Gewichtszu- oder -abnahme in jedem einzelnen Falle ist selbstverständlich abhängig von einer Reihe von Faktoren (Widerstandskraft, Alter, Wachstum der Tiere, Zeitraum zwischen den beiden Tagen der Gewichtsbestimmung usw.), hat aber für unsere Betrachtung nicht so große Bedeutung. Ich habe aus den 
einzelnen Gewichtsnotierungen - die Lebensbedingungen der Tiere, Futter usw. waren natürlich die gleichen - folgende Tabelle zusammengestellt, in der ich aus vorstehender Erwägung die Größe der Gewichtszu- oder -abnahme und auch den zwischenliegenden Zeitraum außer Betracht gelassen habe und nur die Zu- oder Abnahme des Körpergewichts bei den Tieren der verschiedenen Gruppen festgelegt habe.

Gewichtstabelle.

\begin{tabular}{|c|c|c|c|c|c|c|c|c|c|}
\hline 䚻 & Art des Fettes & 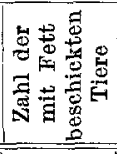 & 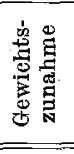 & 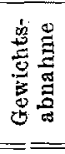 & 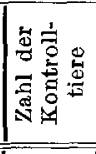 & 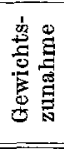 & 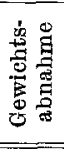 & 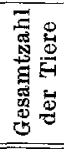 & \\
\hline I & $\begin{array}{l}\text { geschmolzenes } \\
\text { Kaninchenfett }\end{array}$ & 6 & $\longrightarrow$ & 6 & 2 & 2 & 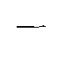 & 8 & \\
\hline II & $\begin{array}{c}\text { Äther extr. Ka- } \\
\text { ninchenfett }\end{array}$ & 10 & 4 & 6 & 7 & 6 & $\left.1^{1}\right)$ & 17 & $\begin{array}{l}\text { 1) Tier } \\
\text { Nr. } 36\end{array}$ \\
\hline III & $\begin{array}{l}\text { ätherhalt. Kanin- } \\
\text { chenfettemulsion }\end{array}$ & 4 & 1 & 3 & 2 & 2 & - & 6 & \\
\hline IV & $\begin{array}{c}\text { Äther extr. } \\
\text { menschliches Fett }\end{array}$ & $6^{2}$ & 4 & 2 & 4 & 2 & $\left.2^{2}\right)$ & 10 & $\begin{array}{c}\text { 2) Tier } \\
\text { Nr. } 40 \text { u. } 38\end{array}$ \\
\hline
\end{tabular}

Aus dem Vergleich der hier angeführten Zahlen gehen verschiedene interessante Tatsachen hervor:

Bei sämtlichen sechs Tieren der ersten Gruppe, die gewöhnliches ausgelassenes Kaninchenfett intraperitoneal erhielten, war in der Folgezeit bis zur Nachkontrolle eine Gewichtsabnahme zu konstatieren. Es stimmt das überein mit der Reaktion der Tiere auf das in dieser Weise gewonnene Fett: stärkeres Krankheitsgefühl in den ersten Tagen und gröbere Veränderungen in der Bauchhöhle, die das Allgemeinbefinden der Tiere längere Zeit beeinträchtigten. Die beiden Kontrolltiere dieser Gruppe wiesen beide eine Gewichtszunahme auf.

Bei den zehn Tieren der zweiten Gruppe, die ätherextrahiertes Kaninchenfett erhalten hatten, machte sich die Besserung im Befinden der Tiere auch insofern bemerkbar, als bei vier Tieren eine Gewichtszunahme konstatiert werden konnte, während nur sechs Tiere noch eine Gewichtsabnahme aufwiesen. Es läBt sich das also bis zu einem gewissen Grade in Einklang bringen mit der oben schon betonten geringeren Reaktion der Tiere auf das durch Ätherextraktion dargestellte Fett.

Von den zu dieser Gruppe gehörigen sieben Kontrolltieren war bei sechs eine Gewichtszunahme festzustellen, das einzige Tier, das eine Gewichtsabnahme aufwies, kommt für die Beurteilung hier nicht in Betracht, da es sich um ein sehr elendes decrepides Tier handelte, das infolge seiner Schwäche zugrunde ging. 
Bei den vier Tieren der dritten Gruppe, die ätherhaltige Kaninchenfettemulsion erhalten hatten, war hingegen nur einmal Gewichtszunahme, aber dreimal Gewichtsabnahme zu konstatieren. Auch diese Zahlen lassen sich zur Bekräftigung der oben begründeten Ansicht heranziehen, daß die Emulsion auf den Zustand der Tiere ungünstiger einwirkte als das ätherextrahierte arteigene Fett. Die zu dieser Gruppe gehörigen Kontrolltiere wiesen auch hier eine Gewichtszunahme auf.

Von den sechs Tieren der vierten Gruppe endlich, die ätherextrahiertes menschliches Fett erhalten hatten, war viermal eine Gewichtszunahme und nur zweimal eine Gewichtsabnahme festzustellen. Auch diese Feststellung stimmt gut überein mit der oben schon festgelegten Tatsache, daß die Reaktion der Kaninchen auf die intraperitoneale Einverleibung des menschlichen Fettes eher geringer war, jedenfalls daß das Fett aus den angegebenen Gründen von den Tieren besonders gut vertragen wurde.

Von den vier zu dieser Gruppe gehörigen Kontrolltieren war in 2 Fällen Gewichtszunahme, in 2 Fällen Gewichtsabnahme festzustellen. Diese beiden letzteren Fälle finden ihre Erklärung in einer stärkeren Schädigung der Tiere durch zu reichliche Jodeinwirkung, infolge deren das eine Tier Nr. 40 am 6. Tage post op. ad exitum kam, während das zweite Kontrolltier Nr. 38 zwar am Leben blieb, aber bei der Sektion am 22. Tage starke Adhäsionsbildung aufwies als Zeichen besonders ausgiebiger Jodschädigung.

Die Zahlen der Gewichtstabelle lassen sich also in vielen Punkten zur Bekräftigung der schon vorher an der Hand der Versuchsprotokolle gefundenen Beobachtungen heranziehen.

Wenden wir uns nunmehr wieder der letztbesprochenen Gruppe der mit menschlichem Fett behandelten Tiere $z u$, so ist noch folgendes nachzutragen.

Die Veränderungen, die sich nach der Fetteinbringung in der Bauchhöhle ausbildeten, wurden nach einem Zeitraum von 6, 14, 20, 22, 49, 52, 79 Tagen nachkontrolliert und zwar einmal durch Relaparatomie, dreimal durch Sektion der durch Chloroform getöteten Tiere. Die Bauchhöhle bot ein ähnliches Bild, wie wir das, von den früheren Versuchen mit arteigenem Fett der verschiedenen Darstellung zu sehen gewohnt waren. Dünne feine schleierartige Auflagerungen auf der parietalen und visceralen Serosa, besonders ausgeprägt fanden sich diese Auflagerungen auf den verwundeten Peritonealflächen, auf der Leberoberfläche und in der Zwerchfellkuppe. Fett in größeren Anhäufungen oder in flüssigem Zustande wurde in keinem der Fälle bei der Revision in der Bauchhöhle mehr festgestellt. Es war auffallend, daß nach der Injektion von menschlichem Fett die fettmembranartigen Auflagerungen nicht so reichlich und nicht so stark sich ausge- 
postoperativer peritonealer Adhäsionen mittels arteigenen flüssigen Fettes. 551

bildet hatten wie nach der Injektion von arteigenem Fett. In einem Falle 23a waren diese Fettauflagerungen besonders geringfügig, statt dessen fand sich hier das eingebrachte Fett zum Teil im Netz als multiple in Bindegewebe eingekapselte Fetteinschlüsse wieder. Allerdings ist es ja bekannt, daß es in der Reaktion des Peritoneums große individuelle Unterschiede gibt.

Der histologische Befund der Fettauflagerungen bot keine wesentlichen Unterschiede gegenüber den in den früheren Versuchen beschriebenen Befunden. Die Auflagerungen bestanden aus lockermaschigem jungen Bindegewebe mit reichlich neugebildeten Capillaren. Die oberen Schichten zeigten zum Teil zottenartige Erhebungen, die allerdings nicht so stark ausgebildet waren wie in den früheren Fällen; meist zogen die Auflagerungen in gleichmäßiger Anordnung über die darunter liegende Peritonealfläche. In den Maschen und Lücken dieses Bindegewebsgerüstes waren Fetttröpfen in größerer und kleinerer Menge eingelagert, besonders in den Basalschichten. Der freie Rand der Auflagerungen war, vor allem auch auf den polypös zottenartigen Auswüchsen, mit einer zusammenhängenden Endothelschicht bedeckt.

Was die Entstehung von Adhäsionen angeht, so vermochte das injizierte menschliche Fett in Versuch 23a, 24, 27a die Ausbildung von Verwachsungen zu verhüten, während in den zugehörigen Kontrollversuchen die gleiche Schädigung des Peritoneums zu Verwachsungen geführt hatte. In Versuch 25 a und $26 \mathrm{a}$ entstanden zwar trotz des Fettes feine fadenförmige Adhäsionen, während bei den entsprechenden Kontrolltieren die gleiche Peritonealschädigung zu ausgedehnteren festeren Verwachsungen geführt hatte. In diesen beiden letzten Fällen war das Fett zwar nicht imstande gewesen, die Ausbildung von Adhäsionen ganz zu verhüten, da die gesetzte Schädigung (zu starke Jodierung) zu groß war, vermochte aber dieselbe doch merklich im Vergleich zu den Kontrollversuchen herabzusetzen.

Auch in dieser letzten Versuchsreihe mit menschlichem Fett habe ich bei zwei überlebenden Tieren (Nr. 23 und 26) 45 bzw. 60 Tage nach der ersten Relaparatomie, also 49-80 Tage nach der ursprünglichen Fetteinbringung, den Befund der Bauchhöhle nachkontrolliert. Auch hier fanden sich keine Adhäsionen, die schon bei der ersten Relaparatomie auffallend geringen peritonealen Auflagerungen hatten sich weiter zurückgebildet und waren nur noch in spärlichen Resten vorhanden.

Die geschilderten peritonealen Veränderungen gleichen sich also wie aus dem histologischen Befund dieser letzten Gruppe und aus den vorher geschilderten Befunden hervorgeht, ihrem Charakter nach völlig, sie differieren nur in ihrer Stärke nach der Art des Fettes und vor allem dessen Darstellung und Anwendung bzw. der Größe des von dem Fett ausgehenden Reizes. 
Wenn wir die nach der intraperitonealen Einverleibung von arteigenem und artfremdem flüssigen Fett auftretenden Veränderungen an der Hand der geschilderten makroskopischen Befunde in der Bauchhöhle und deren histologischer Deutung noch einmal zusammenfassend kritisch bewerten wollen, so kommen wir zu folgenden Ergebnissen:

Das in die Bauchhöhle gebrachte sterile flüssige, arteigene und artfremde Fett übt einen Fremdkörperreiz auf das Peritoneum aus, das seinerseits mit der Ausbildung einer reaktiven Peritonitis antwortet. Es kommt also auch nach arteigenem flüssigem Fett zu der Ausbildung von Veränderungen am Peritoneum, wie sie nach der Einbringung der verschiedensten körperfremden, chemisch oder mechanisch wirkenden Substanzen in flüssigem oder festem Zustande beobachtet worden sind.

Diese Tatsache, an der nach meinen Erfahrungen nicht zu zweifeln ist, müßte uns eigentlich von vornherein stutzig machen, da ein Mittel, das im Sinne einer Fremdkörperreizung wirkt, eigentlich kaum zu dem beabsichtigten $Z$ wecke der Verhütung von Verwachsungen geeignet sein könnte. Ich war deshalb auch bestrebt, das Fett in einer Form und Darstellung zur Anwendung zu bringen, bei der dieser Reiz nach Möglichkeit herabgemindert wurde. Die Ätherextraktion des frischen Fettgewebes in der oben beschriebenen Art möchte ich nach meinen Erfahrungen für eine Darstellungsart halten, die diesen Forderungen in der weit möglichsten Weise entspricht. Aber auch dem so dargestellten reinen Fett ist eine Wirkung im Sinne eines Fremdkörperreizes auf das Peritoneum nach meinen Beobachtungen nicht ganz abzusprechen. Doch ist dieselbe nicht so groß, als daß sie zur Ent. stehung von Adhäsionen führen müßte.

Es ist ja auch von anderer Seite, Kawasoye und Hoehne, selbst nach der intraperitonealen Einbringung von Campheröl, "as nach Ansicht der genannten Autoren eine sehr starke reaktive Peritonitis, jedenfalls viel ausgedehnter und stärker wie bei unseren Versuchen, zur Folge hatte, die Entstehung von Verwachsungen nicht beobachtet worden.

In den ersten Tagen nach der Fetteinbringung sieht man das parietale und viscerale Peritoneum diffus überzogen von einer mattglänzenden hauchartigen Schicht feinst verteilten Fettes. Dieser dünne Überzug verdichtet sich bald und man erkennt schon makroskopisch ein feines Fibringerüst in den Auflagerungen. Mikroskopisch handelt es sich in dieser Zeit vorwiegend um eine degenerative Schädigung der Endothelien bzw. ein Zugrundegehen und schon beginnende Capillarsprossung, Fibroblastenbildung und an einzelnen Stellen geringgradige lymphocytäre und leukocytäre Infiltrate. Leukocyten finden sich nur 
ganz vereinzelt, woraus hervorgeht, daß der entzündliche Reiz äußerst gering ist. Durch Ausschwitzung von Fibrin, das zum Teil in feinen Fäden angeordnet ist, erhalten diese feinen Überzüge eine netzartige Struktur. In diesem zarten Maschenwerk findet sich das Fett in größeren und kleineren Tropfen eingeschlossen.

Diese feinen spinnenwebartigen Auflagerungen (Fettfibrinschleier) werden dann durch von der Serosa einwachsendes neugebildetes Bindegewebe und reichlich aufsprossende feine Capillaren mehr und mehr organisiert. In diesem lockermaschigen Bindegewebe liegt das Fett in den Gewebslücken in größeren und kleineren Tropfen eingelagert, zum Teil ist es schon in einzelnen Tröpfchen in die Zellen aufgenommen. $\mathrm{Ja}$ in älteren Fällen liegt das Fett zum größten Teil intracellulär, so daß die mikroskopischen Bilder den Eindruck eines neugebildeten Fettgewebes machen.

Die freie Oberfläche dieser lockermaschigen Auflagerungen trägt besonders in der ersten Zeit ihres Bestehens und vor allem dann, wenn der Reiz, der zu ihrer Entstehung führte, ein besonders starker gewesen ist, ein mehr oder weniger zottenartiges Aussehen. Diese zottenartigen Fortsätze stellen Bindegewebswucherungen mit jungen Capillaren dar, in denen häufig auch noch feinste Fetttröpfchen eingelagert sind. In den späteren Wochen bilden sich diese zottenartigen polypösen Wucherungen zurück, sie flachen $a b$ und die ganze Auflagerung nimmt eine mehr kompaktere, gleichmäßigere Beschaffenheit an. Die maschenartigen Zwischenräume werden seltener; die bindegewebige lockere Struktur wird straffer. Die Fettansammlung wird durch Resorption spärlicher und ist vorwiegend in den tieferen Schichten angeordnet, zum Teil erkennt man das Fett z. B. an den Leberschnitten in den unmittelbar angrenzenden Leberpartien, nicht in den eigentlichen Leberzellen oder nur ganz spärlich, aber vorwiegend in den Sternzellen angeordnet.

Durch diese geschilderten rückbildenden Vorgänge an den ursprünglich lockermaschigen Auflagerungen kommt es schließlich nach der Resorption des eingeschlossenen Fettes und Überwiegen des stark gewucherten und verdickten Bindegewebes zum Überbleiben einer bindegewebigen Schwiele, bestehend aus straffem zellarmen Bindegewebe.

Diese fettgewebsähnlichen Auflagerungen fanden sich in der ersten Zeit mehr oder weniger diffus verbreitet, um sich später mehr inselförmig zerstreut auf einzelne Bezirke des parietalen und visceralen Peritoneums zu verteilen. Fast ausnahmslos war die unterhalb der Fettauflagerungen gelegene äußere Schicht der betreffenden Partie, auf welche sich die Fettschicht angelagert hatte, der Bauchwand oder der Leberoberfläche bindegewebig schwielig verdickt, besonders wenn 
es sich um eine Stelle handelte, die vorher zwecks Hervorrufung von Adhäsionen geschädigt worden war ${ }^{1}$ ).

Regelmäßig wurden diese fettgewebsartigen Auflagerungen gefunden auf den geschädigten Serosastellen, vor allem des parietalen Peritoneums. Das verwundete parietale Peritoneum lag gewissermaßen geschützt unter der deckenden Fettschicht, und möchte ich diesen Befund in erster Linie mit heranziehen für die Erklärung der Tatsache, daß es in diesen Fällen nicht zu Adhäsionen mit der Bauchwand gekommen ist. Für das Nichtauftreten von Verwachsungen dürfte dann vor allem ferner maßgebend sein, daß die geschilderten Auflagerungen meist von einem zusammenhängenden Endothelüberzug bekleidet war.

Es decken sich meine Befunde hier mit den Untersuchungen von Hoehne und Kawasoye. Kawasoye, der die Veränderungen der Bauchorgane nach Campherölinjektion studierte, erhielt bei seinen Tierversuchen Befunde, die zwar im allgemeinen zu stärker ausgebildeten Veränderungen führten, entsprechend der stärkeren Reizwirkung des Campheröls, die aber in ihrem Charakter und Aufbau doch vielfach Ähnlichkeiten mit meinen Befunden aufweisen. Die nach Campherölinjektion sich bildenden peritonealen Auflagerungen führten trotz langer Beobachtungszeit nie zu Darmadhäsionen; auch Kawaso ye beobachtete stets in seinen Präparaten den freien Rand der Auflagerungen, bedeckt mit einer zusammenhängenden Endothelschicht. Auch Hoeh ne vertritt den Standpunkt, daß das Campheröl nicht mit Sicherheit die Entstehung von Adhäsionen verhütet, aber auch trotz der sehr starken reaktiven Veränderungen am Peritoneum keine Adhäsionen. veranlaßt.

Wir haben also aus den obigen Befunden die interessante Tatsache zu verzeichnen, daß aus flüssigem, in die Bauchhöhle gebrachten arteigenem oder artfremdem Fett sich eine fetthaltige Gewebsschicht an einzelnen Stellen des Peritoneums niederschlägt, die in ihrem histologischen Aufbau dem Fettgewebe entspricht.

Auch Eden und Lindig fanden, daß die nach einem längeren Zeitraum unter der Leber und im subphrenischen Raum sich ansammelnden Fettlager den Eindruck ganz feinen jungen Fettgewebes machten; eine ähnliche Beobachtung, daß Humanol in Fettlager verwandelt wurde, hatte Eden schon bei anderen Kaninchenversuchen, bei Plombierung einer Pleurahöhle feststellen können.

Überblicken wir noch einmal das Ergebnis der letzten Versuchsgruppe mit menschlichem Fett, so haben wir die auffällige Tatsache zu konstatieren, daß das artfremde Fett von den Tieren nicht nur

1) Herrn Prosektor A. Frank, der meine Präparate durchgesehen und mich bei der Deutung der bistologischen Befunde in liebenswürdiger Weise beraten hat, darf ich auch an dieser Stelle meinen verbindlichsten Dank aussprechen. 
postoperativer peritonealer Adhäsionen mittels arteigenen flüssigen Fettes. 555

nicht schlechter, sondern sogar besser vertragen wurde als das arteigene. Die Tiere reagierten mit einem geringeren Krankheitsgefühl, und vor allem waren die später in der Bauchhöhle festgestellten Veränderungen zwar in ihrem makroskopischen Aussehen und ihrem histologischen Aufbau den nach arteigenem Fett aufgetretenen Veränderungen gleich, aber nicht so ausgedehnt und nicht so stark ausgebildet.

Weiter - und das interessiert uns hier in erster Linie - war das ätherextrahierte menschliche Fett genau so gut wie das ätherextrahierte arteigene Kaninchenfett imstande, die Entstehung postoperativer Adhäsionen zu verhindern bzw. bei besonders schwerer Schädigung des Peritoneums die Ausbildung der Adhäsionen herabzumindern. Es mußte also, vor allem unter Berücksichtigung der Tatsache der geringeren peritonealen Reaktion, das artfremde menschliche Fett auf das Kaninchenperitoneum einen geringeren Reiz ausüben als das arteigene Kaninchenfett.

Diese auffällige Tatsache schien mir ihre Erklärung zu finden in dem bedeutend niedrigeren Schmelzpunkt des Menschenfettes. Der Schmelzpunkt des menschlichen Fettes liegt, wie wir gesehen haben, bei $17,5^{\circ}$, während das Kaninchenfett erst bei $40-42^{\circ}$ nach Amthor und Zink, nach Drumel gar erst bei $44-46^{\circ}$ flüssig wird (s. A bderhalden, Biochem. Handlexikon Bd. 3).

Ein Fett, das bei der normalen Körpertemperatur eines Tieres nicht mehr flüssig ist, wird natürlich, wenn es vollkommen flüssig eingebracht wird, bald gerinnen und eine salbenartige Konsistenz annehmen. Diese Änderung seines Aggregatzustandes muß naturgemäß einen stärkeren Reiz auf das Peritoneum ausüben und dadurch leichter zu einer reaktiven Peritonitis führen, als eine andere Fettart, die bei Körpertemperatur sich in absolut flüssigem Zustande befindet und die diesen flüssigen Zustand nach ihrer intraperitonealen Einverleibung beibehält.

Es hat nach meinen Erfahrungen den Anschein, als ob es nicht so sehr darauf ankommt, ob das einverleibte Fett ein artgleiches oder artfremdes ist. Ich befinde mich hier nicht in Übereinstimmung mit Eden und Lindig, die nach ungünstigen Erfahrungen in zwei Tierversuchen mit artfremden Humanol (ein Kaninchen und eine Ratte) im Gegensatz zu einer Reihe günstiger Kaninchenversuche mit artgleichem Fett es für empfehlenswert halten, der homoplastischen Fettübertragung gegenüber der heteroplastischen den Vorzug zu geben. Ich halte es sogar nicht für ausgeschlossen, daß ein anderes tierisches Fett mit niederem Schmelzpunkt, z. B. das Fett von Kaltblütern, auf gleiche Weise chemisch rein dargestellt, auch vielleicht günstige Resultate in der angegebenen Richtung geben könnte. Das hindert 
natürlich nicht, daß die Anwendung des gleichen Materials beim Menschen das gegebene Verfahren darstellen dürfte, da das menschliche Fett ja den günstigen niederen Schmelzpunkt besitzt, die Beschaffung des Ausgangsmaterials, fettreiche Netzhernien, Lipome und vor allem fettreiche Bauchdecken, die bei gynäkologischen Operationen beim Pfannenstielschen Querschnitt z. B. es ohne weiteres erlauben, eine größere sichelförmige Scheibe zu exzidieren, nicht schwierig ist, und schließlich die Verwendung artgleichen Fettes beim Menschen von vornherein als die sympathischste Methode erscheinen dürfte.

Die Erfahrungen, die mit der freien Fetttransplantation gemacht sind, lassen sich meines Erachtens nicht ohne weiteres übertragen auf die Einverleibung eines Fettes in flüssigem Zustande.

Bei der plastischen Überpflanzung lebendfrischen Fettgewebes heilt der transplantierte Lappen nach Lexer bei Autotransplantation nach einer ursprünglichen degenerativen und anschließenden Regenerationsperiode als vollwertiges lebendes Fettgewebe mit sehr geringer Schrumpfung ein (nach 150 Tagen), während bei homoplastisch transplantierten Fettlappen degenerative nekrotisierende Prozesse mit anschließender Schrumpfung überwiegen und die Regeneration zwar auch in gewissem Umfange eintritt, aber bedeutend geringer und viel langsamer als bei der Autoplastik. Während bei der freien Fetttransplantation die Homoioplastik praktisch so gut wie gar keine Rolle spielt, kommt die Heteroplastik überhaupt nicht in Betracht.

Bei der Überpflanzung - um den Ausdruck beizubehalten - eines Fettes in flüssigem Zustande liegen die Verhältnisse insofern anders, als wir nur das aus dem ursprünglichen Fettgewebe gewonnene Fett ohne jede Beimengung seiner gewebsaufbauenden Zwischensubstanz übertragen. Es kann also wohl kaum ein Unterschied bestehen, ob ich das flüssige Fett aus Fettgewebe desselben Individuums oder eines anderen artgleichen Individuums gewinne. Praktisch kommt die Verwendung des flüssigen Fetts von demselben Individuum im Sinne einer autoplastischen Utbertragung ja auch wohl nicht in Betracht.

$\mathrm{Ob}$ die Artgleichbeit des einverleibten Fettes überhaupt hier eine Hauptrolle spielt, scheint mir nach meinen Beobachtungen zum wenigsten zweifelhaft. Sicher kommt dem prozentualen Mengenverhältnis der einzelnen Fettbestandteile, das natürlich bei artgleichem Fett am günstigsten ist, bei der parenteralen Einverleibung eine gewisse Bedeutung $\mathrm{zu}$, vor allem was die Resorption angeht, ich habe aber aus meinen Versuchen den Eindruck gewonnen, daß, wenigstens bei intraperitonealer Einverleibung, dem günstig liegenden niedrigen Schmelzpunkt die ausschlaggebende Bedeutung zukommt.

Eine weitere günstige Eigenschaft des menschlichen Fettes, die ich nicht unerwähnt lassen möchte, hebt Lexer hervor. Nach Lexer 
kommt dem freien Fett eine gerinnungshemmende Wirkung zu. Sie erklärt sich damit, daß dem reinen Fett oder öl benetzungsfähige Substanzen fehlen, an welchen sich die Gerinnung vollziehen und aufbauen kann. Lexer stützt diese Behauptung durch einen einfachen Reagensglasversuch; er versetzte $1 \mathrm{ccm}$ flüssiges Menschenfett mit $8 \mathrm{~cm}$ Venenblut derselben Person im Reagenşglas, in einem zweiten Glase nur die gleiche Menge Venenblut. Letzteres gerann nach kurzer Zeit vollständig, während in dem mit Fett versetzten und etwas geschütteltem Blut nur ein kleines Gerinnsel sich auf der Oberfläche bildete, im übrigen blieb das Blut mit den gleichmäßig verteilten Fetttröpfchen flüssig. Die Verhütung der Gerinnselbildung wirkt aber der Entstehung. von Verwachsungen entgegen.

Es kommt also dem flüssigen menschlichen Fett neben seinen anderen günstigen Eigenschaften auch noch eine gerinnungshemmende Wirkung zu, ein Vorteil, um dessentwegen allein man ja schon besondere Stoffe zur Verhütung von Adhäsionen intraperitoneal eingeführt hat, ich erinnere an die ergebnislosen Versuche Vogels mit Magn. sulf. und Peptonlösung und an die Versuche von Schmiedt mit Hirudin.

Es dürfte demnach das menschliche Fett aus den genannten Erwägungen heraus besonders gut für die intraperitoneale Einverleibung geeignet sein, ein Umstand, der uns nach unseren Erfahrungen um so eher veranlassen wird, von der intraperitonealen Anwendung flüssigen Menschenfettes zur Verhütung postoperativer Adhäsionen Gebrauch zu machen.

Wir haben bisher noch nicht Gelegenheit genommen, das flüssige menschliche Fett in dem angegebenen Sinne bei Menschen zur Anwendung zu bringen, da wir uns, wie eingangs meiner Arbeit erwähnt, zunächst im Tierexperiment von der Unschädlichkeit des Fettes für den Organismus und von seiner Fähigkeit, das Entstehen von Adhäsionen zu verhindern bzw. zu verringern, überzeugen wollten.

Eden und Lindig haben, wie aus ihrer mehrfach zitierten Arbeit hervorgeht, schon seit längerer Zeit Humanol in die Bauchhöhle gebracht, wenn es sich um Verwachsungsoperationen handelte oder wenn bei der Operation mit Entstehung derartiger Verwachsungen gerechnet werden mußte. Sie konnten zwar an ihren bisherigen Fällen nicht feststellen, wieviel der Methode in der Verhütung von Adhäsionen zu verdanken ist und ob nicht trotzdem solche wieder entstanden sind. Es sei aber keiner der Fälle bekannt geworden, der infolge neuer oder wieder einsetzender Beschwerden zur Wiederaufnahme in die Klinik oder zur Relaparatomie Anlaß gegeben hätte. Die beiden Autoren halten sich jedenfalls nach ihren bisherigen Erfahrungen für berechtigt, zur Verwendung des Humanol als verwachsungshemmendes bzw. verhütendes Mittel aufzufordern. 
Auch König und Treplin hat sich das Humanol in der Praxis nach Lösen flächenhafter Verwachsungen bewährt. Müller (Rostock) glaubt, daß die Fetteinbringung in Form des Humanol noch am ehesten. Verwachsungen hintanzuhalten geeignet sei, ohne selbst eigene Erfahrungen mitzuteilen. Auch Roedelius empfiehlt die Anwendung des Humanol der experimentellen Nachprüfung.

Nach meinen im Tierexperiment gewonnenen Erfahrungen halte ich die intraperitoneale Einverleibung von flüssigem Menschenfett für eine das Tier nicht schädigende Maßnahme, die wohl imstande ist, die Entstehung postoperativer Verwachsungen zu verhüten bzw. herabzumindern.

Ich halte es deshalb für gerechtfertigt, das flüssige arteigene Fett beim Menschen zur Anwendung zu bringen, da wohl anzunehmen ist, daß dasselbe erst einmal als arteigener Stoff, dann aber vor allem infolge seiner günstigen physikalischen Eigenschaften noch besser vom Peritoneum vertragen wird als im Tierversuch.

Meine vergleichenden Versuchsreihen haben mir ferner die Überzeugung gebracht, daß die Art der Darstellung des Fettes für den beabsichtigten Erfolg der Adhäsionsverhütung eine nicht zu unterschätzende Bedeutung hat. Aus den oben im einzelnen dargelegten Gründen halte ich für unsere Zwecke die bisher allgemein übliche Darstellung des flüssigen Menschenfettes als Humanol durch einfaches Auslassen im Wasserbad oder gar durch Schmelzen im Tiegel für eine nicht geeignete Methode, möchte vielmehr die Darstellung durch Ätherextraktion empfehlen, da auf diese Weise die chemisch reinste Gewinnung des Materials gewährleistet ist.

Die im Tierexperiment erwiesene Unschädlichkeit des Verfahrens rechtfertigt die Übertragung auf den Menschen.

Ob die Methode sich bewähren wird, werden erst ausgedehnte klinische Versuche, längere Zeit fortgesetzte Beobachtungen evtl. Nachkontrolle durch Pneumoperitoneum und gelegentliche Relaparatomien erweisen müssen.

\section{Literatur.}

1) Abderhalden, Biochemisches Handlexikon. III. Bd. Berlin 1911. 2) Benthin, Die Ätherbehandlung der Peritonitis. Dtsch. Zeitschr. f. Chirurg. 153, 376. 1920. - ${ }^{3}$ ) Borst, Das Verhalten der Endothelien bei der akuten und chronischen Entzündung, wie bei dem Wachstum der Geschwülste. Verhandl. d. physiol.-med. Ges. Würzburg 33, 1. - ${ }^{4}$ ) v. Br unn, Über die plastische Deckung von Defekten intraperitonealer Hohlorgane. Berl. klin. Wochenschr. 1904. $\left.{ }^{5}\right)$ Busch und Bibergeil, Experimentelle Untersuchungen über Verhütung von peritonealen Adhäsionen. Arch. f. klin. Chirurg. 87, 101. - ${ }^{6}$ ) Clairmont und Haberer, Über das Verhalten des gesunden und veränderten tierischen Peritoneums. Wien. klin. Wochenschr. 1902. - ${ }^{7}$ ) Danielsen, Über die Schutzvor- 
richtungen in der Bauchhöhle mit besonderer Berücksichtigung der Resorption. Bruns' Beitr. z. klin. Chirurg. 54, 458. - ${ }^{8}$ ) v. De mbowsky, Zur Entstehung der peritonealen Adhäsionen. Zentralbl. f. Gynäkol. 1891, Nr. 15. - ${ }^{9}$ ) v. Dembowsky, Über die Ursache der peritonealen Adhäsionen nach chirurgischen Eingriffen mit Rücksicht auf die Frage des Tleus nach Laparotomie. Arch. f. klin. Chirurg. 37, 745. - $\left.{ }^{10}\right) \mathrm{Dubs}$, Die Ätherbehandlung der Peritonitis. Dtsch. Zeitschr. f. Chirurg. 153, 376. 1920. - $\left.{ }^{11}\right)$ Duschinsky, Experimentelle Untersuchung über die Vermeidung von Adhäsionen nach Laparotomien. Inaug.-Diss. München 1908. - ${ }^{12}$ ) Eden und Lindig, Ủber die Verhütung postoperativer Verwachsungen. Dtsch. med. Wochenschr. 1920, Nr. 39. - 13) Engelmann und Stade, Über die Bedeutung des Blutegelextraktes für die Therapie der Eklampsie. Münch. med. Wochenschr. 1909, Nr. 43. - $\left.{ }^{14}\right)$ Flesch - Thebesius, Über Ileus durch Verwachsungen und Stränge. Dtsch. Zeitschr. f. Chirurg. 15\%, 60. 1920. - ${ }^{15}$ ) Fritsch, Die Resultate der aseptischen Laparotomien. Zentralbl. f. Gynäkol. 1890, Nr. 29. - $\left.{ }^{16}\right)$ From me, Die Peritonitis in Veit, Handbuch der Gynäkologie Bd. 4. 1910. - 17) Gersuny, Peritoneale Adhäsionen und ihre Beziehung zum weiblichen Genitale. Wien. klin. Wochenschr. 1899, Nr, 22, S. 601. - ${ }^{18}$ ) Girgolaff, Peritonealplastik mit isolierten Netzstuicken. Zentralbl. f. Chirurg. 1906, Nr. 46. ${ }^{19}$ ) Glimm, Über Bauchfellresorption und ihre Beeinflussung bei Peritonitis. Dtsch. Zeitschr. f. Chirurg. 83, 254. - ${ }^{20}$ ) Graser, Untersuchungen über die feineren Vorgänge bei der Verwachsung peritonealer Blätter. Dtsch. Zeitschr. f. Chirurg. 2r. 1888. - ${ }^{21}$ ) Gruzdew, Beitrag zur Frage der Fremdkörper in der Bauchhöhle und über das Verhalten des Bauchfells den Fremdkörpern gegenüber. Zentralbl. f. Gynäkol. 1906, Nr. 46. - ${ }^{22}$ ) Heinz, Über die Herkunft des Fibrins und die Entstehung von Verwachsungen bei akuter adhäsiver Entziundung seröser Häute. Virchows Arch. f. pathol. Anat. u. Physiol. 160, 365. 1900. - ${ }^{23}$ ) Heinz, Über Jod und Jodverbindungen. Virchows Arch. f. pathol. Anat. u. Physiol. 151, 45. - ${ }^{24}$ ) Herxheimer, Über fibrinöse Entzündung des Darmes und der serösen Häute. Virchows Arch. f. pathol. Anat. u. Physiol. 162, 443. -. ${ }^{25}$ ) Heusner, Die physiologische Bedeutung des großen Netzes. Münch. med. Wochenschr. 1905, Nr. 24. - ${ }^{26}$ ) Hilse, Experimentelle Untersuchungen über freie Fetttransplantation bei Blutungen parenchymatöser Bauchorgane. Arch. f. klin. Chirurg. 103, 1042. 1914. - ${ }^{27}$ ) Hinsberg, Über die Beteiligung des Peritonealepithels bei der Einheilung von Fremdkörpern. Virchows Arch. f. pathol. Anat. u. Physiol. 152, Heft 3. -..28) Hirschel, Der heutige Stand der operativen Therapie der akuten diffusen Peritonitis. Bruns' Beitr. z. klin. Chirurg. 56, 263. - ${ }^{29}$ ) Hirschel, Die Behandlung der diffusen eitrigen Peritonitis mit 1 proz. Campheröl. Münch. med. Wochenschr. 1910, Nr. 15. — ${ }^{30}$ ) Hoehne, Experimentelle Untersuchungen über den Schutz des Tierkörpers gegen peritoneale Infektion. Arch. f. Gynäkol. 93, 563. 1911. - ${ }^{31}$ ) Hoehne, Experimentelle Versuche zur Prophylaxe der Peritonitis. Verhandl. d. Dtsch. Ges. f. Gynäkol. 13, 281. ${ }^{32}$ ) Hoehne, Zur Prophylaxe der postoperativen Peritonitis. Münch. med. Wochenschr. 1909, S. 2508. — 33) Holländer, Über plastisch-kosmetische Operationen. Berl. klin. Wochenschr. 1909, S. 816. - ${ }^{34}$ ) Holländer, Fall von fortschreitendem Schwund des Fettgewebes und sein kosmetischer Ersatz durch Menschenfett. Münch. med. Wochenschr. 1910, Nr. 34. - 35) Holländer, Bemerkungen zu Wederhake. Berl. klin. Wochenschr. 1918, S. 213. - ${ }^{36}$ ) Hollä nder, Behandlung von Knochenhöhlen mit Humanol. Zentralbl. f. Chirurg. 1918, S. 334. - ${ }^{37}$ ) Jenckel, Diskussionsbemerkung zu Schnippel. XX. Tag nordwestd. Chirurg., 6. XI. 1920; ref. Zentralbl. f. Chirurg. 1921, Nr. 13. - ${ }^{38}$ ) Kawa so ye, Über die anatomischen Veränderungen an den Bauch. und Brustorganen insbesondere am Peritoneum von Tieren nach intraperitonealer Campherölinjektion. 
Arch. f. Gynäkol. 1914, S. 100. _- 39) Kelterbor n, Versuche über die Entstehungsbedingungen peritonealer Adhäsionen nach Laparotomien. Zentralbl. 1 . Gynäkol. 1890, Nr. 51. - ${ }^{40}$ ) Kirschberg, Druck- und Saugbehandlung in der ärztlichen Praxis. Münch. med. Wochenschr. 1913, Nr. 30. - ${ }^{41}$ ) Kirschberg, Narbenbehandlung. Dtsch. med. Wochenschr. 1912, Nr. 29. - ${ }^{42}$ ) Kocher, Diskussion zu Pribram, Nene Experimente zur Vermeidung peritonealer Adhäsionen. 43. Chirurg.-Kongr: 1914, S. 242. - ${ }^{43}$ ) Kolossow, Über die Struktur des Pleuraperitoneal- und GefäBepitheis (Endothels). Arch. f. mikroskop. Anat. 42. 44) Körte, Erkrankungen und Verletzungen des Peritoneums v. Bergmann. Stuttgart 1908. - $\left.{ }^{45}\right) \mathrm{K}$ roh, Beitrag zur Behandlung peritonealer Adhäsionen. Münch. med. Wochenschr. 1914, Nr. 7. - ${ }^{46}$ ) La ndsberg, Diskussion zu P. Müller. Verhandl. d. Dtsch. Ges. f. Gynäkol. I. Kongr. 1866. - ${ }^{47}$ ) La uenstein, Verwachsungen und Netzstränge im Leibe als Ursache schwerer Koliken. Arch. f. klin. Chirurg. 45. 1893. - ${ }^{48}$ ) Lexer, Die freien Transplantationen in Neue dtsch. Chirurg. 26a. Stuttgart 1919. - ${ }^{49}$ ) Marchand, Zur Kenntnis der fibrinösen Exsudation bei Entzündungen. Virchows Arch. f. pathol. Anat. u. Physiol. 145, 279. - 50) Marchand, Über die Veränderungen der Peritonealepithelien (Deckzellen) bei der Einheilung kleiner Fremdkörper. Marburger naturwiss. Sitzungsber. 1897. - ${ }^{51}$ ) Maslowsky, Exstirpation beider Ovarien mit einem kurzen Bericht über die Geschichte der Ovariotomie in Rußland. Arch. f. klin. Chirurg. 9, 527. 1868. — ${ }^{52}$ ) Ma yer, A., Über die Behandlung von Insuffizienz des Blasenschließmuskels mit Injektion von flüssigem Menschenfett. Zentralbl. f. Gynäkol. 1918, Nr. 28. - ${ }^{53}$ ) Momburg, Die intraperitoneale Ölanwendung. Dtsch. med. Wochensehr. 1913, Nr. 12. - ${ }^{54}$ ) Mönkeberg, Über das Verhalten des Pleuraperitonealepithels bei der Einheilung von Fremdkörpern. Zieglers Beitr. z. allg. Pathol. u. pathol. Anat. 34. - ${ }^{55}$ ) Müller, P., Zur Nachbehandlung schwerer Laparotomien. Verhandl. d. Dtsch. Ges. f. Gynäkol. I. Kongr. 1886. ${ }^{56}$ ) Müller (Rostock), Diskussionsbemerkung zu Schnip pel, Behandlung abdom. Verwachsungen. XX. Tag d. Ver. Nordwestd. Chirurg., 6. XI. 1920; ref. Centralbl. f. Chirurg. 1921, Nr. 13, S. 455. - ${ }^{57}$ ) M uscatello, Über den Bau und das Aufsaugungsvermögen des Peritoneums. Virchows Arch. f. pathol. Anat. u. Physiol. 14\%, 327. - 58) Nägeli, Postoperative Verwachsungen nach Laparotomien. Zentralbl. f. Chirurg. 46, Nr. 41. 1919. - ${ }^{59}$ ) Noetzel, Über peritoneale Resorption und Infektion. Arch. f. klin. Chirurg. 57, 311. 1898. - $\left.{ }^{60}\right)$ Noetze1, Die Prinzipien der Peritonitisbehandlung. Bruns' Beitr. z. klin: Chirurg. 46, 514. 61) Oehlecker, Diskussionsbemerkung zu Schnippel. XX. Tag d. Ver. Nordwestd. Chirurg., 6. XI. 1920; ref. Zentralbl. f. Chirurg. 1921, Nr. 13. - ${ }^{62}$ ) Ols hausen, Diskussion zu Müller. Verhandl. d. Dtsch. Ges. f. Gynäkol. I. Kongr. 1886. - ${ }^{63}$ ) Pa yr, Zur Prophylaxe und Therapie peritonealer Adhäsionen. Eisenfüllung des Magendarmkanals und Elektromagnet. Münch. med. Wochenschr. 1913, Nr. 47. - ${ }^{64}$ ) Porges and Neubauer, Physikalisch-chemische Untersuchungen über Lecithin und Cholestearin. Biochem. Zeitschr. $\%, 152.1907 .-$ ${ }^{65}$ ) Pribram, Neue Experimente zur Frage der Vermeidung peritonealer Adhäsionen. 43. Chirurg.-Kongr. 1914, S. 312. - ${ }^{66}$ ) v. Recklingha usen, Zur Fettresorption. Virchows Arch. f. pathol. Anat. u. Physiol. 26, 172. 1863. - 67) Reichel, Zur Pathologie des .Ileus und Pseudoileus. Dtsch. Zeitschr: f. Chirurg. 35, 495. 1893. - ${ }^{68}$ ) Richarz, Über die klinische Bedeutung der peritonealen Adhäsionen. Diss. Bonn 1904. - ${ }^{69}$ ) Riedel, Über Adhäsionsentzündungen in der Bauchhöhle. Langenbecks Arch. 47. - $\left.{ }^{70}\right)$ Roedeli us, Diskussion zu Sch nippel. XX. Tag d. Ver. Nordwestd. Chirurg., 6. XI. 1920; ref. Zentralbl. f. Chirurg. 1921, Nr. 13. - ${ }^{71}$ ) Rübsamen, Tödliche Camphervergiftung nach Anwendung von offizinellem Campheröl zur postoperativen Peritonitisprophylaxe. Zentralbl. 
f. Gynäkol. 1912, Nr. 31, S. 1009. - $\left.{ }^{72}\right)$ Rü̈bsamen, Zur Klinik und Therapie der Extrauteringravidität. Gynäkol. Ges. Dresden; ref. Zentralbl. f. Gynäkol. 1920, Nr. 27. - - ${ }^{73}$ ) Saenger, Diskussionsbemerkung zu Müller. Verhandl. d. Dtsch. Ges. f. Gynäkol. I. Kongr. 1886. - ${ }^{74}$ ) Saenger, Kurze Mitteilung über feuchte Asepsis in der Bauchhöhle. Verhandl. d. Dtsch. Ges. f. Gynäkol. 6. Kongr. 1895. - ${ }^{75}$ ) Salzer, Über peritoneale Verwachsungen. Wien. klin. Wochenschr. 1893. - ${ }^{76}$ ) Schmaus - Herxheimer, Grundriß der pathologischen Anatomie. Wiesbaden 1912. - ${ }^{77}$ ) Schmiedt, Versuche über Adhäsionsbeschränkung in der Bauchhöhle durch Hirudinbehandlung. Arch. f. klin. Chirurg. 1914, S. 1030. - $\left.{ }^{8}\right)$ Schnippel, Behandlung abdominaler Verwachsungen. XX. Tag d. Ver. Nordwestd. Chirurg., 6. XI. 1920; ref. Zentralbl. f. Chirurg. 1921, Nr. 13, S. 455. - $\left.{ }^{79}\right)$ Schnitzler und Ewald, Zur Kenntnis der peritonealen Resorption. Dtsch. Zeitschr. f. Chirurg. 41. - ${ }^{80}$ ) Schrü nder, Experimentelles zur Frage der Adhäsionsbehandlung in der Bauchhöhle. Diss. Heidelberg 1914. - ${ }^{81}$ ) Seifert, Zur Bewertung der Äthertherapie bei Peritonitis. Münch. med. Wochenschr. 1919, Nr. 5. - ${ }^{82}$ ) Seubert, Zur Ätherbehandlung der Peritonitis. Münch. med. Wochenschr. 1918, Nr. 52. - ${ }^{83}$ ) Sigwart, Ätherbehandlung der Peritonitis. Zentralbl. f. Gynäkol. 1919, Nr. 43. - ${ }^{84}$ ) S piegelberg und Walde yer, Untersuchungen über das Verhalten abgeschnürter Gewebspartien in der Bauchböhle sowie der in dieser zurückgelassenen Ligaturen und Brandschorfe. Virchows Arch. f. pathol. Anat. u. Physiol. 44, 69. - ${ }^{85}$ ) Stern, Durch welche Mittel kann man das Entstehen von pseudomembranösen Verwachsungen bei intraperitonealen Wunden verhindern. Bruns' Beitr. z. klin. Chirurg. 1889. 4. - ${ }^{86}$ ) Stern, Virchows Arch. f. pathol. Anat. u. Physiol. 152. 1898. - ${ }^{87}$ ) Vogel, Klinische und experimentelle Beiträge zur Frage der peritonealen Adhäsionen nach Laparotomien. Dtsch. Zeitschr. f. Chirurg. 63, 296. 1902. — ${ }^{88}$ ) Vogel, Zur Frage der Verhütung der Rezidive peritonealer Adhäsionen. Zentralbl. f. Chirurg. 1917, Nr. 30, S. 666. _ ${ }^{89}$ ) Wederhake, Über die Verwendung des menschlichen Fettes in der Chirurgie. Berl. klin. Wochenschr. 1918, Nr. 3. - ${ }^{90}$ ) Wegner, Chirurgische Bemerkung über die Peritonealhöhle. Langenbecks Arch. 40, 51. - ${ }^{91}$ ) Ziegler, Über fibrinöse Entzündung der serösen Häute. Zieglers Beitr. z. allg. Pathol. u. pathol. Anat. 21. 